\title{
Cardiovascular abnormalities in familial combined hyperlipidemia
}

Citation for published version (APA):

Keulen, E. T. P. (2001). Cardiovascular abnormalities in familial combined hyperlipidemia. [Doctoral Thesis, Maastricht University]. Datawyse / Universitaire Pers Maastricht.

https://doi.org/10.26481/dis.20011220ek

Document status and date:

Published: 01/01/2001

DOI:

10.26481/dis.20011220ek

Document Version:

Publisher's PDF, also known as Version of record

\section{Please check the document version of this publication:}

- A submitted manuscript is the version of the article upon submission and before peer-review. There can be important differences between the submitted version and the official published version of record.

People interested in the research are advised to contact the author for the final version of the publication, or visit the DOI to the publisher's website.

- The final author version and the galley proof are versions of the publication after peer review.

- The final published version features the final layout of the paper including the volume, issue and page numbers.

Link to publication

\footnotetext{
General rights rights.

- You may freely distribute the URL identifying the publication in the public portal. please follow below link for the End User Agreement:

www.umlib.nl/taverne-license

Take down policy

If you believe that this document breaches copyright please contact us at:

repository@maastrichtuniversity.nl

providing details and we will investigate your claim.
}

Copyright and moral rights for the publications made accessible in the public portal are retained by the authors and/or other copyright owners and it is a condition of accessing publications that users recognise and abide by the legal requirements associated with these

- Users may download and print one copy of any publication from the public portal for the purpose of private study or research.

- You may not further distribute the material or use it for any profit-making activity or commercial gain

If the publication is distributed under the terms of Article $25 \mathrm{fa}$ of the Dutch Copyright Act, indicated by the "Taverne" license above, 


\section{Cardiovascular abnormalities in Familial Combined Hyperlipidemia}


(C) Eric Keulen, Maastricht 2001

ISBN 9052783306

Cover design: Dimitri Delnoye

Production: Datawyse | Universitaire Pers Maastricht

Financial support by the Netherlands Heart Foundation for the publication of this thesis is gratefully acknowledged.

Printing of this thesis was financially supported by Amgen bv. (Breda), Astra Zeneca, Aventis, Bayer bv., Bristol-Myers Squibb, Byk Nederland bv., Merck Sharp \& Dohme bv. ,Novartis Pharma bv., Novo Nordisk Pharma bv., Pfizer bv. and Roche. 


\title{
Cardiovascular abnormalities in Familial Combined Hyperlipidemia
}

\author{
PROEFSCHRIFT \\ ter verkrijging van de graad van doctor \\ aan de Universiteit Maastricht, \\ op gezag van Prof. dr. A.C. Nieuwenhuijzen Kruseman, \\ rectar magnificus, \\ volgens het besluit van het College van Decanen, \\ in het openbaar te verdedigen \\ op donderdag 20 december 2001 om 14.00 uur
}

door

Eric Theodorus Petronella Keulen geboren op 31 maart 1972 te Geleen

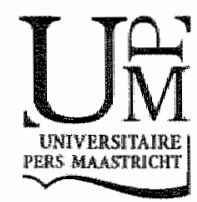




\section{Promotor}

Prof.dr. T.W.A. de Bruin

\section{Beoordelingscommissie}

Prof.dr. P.W. de Leeuw (voorzitter)

Prof.dir. H.J.G.M. Crijns

Prof.dir. M.J.A.P. Doemen

Prof.dir. D.E. Grobbee (Universiteit Utrecht, Julius Instituut voor

Patiëntgebonden onderzoek)

Prof.dr. C.D.A. Stehouwer (Vrije Universiteit Amsterdam) 
Life is what happens to you while you're busy making other plans John Lennon

Aan: Bianca en Eva 



\section{Contents}

\section{Abbreviations 9}

Chapter 1 General introduction and aims of the thesis 11

Chapter 2 Subjects and general methods and epidemiological aspects of Familial Combined Hyperlipidemia 21

Chapter 3 Pathophysiological and genetic mechanisms in Familial Combined Hyperlipidemia, our current understanding 37

Chapter 4 Familial Dyslipidemic Hypertension Syndrome: further delineation in Familial Combined Hyperlipidemia, and the role of abdominal fat mass 53

Chapter 5 QT-interval (QTc) is prolonged in Familial Combined Hyperlipidemia: association with insulin resistance 69

Chapter 6 Pro-coagulant endothelium in Familial Combined Hyperlipidemia 83

Chapter 7 Reduced structural and functional skin capillaries in Familial Combined Hyperlipidemia: association with increased remnantlike lipoprotein cholesterol levels 91

Chapter 8 uncreased intima media thickness in Familial Combined Hyperlipidemia: association with apolipoprotein B 105

Chapter 9. General discussion and conclusions 119

Chapter 10. Summary 129

Chapter 11. Samenvatting 137

List of publications 143

Dankwoord 147

Curriculum Vitae 153 



\section{Abbreviations}

$\begin{array}{ll}\text { ADD1 } & \text { alpha adducin A gene } \\ \text { ALP } & \text { atherogenic lipoprotein phenotype } \\ \text { Apo } & \text { apolipoprotein } \\ \text { ASP } & \text { acylation stimulatory protein } \\ \text { BC } & \text { basal number of capillaries } \\ \text { BMI } & \text { bady mass index } \\ \text { CABG } & \text { coronary artery bypass graft } \\ \text { CAD } & \text { caronary artery disease } \\ \text { CI } & \text { confidence interval } \\ \text { CR } & \text { capillary recruitment } \\ \text { CV } & \text { coefficient of variation } \\ \text { CVA } & \text { cerebrovascular accident } \\ \text { CVD } & \text { cardiovascular disease } \\ \text { DBP } & \text { diastolic bload pressure } \\ \text { DH } & \text { dyslipidemic hypertension } \\ \text { FBG } & \text { fasting blood glucose concentration } \\ \text { FCHL } & \text { familial combined hyperlipidemia } \\ \text { FDH } & \text { familial dyslipidemic hypertension } \\ \text { FFA } & \text { free fatty acids } \\ \text { FI } & \text { fasting insulin } \\ \text { HC } & \text { hypercholesterolemia } \\ \text { HDL } & \text { high-density lipoprotein } \\ \text { HL } & \text { hepatic lipase } \\ \text { HL-relative } & \text { hyperlipidemic relative } \\ \text { HOMA } & \text { homeostasis model assessment } \\ & \text { (calculated marker for insulin resistance) } \\ \text { HSL } & \text { hormone sensitive lipase } \\ \text { HT } & \text { hypertriglyceridemia } \\ \text { IDL } & \text { intermediate density lipoprotein } \\ \text { IMT } & \text { intima media thickness } \\ \text { IRS } & \text { insulin resistance syndrome } \\ \text { LCAT } & \text { lecithin: cholesterol acyltransferase } \\ \text { LDBF } & \text { laser Doppler basal flow } \\ \text { LDF } & \text { laser Doppler fluxmetry } \\ \text { LDL } & \text { low-density lipoprotein } \\ \text { LDPF } & \text { laser Doppler peak flow } \\ \text { LDPRH } & \text { laser Doppler post-occlusive reactive hyperemia } \\ \text { LP(a) } & \text { lipoprotein(a) } \\ \text { LPL } & \text { lipoprotein lipase } \\ \text { MAP } & \text { mean arterial pressure } \\ \text { MI } & \text { National Heart, Lung and Blood Institute } \\ \text { NEFA } & \end{array}$




\begin{tabular}{|c|c|}
\hline NL relative & normolipidemic relative \\
\hline OR & odds ratio \\
\hline $\mathrm{PAl}-1$ & plasminogen activator inhibitor 1 \\
\hline $\mathrm{POC}$ & post-occlusive number of capillaries \\
\hline $\mathrm{PP}$ & pulse pressure \\
\hline PPAR & peroxisome proliferator-activated receptor \\
\hline PTCA & percutane transluminal coronary angioplasty \\
\hline PU & perfusion units \\
\hline QTC & heart-rate corrected QT-interval \\
\hline RF & radiofrequency \\
\hline RLP & remnant-like lipoprotein particles \\
\hline SBP & systolic blood pressure \\
\hline sdLDL & small dense low-density lipoprotein \\
\hline TC & total cholesterol \\
\hline TFPI & tissue factor pathway inhibitor \\
\hline TG & plasma triglyceride \\
\hline TNF & tumor necrosis factor \\
\hline 1-PA & tissue type plasminogen activator \\
\hline VIF & variance inflation factor \\
\hline VLDL & very-low-density lipoprotein \\
\hline WWF & von Willebrand factor \\
\hline WHR & waist to hip ratio \\
\hline
\end{tabular}




\section{Chapter 1}

General introduction and aims of the thesis

ETP Keulen 


\subsection{Cardiovascular disease and cardiovascular risk factors}

Cardiovascular disease (CVD) is a major cause of death in our western saciety. In 1995, cardiovascular diseases combined were responsible for $39 \%$ of all deaths and $16 \%$ of all hospital admissions in the Netherlands'. Over the last decades, epidemiological studies have together written a cohesive story that convincingly links a number of important risk factors to the development of CVD ${ }^{2-5}$. The Framingham study, initiated in 1948 in Framingham, Massachusetts, USA, has developed into one of the most important longitudinal cohort studies of risk of cardiovascular disease, in both men and women. This study and other langitudinal studies have identified many of the major cardiovascular risk factors and have refined assessment of absolute risk that is slowly adapted into clinical practice.

Major cardiovascular risk factors, including increasing age, male gender ${ }^{3}$, previous history of cardiovascular disease ${ }^{6}$, positive family history of cardiovascular disease ${ }^{7}$, smoking ${ }^{8}$, hypertension, elevated total $(\mathrm{TC})^{9}$ and lowdensity lipoprotein (LDL) cholesterol ${ }^{10}$, reduced high-density lipoprotein (HDL) cholesterol $^{11}$ and diabetes mellitus ${ }^{12}$, are currently known. Newer risk factors, also known as "non-classical" risk factors, like hypertriglyceridemia, 13, hyperinsulinemia ${ }^{14,15}$, elevated apolipoprotein B concentrations ${ }^{16,17}$, elevaled lipoprotein (a) ${ }^{18}$, homocysteine ${ }^{19}$, C-reactive $\operatorname{protein}^{20}$, fibrinogen ${ }^{21}$, von Willebrand factor ${ }^{22}$ and plasminogen activator inhibitor $1^{21}$ concentrations have emerged over the past years. These newer risk factors often provide smaller increases in absolute cardiovascular risk than major risk factors, but are potentially important in clinical management of premature atherosclerosis. The increased number of classical and non-classical risk factors will, over time, provide us with the possibility to establish the cardiovascular risk profile and absolute cardiovascular risk of an individual more clearly. Not every classical or newly discovered risk factor can be adequately reduced or treated with current dietary or medical therapy. Therefore, knowledge of classical and non-classical risk factors may provide us with increased insight in cardiovascular risk profile assessment and possible atherogenic pathways, but leave us with limited therapeutic options to decrease the risk of subsequent cardiovascular events.

In clinical practice a distinction can be made between cardiovascular risk factors with potential therapeutic options and risk factors without therapeutic options. Despite the many cardiovascular risk factors currently known, few major risk factors have the biggest impact on subsequent cardiovascular events. For instance, without accounting for the impact of other risk factors, $42.7 \%$ of all subjects who died of CVD in the United States had a total cholesteral $\geq 5.2$ $\mathrm{mmol} / \mathrm{L}^{23}$. Furthermore, of the subjects who died of CVD, $32.1 \%$ were obese; $28.9 \%$ had a systolic blood pressure above $140 \mathrm{mmHg}, 25.1 \%$ were current or former smokers and $13.1 \%$ were diagnosed as having diabetes mellitus ${ }^{23}$. 
Since a decade, more attention has and still is been paid to genefically determined risk factors of cardiovaseular disease, using linkage and association studies and identification of contributing genetic polymorphisms. Several genetic polymorphisms, specifically in genes participating in classical risk factor pathways, have been associated with increased risk of cardiovascular disease. Identification of gene-environment interactions will be important to identify subgroups at higher cardiovascular risk ${ }^{24}$. Funthermore, genetic risk factor screening in cardiovascular disease is absolutely necessary to improve our understanding of biochemical atherogenic pathways eventually leading to subsequent clinical events.

\subsection{Familial Combined Hyperlipidemia and cardiovascular risk}

Multiple combinations of the above mentioned major cardiovascular risk factors will lead to an exponentially increased risk of early cardiovascular disease $2,5,25,26$. Mareover, classical, non-classical and genetic risk factors together often cluster in familial disorders. Increased clustering of cardiovascular risk factors and cardiovascular events in families can provide us with a powerful strategy to identify genetic contributors to specific cardiovascular diseases.

One of the famillial diseases with increased risk of cardiovascular disease is Familial Combined Hyperlipidemia (FCHL). FCHL, originally delineated in survivors of myocardial infarction, is one of the most common genetic lipid disorders ${ }^{27.30}$ affecting approximately $10 \%$ of the survivors of myocardial infarction $27,29,31$, whereas the population frequency is estimated from 1:200 to $1: 100$ or $0.5-1.0 \% 27,29,32$. FCHL is therefore associated with a substantially increased risk of CVD in index cases. Recently, two reports also addressed the seriously increased risk of fatal and non-fatal coronary artery disease in relatives of FCHL probands and found overall odds ratios of 1.7 and 5.1, respectively ${ }^{33,34}$. The differences in odds ratios may relate to the different risk of CVD in the control population in each studly ${ }^{33,34}$,

FCHL presents, by definition, with a multiple lipoprotein phenotype among relatives in a family, i.e. elevated very-low-density lipoproteins (VLDL, type IV hyperlipidemia), elevated low-density lipoproteins (LDL, type lla hyperlipidemia), or both (type llb hyperlipidemia) ${ }^{27}$. Moreover, the pattern of hyperlipidemia may change within one individual over time. Lipid levels are usually only moderately elevated in FCHL, with typical total cholesterol concentrations between 6 and 9 mmol/ $L$ and fasting triglyceride concentrations ranging from 2 to $6 \mathrm{mmol} / \mathrm{L}$. Patients with FCHL are characterised by an overpraduction of apolipoprotein B containing lipoproteins, including $V L D L^{35,36}, \mathrm{LDL}^{37}$, and small dense $L D L$ particles $^{38-44}$, in combination with a relative impairment of lipoprotein catabolism $^{32}$. Furthermore, FCHL affected patients are frequently insulin resistant ${ }^{n, 44}$. Clearly, the aggregate of these abnormalities results in an unfavourable, atherogenic risk profile. However, these lipid-related cardiovascular risk factors alone may not fully explain the high CVD risk in FCHL. 


\subsection{Atherosclerosis}

Established cardiovascular risk factors will, over time, result in advanced atherosclerosis and subsequent cardiovascular events. For a long time, atherosclerosis was viewed as a steadily progressive process in which fairly inert components relentlessly collected in the vessel wall until an artery developed stenosis, eventually leading to occlusion and subsequent cardiovascular events. Nowadays, it has been established that stable atherosclerotic lesions with a thick fibrous cap and protruding into the vascular lumen, are not the major cause of acute clinical events. Instead, most clinical events arise from lesions causing only mild to moderate angiographic stenosis or even from lesions that are invisible on angiography ${ }^{45.46}$. Furthermore, it is currertly known that lesion progression can be slowed, stopped and even regressed. Atherosclerosis is presently understood as a very dynamic process, with many different cellular elements that play a role in different stages of the process ${ }^{47}$. Atherosclerosis has been divided in several stages, especially depending on the cellular elements involved and progression and regression characteristics of the lesions ${ }^{48,49}$. However, one must bear in mind the continuous process of atherosclerosis ${ }^{50}$. Moreover, several different stages of the atherosclerotic process will occur next to each other in the human vasculature. In the prevalent view, atherosclerosis is considered as an immune, inflammatory or healing response of the intima to injury, also known as the 'response to injury" theory, first presented by Russell Ross $20,45,50,51$. The endothelium, long considered merely as a semi-permeable membrane, is now viewed a critical layer to maintain blood flow and vascular integrity. Healthy endothelium has anti-atherosclerotic properties and tends to favour vasodilatation, antithrombosis, fibrinolysis, and monocyte disadhesion ${ }^{52}$. Endothelial dysfunction is now regarded as the first step in the development of atherosclerosis. In principle, endothelial dysfunction is a reversible state. Dysfunctional endathelium is characterised by increased uptake of LDL and monocyte recruitment into the vessel wall, which are both pivotal initiating events in atherosclerosis ${ }^{53}$. Atherosclerosis is viewed as a disorder restricted to the intima layer of the arterial vessel wall. Accumulation of lipid-filled macrophages, or foam cells, in the intima represents the bulk of the initial lesion named fatty streak. Chemo-attraction of smooth muscle cells of the media layer and subsequent deposition of connective tissue matrix will lead to a fibro-fatty lesion. As the lesions progress, the cells in the lesions undergo rearrangements that may lead to the advanced atherosclerotic lesions or fibrous plaque ${ }^{50}$. The fibrous plaque is characteristically covered by a dense cap of fibrous tissue overlaying a cholesterol-rich inner layer. Unstable lesions are characterised by a lipid-rich core, a thin fibrous cap, few smooth muscle cells and fibroblasts, and a large number of foam cells, particularly at the shoulders of the caps. Unstable lesions are prone to rupture and lead to hemorrhage in the vessel wall or thrombotic occlusions, with subsequent ischemia and clinical cardiovascullar events ${ }^{45}$. Thus, before development of clinically manifest atherosclerosis and subsequent events, subclinical abnormalities in the different vascular beds will occur. Early detection of initial atherosclerotic lesions should give the physician more time to prevent 
further deterioration of the process and the occurrence of devastating cardiovascular events.

\subsection{Aims of the study}

Although FCHL is now known for more than 25 years, most of the research has been focussed upon the pathophysiology of lipid abnormalities and insulin resistance found in FCHL. Moreover, a lot of effort has been directed to identify the genes contributing to FCHL. First described as single gene disease, FCHL is nowadays regarded as a clinical enfity caused by one or two major genes and a range of modifier genes. Most of the genetic researches have been focussed at genes involved in the lipid or insulin pathways. However, despite the high cardiovascular risk in FCHL families, little is known about early manifestations of vascular abnormalities, and the atherosclerotic process in FCHL. Furthermore the presently known high risk of developing a cardiovascular event in $\mathrm{FCHL}$ can not be solely explained by the lipid-related cardiovascular risk factors studied so far.

Therefore, the overall objective of this thesis is:

A to describe cardiovascular risk factors that potentially contribute to the high risk of cardiovascular disease in Familial Combined Hyperlipidemia.

$B$ and to characterise early cardiovascular abnormalities in a range of vascular beds to provide us with a better view of early manifestations of the atherosclerotic process in subjects affected with Familial Combined Hyperlipidemia.

In this light, we studied:

1) The association of dyslipidemia and hypertension, in which abdominal fat mass is important (chapter 4).

2) The heart rate corrected QT-interval (QTC), and its alssociation with insulin resistance (chapter 5).

3) Abnormalities in endothelium-derived proteins of the coagulation and fibrinolytic systems (chapter 6).

4) Capillary structure and function, and the potential association with hyperlipidemia, blood pressure values and insulin resistance (chapter 7).

5) Intima media thickness, and the potential association with hyperlipidemia, blood pressure values and insulin resistance (chapter 8 ).

Because a single biochemical or genetic marker for FCHL is unavailable at present, family studies are still required to establish the diagnosis. In chapter 2, the family survey methodology is described, including descriptive epidemiological aspects of environmental factors in ascertained FCHL families. Moreover, the range of different measurement methodologies used in each subsequent chapter is described. Chapter 3 summarises our current pathophysiological view of lipid abnormalities and insulin resistance found in FCHL. Furthermore a brief overview on FCHL modifier genes identified up till now is presented. 


\section{References}

1. Reitsma JB, Dalstra JA, Bonsel GJ, van der Meulen JHP, Koster RW, GunningSchepers ${ }_{1}$, Tijssen JGP. Cardiovascular disease in the Netherlands, 1975 to 1995 : decline in mortality, but increasing numbers of patients with chronic conditions. Hearf $1999 ; 82: 52-56$

2. Yusuf $H R$, Giles $W H$, Croft JB, Anda RF, Casper ML. Impact of multiple risk factor profiles on determining cardiovascular disease risk. Preventive Medicine 1998;27:1. 9.

3. Castelli WP. Epidemialogy of caronary heart disease: the Framingham study. American Journal of Medicine 1984;76:4-12.

4. Assmann $G_{f}$ Schulte $H$. Relation of high-density lipoprotein cholesterol and triglycerides to incidence of atheroscleratic coronary artery disease the PROCAM experiencel. Prospective Cardiovascular Munster study. American Joumal of Cardiology 1992;70:733-737.

5. Stamler J, Dyer AR, Shekelle RB, Neaton J, Stamler R. Relationship of baseline major risk factors to coronary and all-cause mortality, and to longevity: findings from long. term follow-up of Chicago cahorts. Cardiology 1993;82:191-222.

6. Rosengren A, Hagman M, Wedel H, Wilhelmsen L. Serum cholesterol and long-term prognasis in middle-aged men with myocardial infarction and angina pectoris. A 16 year follow-up of the Primary Prevention Study in Goteborg, Sweden. European Heart Journal 1997;18:754-761.

7. Eaton CB, Bostom AG, Yanek L, Laurino JP, McQuade W, Huma A, Selhub J. Family history and premature coronary heart disease. Journal of the American Board of Family Practice 1996;9:312-318.

8. Lakier JB. Smoking and cardiovascular disease. American Joumal of Medicine $1992 ; 93: 85-112 S$.

9. Phillips NR, Waters D, Havel RJ. Plasma Lipoproteins and Progression of Coronary Artery Disease Evaluated by Angiography and Clinical Events. Circulation $1993 ; 88: 2762-2770$.

10. Kraus RM. Low-density lipoprotein subclasses and risk of coronary artery disease. Current Opinion in Lipidology 1991;2:248-252.

11. Gordon DJ, Probsifield JL, Garrison RJ, Neaton JD, Castelli WP, Knoke JD, Jacobs-Ir DR, Bangdiwala $S_{r}$ Tyroler HA. High-density lipoprotein cholesteral and cardiovascular disease. Four prospective American studies. Circulation 1989;79:815.

12. Haffner SM, Lehto $S$, Ronnemaa $T$, Pyarala K, Laakso M. Martality from coronary heart disease in subjects with type 2 diabetes and in nondiabetic subjects with and without prior myocardial infarction. New England Journal of Medicine $1998,339: 229-234$.

13. Gotto-Jr AM. Triglyceride: the forgotten risk factor. Circulation 1998;97:1027-1028.

14. Fontbonne $A$, Charless $M A$, Thibault N. Hyperinsulinemia as a predictor of cononary heart disease martality in a healthy population: the Paris prospective study, 15 years follow-up. Diabetologia 1998;34:356-361. 
15. Feskens EJM, Kromhouf D. Hyperinsulinemia, risk factors, and coronary artery diseose. Arteriosclerosis Thrombosis and Vascular Biology 1994;14:1641-1647.

16. Lamarche B, Tchernof A, Mauriege P. Cantin B, Dagenais, Lupien PJ, Depress JP. Fasting insulin and apolipoprotein B levels and low-densify lipoprotein particle size as risk factors for ischemic heart disease. Journal of American Medical Association 1998,279:1955-1961.

17. Lamarche B, Lemieux I, Despres JP. The small, dense LDL phenotype and the risk of coronary heart disease: epidemiology, patho-physiology and therapeutic aspects. Diabetes Metabolism 1999:25:199-211.

18. Scanu AM. Update on lipoprotein (a). Current Opinion in Lipidology 1991:2:253258.

19. Duell PB, Malinow MR. Homocyst(e)ine: an important risk factor for atherosideratic vascular disease. Current Opinion of Lipidology 1997;8:28-34.

20. Ross R. Atherosclerasis--an inflammatory disease. New England Journal of Medicine $1999 ; 340: 115-126$.

21. Thogersen AM, Jansson JH, Boman K, Nilssan TK, Weinehall L, Huhtasaari F, Hallmanss $G$. High plasminogen activator inhibitor and tissue plasminogen activator levels in plasma precede a first acute myocardial infarction in bath men and wamen: evidence for the fibrinolytic system as an independent primary risk factor. Circulation 1998:98:2241-2247.

22. Jager $\mathcal{A}$, van Hinsbergh WW, Kostense PJ, Emeis JJ, Yudkin JS, Nijpels G, Dekker JM, Heine R!, Bouter LM, Stehouwer CD. von Willebrand factor, C-reactive protein, and 5-year mortality in diabetic and nondiabetic subjects: the Hoorn Study. Arteriosclerasis Thrombosis and Vascular Biology 1999;19:3071-3078.

23. Gotto-Jr AM, Pownall HJ. Observational epidemiology and risk factors. In: Manual of lipid disorders, edited by Redford DC. Williams \& Wilkins Inc., 1999;160-191.

24. Talmud PJ, Buiac SR, Hall S, Miller GJ, Humphries SE. Substitution of asparagine for aspartic acid at residue 9 (D9N) of lipoprotein lipase markedly augments risk of ischaemic heart disease in male smokers. Atherosclerosis 2000;149:75-81.

25. Turner RC, Millns H, Neill HA, Strathon IM, Manley SE, Mathewss DR, Holman RR. Risk factors for coronary artery disease in non-insulin dependent diabetes mellitus: United Kingdom Prospective Diabetes Study (UKPDS: 23). Biritish Medical Joumal $1998 ; 316: 823-828$.

26. Anderson KM, Odell PM, Wilson PWF, Kannel WB. Cardiovascular disease risk profiles. American Heart Journal 1991;121:293-298.

27. Goldsiein JL, Schrott HG, Hazzard WR, Bierman EL, Motulsky AG. Hyperlipidaemia in Coronary Heart Disease. II Genetic analysis of lipid levels in 176 families and delineation of a new inherited disorder, combined hyperlipidaemia. Journal of Clinical Investigation 1973;52:1544.1568.

28. Rose HG, Kranz P, Weinstock $M$, Juliano J. Haft Ill. Inheritance of combined hyperlipoproteincemia: evidence for a new lipoprotein phenotype. American Journal of Medicine 1973;54:148-160.

29. Nikkilä EA, Aro A. Family study of serum lipids and apolipoproteins in coronary artery disease. Lancet 1973;78:954-959.

30. Brunzell JD, Schrott HG, Molulsky AG, Bierman EL. Myocardial infarction in the familial forms of thypentriglyceridemia. Metabolism 1976;25:313-320. 
31. Genest-Jr JJ, Martin MS, MCNamara JR, Ordovas JM, Jenner J, Mevers R, Sibermon SR, Wilson PWF, Salem DN, Sehoefer EJ. Familiol lipoprotein disorders in patients with premature coronary artery disease. Circulation 1992;85:2025-2033.

32. Matulsky AG. Current concepts in genetics. The genetic hyperlipidemios. New England Journal of Medicine 1976;294:823-827.

33. Austin MA, McKnight B, Edwards KL, Bradley CM, McNeely MJ, Psaty BM, Brunzell JD* Motulsky AG. Cardiovascular disease mortality in familial forms af hypertriglyceridemia: A 20-year prospective study. Circulation 2000;101:2777. 2782.

34. Voors-Pette C, de Bruin TWA. Excess coronary heart disease in Familial Combined Hyperlipidemia, in relation to genetic factors and central obesity. Atherosclerasis $2001 ; 157: 481-489$.

35. Venkatesan S, Cullen P, Pacy P, Halliday D, Scat I. Stable isotopes show a direct relation between VLDL apoB overproduction and serum triglyceride levels and indicate a metabolically and biochernically coherent basis for familial cambined hyperlipidemia. Arteriosclerosis Thrombosis and Vascular Biology 1993,13:1110. 1118.

36. Castro Cabezas $M$, de Bruin TWA, de Valk HW, Shoulders CC, Jansen $H$, Erkelens DW. Impaired fatty acid metabolism in familial combined hyperlipidemia. A mechanism associating hepatic apolipoprotein B overproduction and insulin resistance. Journal of Clinical Investigation 1993;92:160-168.

37. Kissebah AH, Alfarsi S, Evans Dע. Low density lipoprotein metabolism in familial combined hyperlipidemia. Mechanism of the multiple lipoprotein phenotypic expression. Arteriosclerosis 1984;4:614-624.

38. Hennekens $\mathrm{CH}$. Increasing burden of cardiovascular disease; current knowledge and future directions for research on risk factors. Circulation 1998;97:1095-1102.

39. Bredie 5J, Kiemeney LA, de Haan AF, Demacker PN, Stalenhaef AF. Inherited susceptibility determines the distribution of dense low-density lipoprotein subfraction profiles in familial combined hyperlipidemia. American Journal of Human Genetics 1996,58:812-822.

40. Bredie SJ, Demacker PN, Stalenhoef AF. Metabolic and genetic aspects of lamilial combined hyperlipidaemia with emphasis on low-density lipoprotein heterogeneity. European Journal of Clinical Inwestigation 1997;27:802-811.

41. Hokanson JE, Krauss RM, Albers JJ, Austin MA, Brunzell JD. LDL physical and chemical properties in familial combined hyperlipidemic. Arteriosclerosis Thrombosis and Wascullar Biology 1995; 15:452-459.

42. Cabezas MC, de Bruin TWA, Jansen $H$, Kock LA, Kortlandt W, Erkelens DW. Impaired chylomicron remnant clearance in familial combined hyperlipidemia. Arteriosclerosis and Thrombosis 1993;13:804-814.

43. Bredie SJH, Tack CJA, Smits P, Stalenhoef AFH. Non-obese patients with familial combined thyperlipidemia are insulin resistant as compared with their non-affected relatives. Arteriosclerosis Thrombosis and Vascular Biology 1997;17:1465-1471.

44. Hunt SC, Wu LL, Hopkins PN, Stults BM, Kuida H, Ramirez ME, Lalouel JM, Williams RR. Apolipoprotein, low density lipoprotein subfraction, and insulin associations with familial combined hyperlipidemia. Study of Utah patients with familial dyslipidemic hypertension. Arteriosiclerosis 1989;9:335-344. 
45. Fuster $V$, Badimon $L$, Badimon JJ, Chesebro JH. The parthogenesis of coronary artery disease and the acute coronary syndromies. New England Journal of Medicine $1992 ; 326: 242-250$.

46. Brown BG, Zhao X-O, Sacco DE, Albers J1. Lipid lowering and plaque regression: new insights into prevention of plaque disuption and clinical events in coronary disease. Circulation 1993;87:11781-1791.

47. Lusis AJ. Atherosclerosis. Nature 2000;407:233-241.

48. Stary HC, Chandler AB, Glagov S, Guyton JR, Insull W, Rosenfeld ME, Schaeffer SA, Schwartz CJ. Wagner WD, Wissler RW. A definition of initial, fatty streak, and intermediate lesians of atherosclerosis. A report from the Committee on Vascular Lesions of the Council on Arteriosclerosis, American Heart Assaciation. Circulation $1994 ; 89: 2462-2478$.

49. Stary HC, Chandler AB, Dinsmore RE, Fuster $V$, Glagov $S$, Insull W, Rosenfeld ME* Schwartz CJ, Wagner WD, Wissler RW. A definition of advanced types of atherosclerotic lesions and a histological classification of atherosclerosis. A report from the Committee on Vascular Lesions of the Councill an Arteriosclerosis, American Heart Association. Arteriosclerosis Thrombosis and Vascular Biology 1995;15:1512. 1531.

50. Ross R. Cell biology of atherosclerosis. Annual Review of Physiology 1995:57:791. 804.

51. Ross R. Atherosclerosis is an inflammatory disease. American Heart Joumal $1999 ; 138: \$ 419-5420$.

52. Vogel RA. Coronary risk factors, endothelial function, and atherosclerasis: a review. Clinical Cardiology 1997;20:426-432.

53. Fuster $V$, Gotto AM, Libby P, Loscalzo J, McGill HC. 27th Bethesda Conference: matching the intensity of risk factor management with the hazard for coronary disease events. Task Force 1. Pathogenesis of coronary disease: the biologic role of risk factors. Journal of American College of Cardiology 1996;27:964-976. 


\section{Chapter 2}

Subjects and general methods

Epidemiological aspects of Familial Combined Hyperlipidemia Specific methodology 


\subsection{Subjects and general methods}

\subsubsection{Introduction}

Up till now, no unique marker is available to identify a single subject as affected with Familial Combined Hyperlipidemia (FCHL). Therefore, a family study has to be conducted to establish the diagnosis of FCHL. Furthermore, in the framework of genetic and metabolic studies in FCHL, a family survey is needed. In this chapter we will address the collection of FCHL families used in the different studies described in the subsequent chapters of this thesis. Furthermore, the nature and frequency of hyperlipidemia in 'Maastricht' FCHL families and the accurrence and clustering of main cardiovascular risk factors (hypertension, obesity and smoking) is described. Finally, the main survey method used in each following chapter is briefly mentioned.

\subsubsection{Family survey}

In 1991, at the department of Internal Medicine and Endocrinology of the University Hospital Utrecht, Tjerk de Bruin and colleagues started with a family survey of Caucasian FCHL index patients (probands). Twenty-seven unrelated Caucasian probands were identified at the Lipid Clinic. In total, during the period 1991 to $1997,95 \%$ of living relatives over 18 years of age have been collected $(n=470)$, to confirm the diagnosis of FCHL and in the framework of metabolic and genetic studies. Part of these FCHL relatives were used for the blood pressure analyses as described in chapter 4 .

Since 1998, family surveys for FCHL were conducted at the Department of Internal Medicine and Endocrinology of the University Hospital Maastricht. Thirtynine unrelated Caucasian probands were identified at the out-patient clinic of the Department of Internal Medicine and their families were subsequently invited to participate in our FCHL research program. In total, during the period 1998 to $2001,95 \%$ of living relatives of 18 years of age and older have been collected $(n=396)$ to confirm the diagnosis of FCHL

In both places, married-in spouses and partners were asked to participate in our research project to establish a control group (Utrecht, $n=215$; Maastricht, $n=144$ ). All spouses had a negative history for familial premature cardiovascular disease (CVD) or familial hyperlipidemia. Still a single spouse individual could suffer from CVD or have been diagnosed with hyperlipidemia in the past. Part of FCHL affected subjects and spouses from 'Maastricht' families were used for the analysis in chapters 5 to 8 . 


\subsubsection{Diagnosing FCHL}

To establish the diagnosis of FCHL in a family, each of the following criteria were met: first, a proband with a primary hyperlipidemia with varying phenotypic expression including fasting total plasma cholesteral (TC) $>6.5 \mathrm{mmol} / \mathrm{L}(250$ $\mathrm{mg} / \mathrm{dL}$ ) and/or a fasting plasma triglyceride (TG) concentration $>2.0 \mathrm{mmol} / \mathrm{L}$ $(180 \mathrm{mg} / \mathrm{dL}$ ); second, af least one first-degree relative with a different hyperlipidemic phenotype (Fredrickson Classification $11 \mathrm{a}$, $\mathrm{Ib}$ or $\mathrm{M}$ ) from the proband; third, a positive family history of premature cardiovascular disease (CVD). Premature CVD was defined as the accurrence of a myocardial infarction (MI) or cerebrovascular incidence before the age of 60 years in at least one first degree relative of the proband, or the proband him-/herself. Secondary causes of hyperlipidemia (renal or hepatic insufficiency and hypothyroidism), presence of the apo E2/E2 genotype (thus, familial dysbetalipoproteinemia), and subjects with tendon xanthomas or a diagnosis matching familial hypercholesterolemia were excluded. A family tree of a FCHL family is depicted in Figure 2.1. Actual measured lipid values at the screening visit, all untreated, were used to diagnose FCHL relatives as hyperlipidemic or normolipidemic. As stated above, hyperlipidemia was defined as a total cholesterol $>6.5 \mathrm{mmol} / \mathrm{L}$ or fasting plasma triglyceride concentration $>2.0 \mathrm{mmol} / \mathrm{L}$, or a combination of both. Otherwise a relative was diagnosed as normolipidemic.

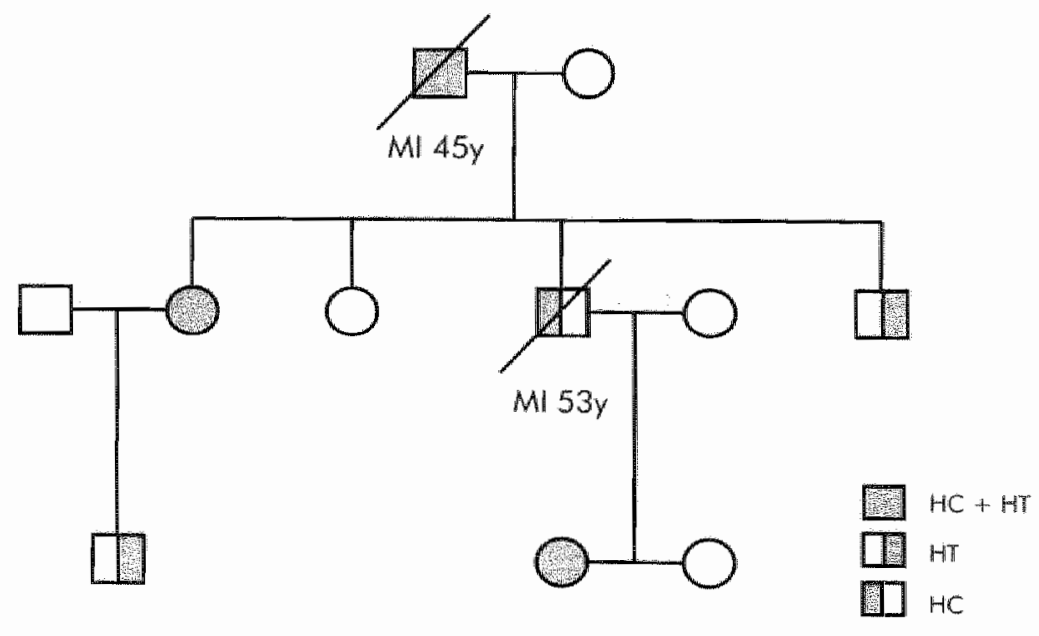

Figure 2.1. FCHL pedigree

Legend: $H C=$ tatal cholesterol $>6.5 \mathrm{mmol} / \mathrm{L}$; $H T=$ fasting plasma triglyceride $>2.0 \mathrm{mmol} / \mathrm{L} ; H C+H T=$ combination of both; $M I=$ myocardial infarction. 


\subsubsection{Materials and methods}

Clinical measurements were performed at the clinical research unit in the morning $\left(08^{00}-11^{00}\right)$ after an overnight fast $(12-14 \mathrm{~h})$. Subjects had refrained from smoking and had not drunk coffee or tea in the morning. Participants also had abstained from alcohol for at least 72 hours. Any lipid lowering medication had been withdrawn for two weeks before blood samples were collected. At the screening visit, a standardised questionnaire for smoking habits, use of alcohol, habitual physical activity, history of cardiovascullar disease and use of medication was obtained from all participating subjects. A detailed family history was obtained from all probands. Subsequently, blood pressure values IOMRON Health Care $\mathrm{GmbH}$, Hamburg, Germany) and antropometric parameters, i.e. weight, height, body mass index (BMI), waist and hip circumference, waist to hip ratio (WHR), were obtained. After all physical tests were performed fasting venous blood was collected in pre-cooled EDTA $(1-\mathrm{mg} / \mathrm{mll})$ Vacutainer tubes for measurements of lipid, lipoprotein, glucose and insulin concentrations, using commercially available methods (for details, see method sections in following chapters) 


\subsection{Epidemiological aspects of Familial Combined Hyperlipidemia}

\subsubsection{The epidemiology of cardiovascular risk factors in $\mathrm{FCHL}$}

In the present analyses, a standardised questionnaire, antropometric parameters, blood pressure values, lipid and glucose concentrations were obtained from 35 Maastrich FCHL families, consisting of 362 relatives and 126 married-in spouses, as mentioned above.

Any lipid lowering medication had been withdrawn for two weeks prior to the study. Hyperlipidemia was defined as stated before. Hypertension was defined as either systolic blood pressure $>140 \mathrm{mmH}$ and/or diastolic blood pressure $>90$ $\mathrm{mmHg}$, or the current use of antihypertensive medication ${ }^{1,2}$. Overweight was defined as body mass index $>27.5 \mathrm{~kg} / \mathrm{m}^{2}$ and obesity as $\mathrm{BMI}>30 \mathrm{~kg} / \mathrm{m}^{2}$.

The characteristics of the subjects studied are presented in Table 2.1. In these Dutch FCHL families, 143 out of 362 (39.5\%) relatives were currently diagnosed with hyperlipidemia compared to 23 out of $126(18.3 \%$ ) spouses $(p<0.001)$. Hyperlipidemic $\mathrm{FCHL}(\mathrm{HL})$ relatives were significantly older than normolipidemic (NL) relatives, with significantly higher BMI, WHR, waist-circumference, systalic (SBP) and diastolic (DBP) blood pressure and total cholesterol, fasting plasma triglyceride, low-density lipoprotein cholesterol, apolipoprotein B, glucose and insulin concentrations, and significantly lower high-density lipoprotein cholesterol levels. Comparing HL relatives versus spouses revealed the same significant differences as in comparison to NL relatives. Spouses are of the same age as the $\mathrm{HL}$ relatives. NL relatives were significantly younger than spouses, and showed lower WHR and lower plasma tatal cholesterol concentration.

The different hyperlipidemic phenotypes (i.e. HC, HT and HC + HT) were almost equally distributed among affected $\mathrm{FCHL}$ relatives (Figure 2.2). As already mentioned in the preceding chapter, many risk factors contributing to cardiovascular events are currently known. Major cardiovascular risk factors, like increasing age, hyperlipidemia, hypertension, obesity and current smoking, alone or in combination, have an important contribution to a high cardiovascular risk. Increasing age not only increases the absolute risk of cardiovascular events, but has also been associated with an increased prevalence of hyperlipidemia and hypertension in a general population. In our $\mathrm{FCHL}$ population, an increasing prevalence of hyperlipidemia (Figure 2.3) and hypertension (chapter 4) with increasing age was observed, far in excess of our spouse population. The prevalence of hyperlipidemia in FCHL families steeply increased from $15 \%$ (13 out of 86 subjects) under age 30 years up till $71.4 \%$ (25 out of 35 subjects) in the age category $60-69$ years. A striking abservation was that in FCHL subjects, hyperlipidemia accurs almost 20 years earlier than in the population; $p<0.01$ for trend (Figure 2.3). 
Table 2.1. Characteristics of $362 \mathrm{FCHL}$ relatives from $35 \mathrm{FCHL}$ families and 126 married-in spouses.

\begin{tabular}{lccc}
\hline & $\begin{array}{c}\text { Hyperlipidemic } \\
\text { relatives } \\
(\mathrm{n}=143)\end{array}$ & $\begin{array}{c}\text { Normolipidemic } \\
\text { relatives } \\
(\mathrm{n}=219)\end{array}$ & $\begin{array}{c}\text { Spouses } \\
(\mathrm{n}=126)\end{array}$ \\
\hline Age (years) & $48.9 \pm 13.1^{\dagger}$ & $37.6 \pm 14.3^{*}$ & $49.5 \pm 14.2$ \\
BMI $\left(\mathrm{kg} / \mathrm{m}^{2}\right)$ & $27.6 \pm 3.9^{* \dagger}$ & $24.6 \pm 4.4$ & $25.5 \pm 3.4$ \\
WHR & $0.94 \pm 0.08^{* \dagger}$ & $0.87 \pm 0.08^{*}$ & $0.89 \pm 0.09$ \\
Waist $(\mathrm{cm})$ & $97.0 \pm 11.1^{* \dagger}$ & $87.4 \pm 13.0$ & $90.3 \pm 11.0$ \\
SBP $(\mathrm{mmH} / \mathrm{g})$ & $141.7 \pm 21.8^{* \dagger}$ & $127.3 \pm 17.7$ & $133.4 \pm 21.3$ \\
DBP $(\mathrm{mmHg})$ & $88.2 \pm 12.3^{* \dagger}$ & $81.0 \pm 10.1$ & $83.8 \pm 11.0$ \\
TC $(\mathrm{mmol} / \mathrm{L})$ & $6.9 \pm 1.5^{* \dagger}$ & $4.9 \pm 0.9^{*}$ & $5.4 \pm 1.0$ \\
HDL-C $(\mathrm{mmol} / \mathrm{L})$ & $0.87 \pm 0.24^{* \dagger}$ & $0.99 \pm 0.23$ & $1.04 \pm 0.25$ \\
LDL.C $(\mathrm{mmol} / \mathrm{L})$ & $4.6 \pm 1.7^{* \dagger}$ & $3.5 \pm 0.8$ & $3.8 \pm 1.2$ \\
TG $(\mathrm{mmol} / \mathrm{L})$ & $2.8 \pm 2.4^{* \dagger}$ & $1.1 \pm 0.4$ & $1.3 \pm 1.2$ \\
Apo B $(\mathrm{g} / \mathrm{L})$ & $1.4 \pm 0.3^{* \dagger}$ & $1.0 \pm 0.2$ & $1.1 \pm 0.2$ \\
Apo A $(\mathrm{g} / \mathrm{L})$ & $1.4 \pm 0.3^{*}$ & $1.4 \pm 0.3$ & $1.5 \pm 0.3$ \\
Glyceral $(\mathrm{mmol} / \mathrm{L})$ & $77.9 \pm 30.1$ & $76.0 \pm 33.2$ & $71.7 \pm 31.5$ \\
FFA $(\mathrm{mmol} / \mathrm{L})$ & $0.5 \pm 0.2$ & $0.5 \pm 0.2$ & $0.4 \pm 0.2$ \\
Glucose $(\mathrm{mmol} / \mathrm{L})$ & $5.4 \pm 1.2^{* \dagger}$ & $4.9 \pm 0.7$ & $5.0 \pm 1.2$ \\
Insulin $(\mathrm{mL} / \mathrm{mL})$ & $10.5 \pm 7.6^{* \dagger}$ & $5.9 \pm 4.4$ & $6.1 \pm 5.4$ \\
\hline
\end{tabular}

$*=H L$ vs. Spouses, $p<0.01 ;^{\dagger}=$ HL vs. NL, $p<0.001 ;=$ NL vs. Spouses, $p<0.01$

Differences in blood pressure values are age-corrected.

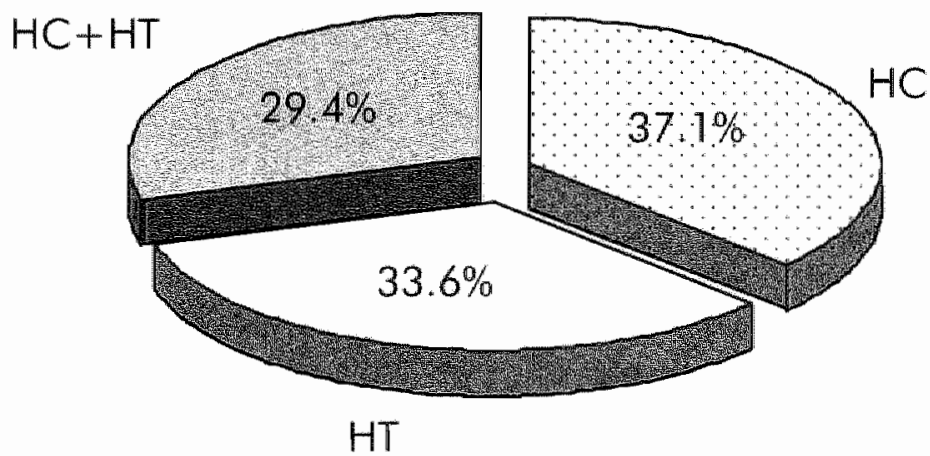

Figure 2.2. Distribution of hyperlipidemic phenolypes in $\mathrm{FCHL}$-affected relatives.

Legend: $\mathrm{HC}=$ total cholesterol $>6.5 \mathrm{mmol} / \mathrm{L} ; \mathrm{HT}=$ fasting plasma triglyceride $>2.0 \mathrm{mmol} / \mathrm{L} ; \mathrm{HC}+\mathrm{HT}=$ combination of both. 


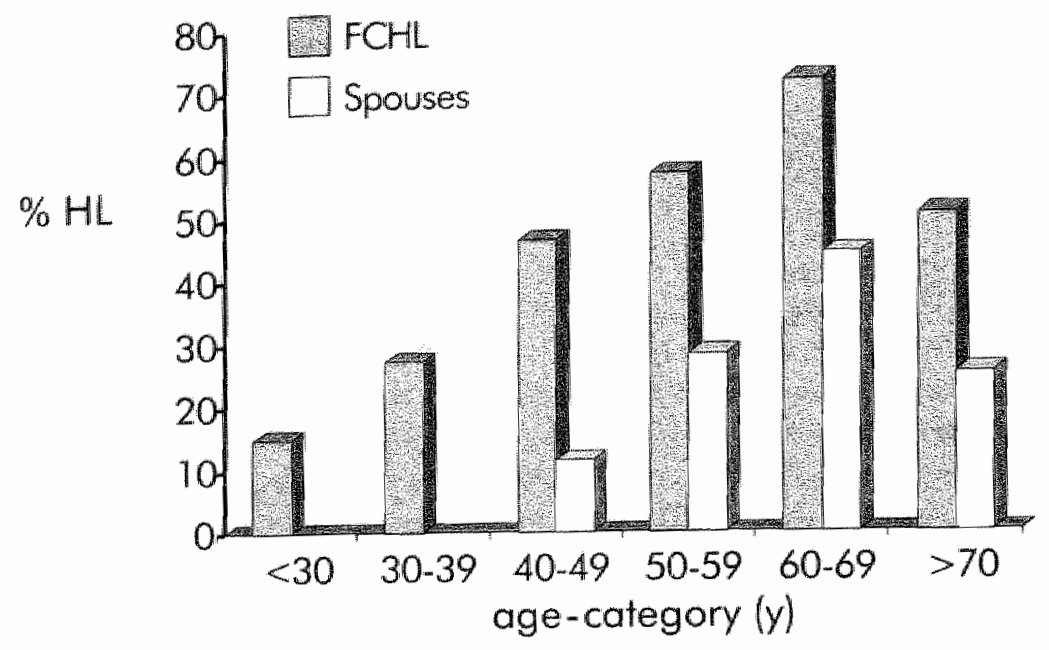

$p<0.01$ for trend

Figure 2.3. Age-dependent prevalence of hyperlipidemia (HL) in 35 FCHL-families $n=362$ ) and 126 married - in spouses.

Subsequently we evaluated the prevalence of several cardiovascular risk factors in HL- and NL-relatives and the spouse group (Table 2.2). Hypertension, overweight and obesity occurred more frequently in HL-relatives compared to spouses $(p<0.01$ for all three), whereas no differences were observed in prevalence of smoking or alcohol use, nor in the amount of cigarettes smoked (pack years) or consumed alcohol units per week. Hypertension, overweight and obesity also accurred more often in HL-relatives than in NL-relatives, even after age-correction $(p<0.001)$. The percentage of NL-relatives using alcohol was significantly thigher in comparison to HL-relatives. However, no difference in the amount of alcohol consumed per week was found.

It is plausible to assume that each single risk factor increases the risk of developing cardiovascular disease. Moreover, multiple combinations of these risk cardiovascular risk factors shall lead to an exponentially increased risk of cardiowascular events. For that reason we andysed the clustering of several risk factors in our study populations. A significant clustering of main cardiovascular risk factors (hyperlipidemia, hypertension, obesity and current smoking) in all FCHL family members was observed compared to spouses; $p<0.05$ for trend (Figure 2.4). Clearly, the aggregate of these abnormalities results in an unfavourable atheragenic risk profile, and hence increased risk of developing subsequent cardiovascular events. This is underlined by the high prevalence of cardiovascular disease imyocardial infarction, CABG, PTCA and cerebravascular accident) found in HL-relatives compared to spouses: $21.0 \%$ ws. $6.3 \%, p<0.005$ (Figure 2.5). 
Table 2.2. Distribution of cardiovascular risk factors in FCHL relatives and spouses.

\begin{tabular}{llll}
\hline & $\begin{array}{r}\text { Spouses } \\
(n=126)\end{array}$ & $\begin{array}{c}\text { Hyperlipidemic } \\
\text { relatives }(n=143)\end{array}$ & $\begin{array}{c}\text { Normolipidemic } \\
\text { relatives }(n=219)\end{array}$ \\
\hline Overweight $(\mathrm{BMI}>27.5)$ & $36(28.6 \%)$ & $66(46.2 \%)^{*}+$ & $45(20.6 \%)$ \\
Obesity $(\mathrm{BM})>30.0)$ & $12(9.5 \%)$ & $37(25.9 \%)^{*}+$ & $24(11.0 \%)$ \\
Hypertension & $45(35.7 \%)$ & $96(67.1 \%)^{*} \dagger$ & $55(25.2 \%)$ \\
Smoking & $38(30.2 \%)$ & $45(31.5 \%)$ & $74(33.9 \%)$ \\
Smoking (packyear) & $9.6 \pm 11.5$ & $11.3 \pm 14.3$ & $6.2 \pm 10.2$ \\
Alcohol & $98(77.8 \%)$ & $100(69.9 \%) \dagger$ & $178(81.7 \%)$ \\
Alcohol (U/week) & $8.5 \pm 9.5$ & $8.9 \pm 9.3$ & $8.2 \pm 8.6$ \\
\hline
\end{tabular}

* = HL vs. Spouses, $p<0.01 ; t=H L$ vs. NL, $p<0.001$; Differences in hypertension prevalence and packyears smoking values have been age-corrected.

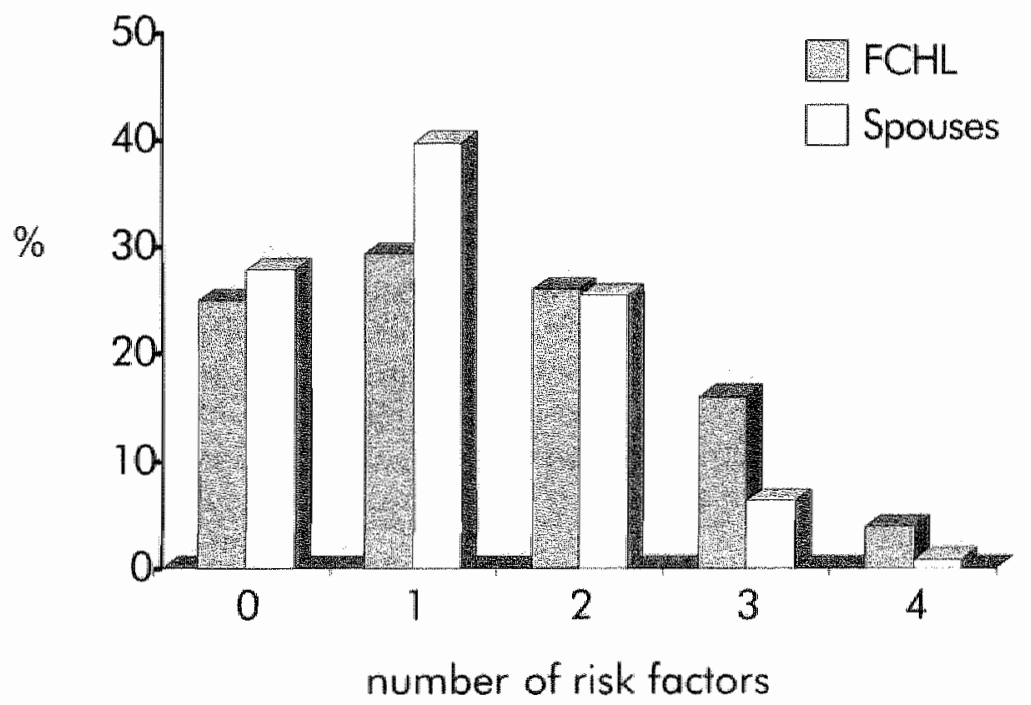

$p<0.05$ foir trend

Figure 2.4. Clustering of cardiovascular risk factors in $35 \mathrm{FCHL}$-families ( $\mathrm{n}=362$ ) and 126 married-in spouses. 


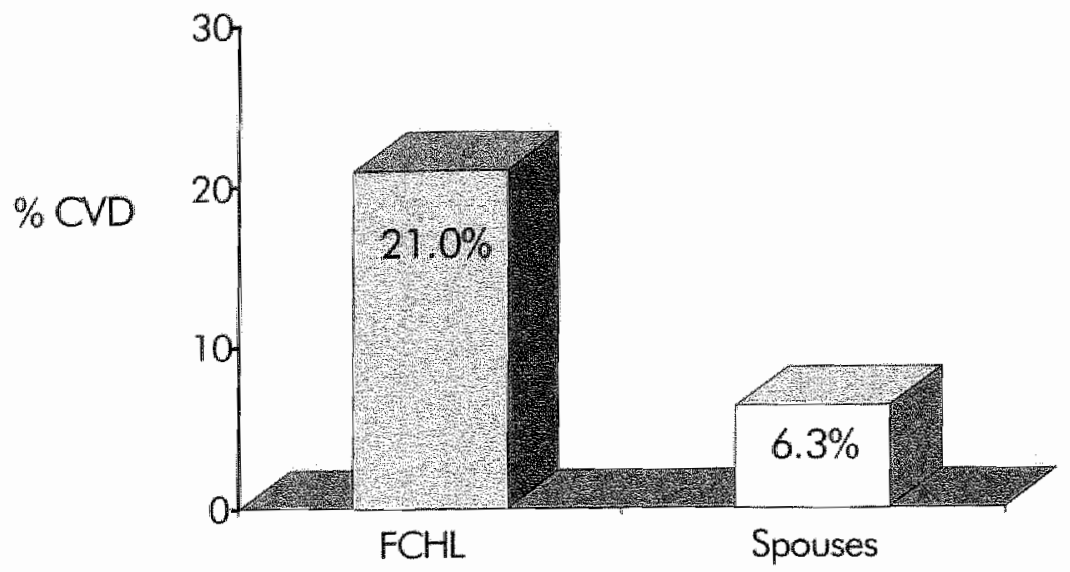

FCHL vs. spouses $=p<0.005$

Figure 2.5. Prevalence of cardiovascular disease in hyperlipidemic FCHL relatives $(n=143)$ and 126 married in spouses.

Legend: $C V D=$ cardiovascular disease.

In conclusion, in a cross-sectional survey almos $40 \%$ of relatives from Dutch FCHL farmilies were hyperlipidemic, with an equal distribution over the three hyperlipidemic phenotypes (HC, HT or the combination). The hyperlipidemia in FCHL is expressed 20 years earlier than in spouses. Furthermore, a clustering of cardiovascular risk factors is observed in FCHL relatives, further aggravating the risk of developing subsequent cardiovascular events. Environmental factors alone might play a minor role in explaining the high cardiovascular risk observed in FCHL, as no differences in smoking or alcohol habits were found. It is more plausible to assume that FCHL subjects are more susceptible to the unfavourable life style in the Western world. This can be caused by more pronounced geneenvironment interactions. 


\subsection{Specific methodology}

\subsubsection{Most important methodology in each subsequent chapter}

The main methodologies used in the investigations and analyses in each subsequent chapter are briefly described below. In chapler 4, FCHL relatives and spouses ascertained in Utrecht were used for the analyses. Part of FCHL affected subjects, and spouses from 'Maastricht' families and healthy controls were used for the analysis in chapters 5 to 8 .

\section{Chapter 4. Blood pressure}

FCHL has been proposed as the leading cause of dyslipidemia in Familial Dyslipidemic Hypertension $(\mathrm{FDH})^{3}$. Furthermore, it is very likely that the presence of both hyperlipidemia and hypertension contribute to the high risk of early cardiovascular disease in FCHL. In this chapter we quantified the simultaneous occurrence of hypertension and combined hyperlipidemia in FCHL families and evaluated a potential common pathogenic ancestry for FDH and FCHL. Therefore, blood pressure was measured twice with a mercury sphygmomanometer in a standardised fashion, with the subject in sitting position after 10 minutes of rest. Cuff size was adjusted to the circumference of the arm, and the arm was placed with the cuff at heart-level. Systolic (SBP) and diastolic blood (DBP) pressures were defined according to Korotkoff sounds I and V. Hypertension has been defined as either SBP $>140 \mathrm{mmHg}$ and/or DBP $>90$ $\mathrm{mmHg}$, or the current use of antihypertensive medication ${ }^{1,2}$.

\section{Chapter 5. Electrocardiogram and heart-rate corrected QT-interval.}

Heart rate corrected QT-interval (QTC) prolongation has been associated with increased risk of coronary heart disease death ${ }^{4 \cdot 6}$ and has been proposed as additional feature of the insulin resistance syndrome ${ }^{7}$. In this chapter we determined whether FCHL subjects had prolonged QTC times relative to spouse controls and investigated the potential relationship of QTc with hyperlipidemia and surrogate markers of the insulin resisfance syndrome. Therefore, a standard resting 12-lead electrocardiography was obtained, using a Marquette 12 SL ECG (GE Marquette Medical Systems, Milwaukee, WI, USA). QT intervals were automatically measured in all 12 leads. The beginning of the QT-interval was defined as the first deflection of the QRS complex, the end as the point of maximal change in the slope as the T-wave merges with the baseline. Heart rate adjusted QT (QTc) interval was automatically calculated with a modified Bazetf formula, using heart rate instead of RR interval for adjustment.

Chapter 6. Endothelium-derived pro-coagulant and anti-fibrinolytic factors

The increased risk of early cardiovascular events in FCHL is not fully explained by classical risk factors such as hyperlipidemia, insulin resistance and hypertension. Abnormal hemostatic properties of endothelium are potentially relevant to the 
development of clinical cardiovascular events in $\mathrm{FCHL}^{8.10}$. Endothelium produces pro-coagulant and anti-coagulant substances (pro-coagulant: von Willebrand factor (WWf); anti-coagulant: tissue factor pathway inhibitor (TFPI) and thrombomodulin) and components of the fibrinolytic system that promote or inhibit fibrinolysis (tissue type plasminogen activator (t-PA) and plasminogen activator inhibitor 1 (PAI-1), respectively). In this study venous blood was collected in pre-cooled tubes containing $3.25 \%$ sodium citrate (dilution $1: 10$ ) to measure $\mathrm{WWF}$, TFPl, soluble thrombomodulin and PAl-1, using commercially available assays. Blood collected in the Biopool stabilyte $^{\text {TM }}$ devices was used to measure t-pa levels. Venous congestion was minimised as much as possible and blood between 2 and $10 \mathrm{ml}$ after start of collection was drawn into the requested tubes. Plasma levels of $\mathrm{xWf}$ were determined by enzyme-linked fluorescent assay (normal range 60-200\%; Coefficient of Variation (CV) 4.2\%, Reader bioMérieux, France). Plasma levels of truncated TFPI were measured using an Elisa (range 40-85 ng/mL, CV 5-7\%, American Diagnostica Inc., Greenwich, USA). Thrombomodulin determination was performed with an enzyme immuno assay (normal range $50-120 \mathrm{ng} / \mathrm{mL}$, mean $76 \pm 22 \mathrm{ng} / \mathrm{mL}, \mathrm{CV} 8-10 \%$, Diagnostica Stago, France). Levels of PAl- 1 were determined by a specific chromogenic assay

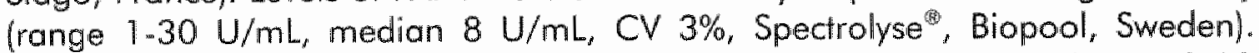
Plasma levels of t-PA were measured with an enzyme immuno assay (range 0-30 $\mathrm{ng} / \mathrm{mL}, \mathrm{CV} 5 \%$, Biopool, Sweden).

\section{Chapter 7. Capillary density and function}

In subjects with hypertension or type 2 diabetes, several abnormalities in the microvasculature have been reported ${ }^{17,12}$. Furthermore, impaired capillary recruitment has been proposed as a link between elevated blood pressure and insulin resistance, in both hypertensive ${ }^{13}$ and normotensive subjects ${ }^{14}$, although this was not confirmed in subjects with type 2 diabetes or impaired glucose tolerance ${ }^{15}$. As a result, the possible relationship between insulin resistance and microvascular abnormalities is not clear. Moreover, the possible role of plasma lipids, lipoproteins and remnant lipoprotein particles in microvascular abnormalities have not yet been taken into account in the above mentioned studies. Furthermore, little is known about microvasculature in hyperlipidemic diseases.

Therefore, the aim of the study described in chapter 7 was to determine whether abnormalities in capillary structure and function were present in FCHL, and furthermore to evaluate the potential association of observed microvascular abnormalities with plasma lipids and remnant-like lipoprotein particles, blood pressure values, and surrogate markers of insulin resistance. After an acclimatisation period of at least 20 minutes in a quiet, temperature-controlled room, the capillary density and laser Doppler fluxmetry were measured before and after 4 minutes of arterial occlusion. Capillary density, using capillary microscopy, was measured approximately $6 \mathrm{~mm}$ proximal to the finger nail fold of the right 4th finger. Finger nail fold capillaries were visualised using a WildLeitz microscope. Light from the microscope that penetrates the skin is scattered, reflected multiple times, and depolarised. If no strong absorbing parts are 
present, the reflected light image will be homogeneously bright. However, the 100-Watt mercury lamp has a peak emission about $420 \mathrm{~nm}$, matching the hemoglobin absorption spectrum. Consequently, the red blood cells appear dark in a bright background. Images $(1.6 \mathrm{~mm}$ ) were videotaped (Panasonic) for offline analysis. The day-to-day coefficient of variation was $8 \%$, as determined in ten subjects on two accasions.

Thermoregulatory skin perfusion was simultaneously determined, using laserDoppler fluxmetry (LDF, Periflux PF3, Perimed, Sweden), at the dorsum of the middle phalanx of the right 3 rd finger. The light $(632.8 \mathrm{~mm})$ of the He. Ne laser in the laser-Doppler device is reflected and scattered by the skin tissue and moving red blood cells. The light beams scattered by moving red blood cells undergo a frequency shift according to the Doppler effect. This frequency shift is a measure of red blood cell flux (red cell velocity times concentration) and equals red blood cell flow ${ }^{16}$. All measurements were performed using the standard probe PF308, filter setting: $12 \mathrm{kHz}$ ('wide band') and time constant $0.2 \mathrm{~s}$. He-Ne laser light penetrates the skin to a depth of about $1-\mathrm{mm}$, and hence the total flux values include signals from capillaries, arterioles, venous plexus and arteriovenous shunts ${ }^{17}$. The day-to-day coefficient of variation of post-occlusive reactive hyperaemia was $16 \%$, as determined in twenty subjects on two occasions.

\section{Chapter 8. Intima media thickness of common carotid artery}

FCHL is the most common genetic dyslipidemia in humans, affecting $0.5-2.0 \%$ of the population ${ }^{18}$. FCHL-affected subjects have a markedly increased risk of premature cardiovascular disease ${ }^{18-20}$. However, the clinical cardiavascular events are preceded by silent atheroscleratic changes in the vessel wall. Ultrasound measurement of intima media thickness (IMT) in the caratid wall is currently used as marker of sillent atherosclerasis. The aim of the study described in chapter 8 was to assess the amount of silent atherosclerosis, by ultrasound carotid IMT measurement, in FCHL-affected subjects and age and gendermatched healthy controls. In addition, we investigated the potential relationship of IMT with lipid-and lipoprotein concentrations, blood pressure values, and surrogate markers of insulin resistance.

The IMT measurements were performed using an Ultramark $4+$ (Ultramark $4+$, ATL, Bothel, Washington, USA), with a linear array transducer of $7.5 \mathrm{MHz}$. All subjects were measured in a supine position in a quiet room. During the measurements the head was tilted to the contra-lateral side at an angle of $45^{\circ}$. The automated radiofrequency (RF) method used to assess IMT has been described in detail before ${ }^{2 !}$. Briefly, a B-mode image was obtained from the common carotid artery (CCA) in a langitudinal section just before the widening of the bulb in the bifurcation. An $M$-line was positioned perpendicular to the posterior wall approximately $10-20 \mathrm{~mm}$ proximal to the carotid bulb, showing a clear intima-media complex during the whole measurement. Subsequently, the ultrasound system was switched to M-mode and ECG-triggered RF data collection was started at a sample frequency of $18.4 \mathrm{MHz}$, an $\mathrm{M}$-line update frequency of $800 \mathrm{~Hz}$, for a time period of 5 seconds, corresponding to $4-6$ heartbeats. For each heartbeat, the derivative with respect to depth of the 
averaged amplitude distribution was considered to distinguish wall signals from other signals. Subsequently, the locations of the intima and the media-adventitia edge were determined and IMT was defined as the distance between both edges. The ratio of intima to adventitia was set at 1.0 to suppress detection of false edges. The resolution for wall thickness detection was approximately $40 \mu \mathrm{m}^{21}$. Only the posteriar wall was investigated because here the reflections from the blood-intima and media-adventitia transition are distinctly visible, whereas at the anterior wall the trailing edge of the adventitia may obscure the media and intima signals. Each heartbeat within a recording resulted in an estimate of IMT. Measurements were repeated seven times at both left and right CCA. The average of the median values for each measurement obtained on both sides was taken as a representative IMT value. Ultrasound M-mode and RF signals method to measure IMT instead of off-line B-made measurement has been validated previously ${ }^{22}$. The intra-observer variability was below $6.5 \%$ as determined in 10 subjects on two different occasions. The inter-observer variability was $4.6 \%$ as determined in 10 subjects. 


\section{References}

1. The sixth report of the Joint National Committee on prevention, detection, evaluation, and treatment of high blood pressure. Archives of Internal Medicine $1997 ; 157: 2413-2446$

2. 1999 World Health Organization-International Saciety of Hypentension Guidelines for the Management of Hypertension. Guidelines Subcommittee. Journal of Hypertension 1999;17:151-183.

3. Williams RR, Hunt SC, Hopkins PN, Stults BM, Wu LL, Hasstedt SJ, Barlow GK, Stephenson SH, Lalovel JM, Kuida H. Familial Dyslipidemic Hypentension. Evidence from 58 Utah families for a syndrome present in approximately $12 \%$ of patients with essential hypertension. Journal of the American Medical Association $1988 ; 259: 3579-3586$.

4. Schwartz PJ, Wolf S. QT interval prolongation as predictor of sudden death in patients with myocardial infarction. Circulation 1978;57:11074-1077.

5. Schouten EG, Dekker JM, Meppelink P, Kok FJ, Vandenbroucke IP, Pool J. QT interval prolongation predicts cardiovascular mortality in an apparently healthy population. Circulation 1991;84:1516-1523.

6. Dekker JM, Schouten EG, Klootwijk P, Pool J, Kromhout D. Association between QT interval and coronary heart disease in middle-aged and elderly men. The Zutphen Study. Circulation 1994;90:779-785.

7. Dekker IM, Feskens EJ, Schouten EG, Klootwiilk P, Pool J, Kromhout D. QTC duration is associated with levels of insulin and glucose intolerance. The Zutphen Elderly Study. Diabetes 1996;45:376-380.

8. Hamsten A, de Faire U, Walldius G, Dahien G, Szamasi A, Landou C, Blomback M, Wiman B. Plasminagen activator inhibitor im plasma: risk factor for recurrent myocardiall infarction. Lancet 1987;2:3-9.

9. Jager A, wan Hinsbergh WW, Kostense PJ, Emeis Jل, Yudkin JS, Niipels $G$, Dekker JM, Heine RJ, Bouter LM, Stehouwer CD. von Willebrand factor, C-reactive protein, and 5-year mortality in diabetic and nondiabefic subjects: the Hoorn Study. Anteriosclerosis Thrombosis and Vascular Biology 1999:19:307 1-3078.

10. Thogersen AM, Jansson JH, Boman K, Nilsson TK, Weinehall L, Huhtasaari F, Hallmans $G$. High plasminogen adivator inhibitor and lissue plasminogen activator levels in plasma precede a first acule myacardial infarction in both men and women: ewidence for the fibrinolytic system as an independent primary risk factor. Circulation 1998; $98: 2241-2247$.

11. Shore $A C$, Tooke JE. Microvascular function in human essential hypertension. Journal of Hypertension 1994;12:717-728.

12. Jaap AJ, Hammersley MS, Shore AC, Tooke JE. Reduced microvascular hyperciemia in subjects at risk of developing type 2 (nom-insulim-dependent) diabetes mellitus. Diabetologia 1994; 37:214-216.

13. Serne EH, Gans ROB, ter Maaten J, ter Wee PM, Donker AM, Stehouwer CDA. Capillary recruitment is impaired in essential hypertension and relates to insulin's metabolic and vascular actions. Cardiovascullar Research 2001;49:161-168. 
14. Serne EH, Stehouwer CD, ter Maaten J, ter Wee PM, Rauwerda JA, Donker AJ, Gans RO. Microvascular function relates to insulin sensitivity and bload pressure in normal subjects. Circulation 1999,99:896-902

15. Jaap AJ, Shore AC, Stockman AJ, Tooke JE. Skin capillary density in subjects with impaired glucose folerance and potients with type 2 diabetes. Diabetic Medicine $1996 ; 13: 160-164$.

16. Driessen $G$, Rutten $W$, Inhoffen $W$, Scheid $H$, Heidimann $H$. Is the laser Doppler How signal a measure of microcirculatary cell flux? International Journal of Microcirculation in Clinical Experiments 1990;9:141-161.

17. Nilsson GE, Tenland T, Oberg PA. Evaluation of a laser Dappler flowmeter for measurement of tissue blood flow. IEEE Transactions on Biomedical Engineering $1980 ; 27: 597-604$.

18. Goldstein JL, Schrott HG, Hazzard WR, Bieman EL, Motulsky AG. Hyperlipidaemia in Coronary Heart Disease. II Genetic analysis of lipid levels in 176 families and delineation of a new inherited disorder, combined hyperlipidaemia. Journal of Clinical Investigation 1973;52:1544-1568.

19. Austin MA, McKnight B, Edwards KL, Bradley CM, MclNeely MJ, Psary BM, Brunzell JD, Motulsky AG. Cardiowascular disease martality in familial forms of hypertriglyceridemia: A 20-year prospective study. Circulation 2000;101:2777. 2782.

20. Voors Pette C, de Bruin TWA. Excess coronary heart disease in Familial Combined Hyperlipidemia, in relation to genetic factors and central obesity. Atherasclerosis $2001 ; 157: 481-489$.

21. Hoeks AG, Willekes $C_{*}$ Boutouyrie $P$, Brands Pl, Willigers $J M_{p}$ Reneman RS. Automated detection of local artery wall thickness based on M-line signal processing. Ultrasound in Medicine and Biology 1997;23:1017-1023.

22. Willekes $C$, Hoeks $A$, Bots $M$, Brands P, Willigers J, Reneman R. Evaluation of off-line automated intima-media thickness detection of the common carotid artery based on M-line signal processing. Uitrasound in Medicine and Biology 1999;25:57-64. 


\section{Chapter 3}

Pathophysiological and genetic mechanisms in Familial Combined Hyperlipidemia: our current understanding 


\section{1 Introduction}

Familial Combined Hyperlipidemia (FCHL) is one of the most common genetic lipid disorders in humans ${ }^{1-4}$, affecting approximately $10 \%$ of survivors of early myocardial infarction (i.e. before 60 years of age) 1.3 .5 , whereas the population frequency is estimated from 1:200 to $1: 100$ or $0.5-1.0 \% 13.6$. FCHL, within one family, may present with elevated very low-density lipoprotein (VLDL, type IV hyperlipidemia), elevated low-density lipoprotein (LDL, partly resembling type lla hyperlipidemia), or both (type Ilb hyperipidemia)'. Moreover, the paitern of hyperlipidemia (i.e. hypercholesterolemia and hypertriglyceridemia) may change within one individuall, and is not often seen before adulthood". Despite the high risk of cardiovascular disease (CVD), lipid levels are only moderately elevated in FCHL, with typical total cholesterol (TC) concentrations between 6.0 and 9.0 $\mathrm{mmol} / \mathrm{L}$ and fasting triglyceride (TG) concentrations of 2.0 to $6.0 \mathrm{mmol} / \mathrm{L}$.

Although FCHL was first described in 1973 by Goldstein and calleagues', the fundamental basis of FCHL remains to be elucidated. As no unique biochemical or genetic marker for $\mathrm{FCHL}$ is available yet, family studies are required to establish the diagnosis of FCHL in a single patient?. Generally, we accept a diagnosis of $\mathrm{FCHL}$ if the index patient and a first-degree relative have different hyperlipidemic phenotypes, in which at least one of the subjects shows a combined hyperlipidemia, and if there is an unequivocal family history of hyperlipidemia and premature CVD.

Patients with FCHL are characterised by an overproduction of apolipoprotein B (apo $B$ ) containing lipoproteins, including $\mathrm{VLDL}^{8,9}, \mathrm{LDL}^{10}$, and small dense $\mathrm{LDL}$ particles 11.14 , in combination with a relative impairment of lipoprotein catabolism ${ }^{15}$. These mechanisms contribute to elevated plasma concentrations of apo B, the structural apoprotein in these lipoproteins. Furthermore, FCHL subjects are often insulin resistant ${ }^{16.20}$. Clearly, the aggregate of these abnormalities results in an unfavourable, atherogenic risk profile and increases the risk of developing cardiovascular events. A recent report by Austin and colleagues showed that the 20-year cardiovascular mortality in FCHL kindred was a factor $\pi .7$ higher than in spouse controls ${ }^{21}$. However, this may represent an underestimation of the true risk, because spouse controls showed a remarkably high cardiovascular mortality of $9.8 \%$ and total mortality of $29.4 \%$. Furthermore, Voors-Pette and colleague showed that FCHL men had a 5.3 times higher risk of developing non-fatal coronary artery disease ${ }^{22}$.

Despite the high risk on CVD mortality and morbidity, and the corresponding serious impact on our health care system, FCHL is often not recognised by the physician in daily clinicall practice. This chapter will summarise our current understanding of the pathophysiology of $\mathrm{FCHL}$, especially focusing on lipid metabolism and insulin resistance. Furthermore, the role of genetic susceptibility and interaction with environment will be addressed briefly. 


\subsection{Lipid metabolism}

Several studies have shown abnormalities in lipoprotein metabolism, including increased hepatic secretion of apolipoprotein B (apo B) containing lipoproteins (very low-density lipoproteins, the large VLDL1 and smaller VLDL2) B, $^{10,23}$, leading to a combined increase of cholesterol and triglyceride concentrations in plasma. It has also been suggested that increased VLDLI residence time in the circulation contributes to hypertriglyceridemia in FCHL. Two subgroups of apo B are known: apo B100 and apo B48. Apo B100 is present in VLDL particles produced by the liver, as well as in intermediate density lipoprotein (IDL) and LDL particles, which are both derived from VLDL catabolism. Apo B48 is present in chylomicrons produced in the gut, and the chylomicron remnants. As mentioned above, in FCHL affected subjects increased apo B concentrations are often found. As each lipoprotein contains only one apo B molecule, an increased apo B concentration is an indicator of increased numbers of circulating lipoproteins. Furthermore, all apo B-containing lipoproteins are potentially atherogenic, where apo B also has been shown to be a better risk indicator of CVD compored to other lipid levels or smoking, diabetes mellitus and hypertension ${ }^{24}$.

Although apo B overproduction in FCHL is known for several years, the underlying mechanism, for instance, increased lipid supply, especially free fatty acids or an intrinsic defect in hepatocytes, wether or not related to insulin resistance, is not known yet. Because of the elevated plasma apo B levels, the apo $B$ gene has been suggested as primary candidate gene for FCHL. However, no genetic abnormalities involved in this apo B averproduction have been detected in FCHL so far. Furthermore, apo B gene defects have been ruled out by linkage analysis in FCHL kindred as primary major gene, despite the effect on lipid levels $\mathrm{s}^{25-28}$.

After secretion, endogenous (from liver) and exogenous (from gut) derived lipoprotein particles are catabolised by a common lipolytic pathway represented by lipoprotein lipase (LPL). Because of the action of the LPL-enzyme, fatty acids are liberated from the lipoproteins and passed to the adipose tissue or skeletal muscle cells to be stored or oxidised. By doing this, LPL converts VLDL into smaller VLDL-remnants or IDL, and finally $L D L$, and chylomicrons are converted into chylamicron remnants. ApoB 100 and apoB48 containing lipoproteins compete for LPL action, where LPL at low concentrations seems to have a preference for apoB 48 containing particles and LPL at high concentrations seems to have an equal preference for either apoB48 or apoB100 containing particles ${ }^{29}$.

Diminished post-heparin LPL activity and mass values have been reported in FCHL subjects ${ }^{30.34}$. Moreover, normal insulin-mediated activation of LPL is diminished in FCHL subjects, which contribute to reduced clearance of triglyceride-rich lipoproteins ${ }^{15}$. However, single LPL-gene mutations have been infrequently found in FCHL subjects ${ }^{35,36}$. Interestingly, such single LPL-gene mutation has a significant additional effect on lipid and lipoprotein phenotype 
expression ${ }^{35,36}$. Linkage analysis revealed no significant relationship between the LPL-gene and $\mathrm{FCHL}^{34,35,37}$. These dato indicate that the LPL-gene does not represent the major single gene causing $\mathrm{FCHL}$, but is a variability gene or a minor gene in $\mathrm{FCHL}$, with potentially important gene-environment interactions, which might contribute to increased risk of $C V D^{30}$.

Hepatic lipase $(\mathrm{HL})$ is a candidate gene for FCHL as well. HL resides in the sinusoidal space in the liver and is involved in the conversion of HDL particles, predominantly acting as a phospholipase, and in processing and removal of remnant lipoproteins. Low activity of HL has been associated with high levels of triglycerides and $\mathrm{HDL}$-cholesterol and reduced $\mathrm{LDL}$ particle size ${ }^{39}$. Furthermore, the $\mathrm{HL}$ gene was also linked to LDL particle size, HDL-cholesterol and TG levels in FCHL families and an association of a HL promoter polymorphism with HDLcholesterol levels was observed ${ }^{20,40,41}$.

Impaired insulin-mediated LPL activation and reduced LPL mass values both contribute to less optimal lipolysis and increased circulation times of TG containing lipoproteins. Moreover, in FCHL a reduced clearance of chylomicron remnants has been observed ${ }^{15}$. Both phenomeno can eventually lead to the formation of smaller, denser $L D L$ particles. Small, dense $L D L$ and its immediate precursor, IDL, have been associated with increased risk of $C V D^{42-44}$. A preponderance of small LDL particles, called LDL phenotype $B$, is associated with a more atheragenic lipoprotein profile than a preponderance of larger, buoyant, LDL (type A phenotype). The presence of small dense LDL particles, which occurs in combination with increased plasma TG and apo B concentrations and with reduced HDL-cholesteral levels, has been termed the "atherogenic lipoprotein phenotype' (ALP) and is independently associated with an increased risk for $\mathrm{CVD}^{42}$. Reduced levels of $\mathrm{HDL}$-cholesterol 7,9 and a preponderance of small, dense LDL particles ${ }^{13,44}$ also frequently, but not always, occur in patients with $\mathrm{FCHL}$, although they are not considered as criteria for the diagnosis of disease. Allayee and colleagues provided evidence that minor FCHL loci also contribute to LDL particle size, and suggested that ALP and FCHL share a subsel of their genetic determinants ${ }^{45}$.

Clearly, the frequent occurrence of small dense LDL in FCHL subjects raises the risk of developing early and severe atherosclerosis and subsequent events. Lipoprotein(a) or $\mathrm{Lp}(\mathrm{a})$ is a lipoprotein with a LDL-like moiety and the addition of apo (a). Increased $L p(a)$ concentrations have been associated with increased CVD risk. Therefore, Lp(a) might play an important role in FCHL as well. In both FCHL and normolipidemic subjects a connection between the metabolism of $L p(a)$ and triglyceride-rich lipoproteins has been suggested ${ }^{46}$. However, no significant differences in $L p(a)$ concentrations between FCHL and healthy normolipidemic subjects have been observed ${ }^{46,47}$. Furthermore, several genome scans in FCHL populations failed to show a significant LOD peak in the Lp(a) gene region ${ }^{48,49}$. So, it is unlikely that $\mathrm{Lp}(\mathrm{a})$ contributes to the expression of $\mathrm{FCHL}$ or to the high CVD risk observed in FCHL. 
In summary, FCHL harbours a complex phenotype with increased concentrations of atherogenic lipoprateins. Furthermore, an increased flux of atherogenic lipoproteins in the vessels, with in addition, increased residence time, suggests an increased exposure of endothelium to atherogenic lipoproteins in FCHL affected subjects.

\subsection{Adipose tissue}

Over the past few years the possible role of adipose tissue in the expression of FCHL has emerged. FCHL affected subjects often show increases in body weight, waist to hip ratio (WHR) and waist-circumference. Although manifest obesity (body mass index (BMI) $>30 \mathrm{~kg} / \mathrm{m}^{2}$ ) is, as secondary cause of hyperlipidemia, an exclusion criteria for FCHL in our laboratory, the increased WHR and waistcircumference indicate increased amounts of adipose tissue, and, perhaps, loss of muscle mass as well ${ }^{50}$. Several hormonal and enzymatic systems in adipose tissue have been studied in relationship to FCHL and will be discussed below. Leptin is a protein hormone produced predominantly by adipocytes. Serum leptin concentrations in healthy individuals are positively correlated with body fat content and BMI. In FCHL women, serum leptin concentrations out of proportion to BMI have been reported ${ }^{51}$. A study by Haluzik and colleagues however, failed to demonstrate a significant difference in leptin levels between FCHL subjects and healthy controls ${ }^{52}$. Also no significant relationship between serum leptin concentrations and lipid levels were observed ${ }^{52}$. Van der Kallen and colleagues have reported evidence that a human chromosome ip locus, harbouring the leptin receptor gene, contributes to plasma leptin concentrations, adiposity and body weight in FCHL subjects ${ }^{53}$. This supports the hypothesis that the leptin receptor gene plays a role in the observed increase in weight and waistcircumference abserved in FCHL subjects. As will be pointed out below, an increased visceral fat mass appears to play a pivotal role in the development of the insulin resistant, hyperlipidemic and hypertensive phenotype found in FCHL. In the postprandial state, storage of TG will take place in adipose tissue. Before entering the adipocyte, TG from VLDL and chylomicrons will have to be hydrolysed by LPL into free fatty acids (FFA) and glycerol. In the adipocyte, intracellular re-esterification to TG takes place, which is mediated by the action of acylation stimulatary protein (ASP) ${ }^{54}$. The possible role of ASP in the development of hyperlipidemia in FCHL is still under study. Impaired FFA 'trapping' has been observed in adipose tissue of subjects with hyper-apo B as well ${ }^{55}$.

In the fasting state, adipocyte TG is lipolysed by hormone sensitive lipase (HSL) for energy delivery to the bloodstream. The lipolytic effect of HSL, which is normally inhibited by postprandial hyperinsulinemia and enhanced by catecholamines, is partly impaired in $\mathrm{FCHL}^{55.57}$. A reduction in maximum enzymatic activity of HSL has also been correlated with serum lipid abnormalities in Swedish FCHL families ${ }^{56}$, although not confirmed in Finnish FCHL families ${ }^{58}$. Both defect in HSL reaction to insulin and an impaired FFA re-esterification in FCHL may result in an increased flux of FFA to the liver and consequently in an 
increased hepatic VLDL synthesis. Although increased FFA flux to the liver is an established metabolic entity in FCHL, genetic analysis have failed to demonstrate an important contribution of the HSL gene to the expression of $\mathrm{FCHL}^{37}$. An alternative hypothesis is that insulin resistance might play an important role in the observed increased FFA flux from adipose tissue to the liver.

\subsection{Insulin resistance}

Because insulin has several important actions on lipid metabolism, the existence of insulin resistance may be an important factor modulating FCHL phenotypes. Several studies have shown that FCHL subjects are equally insulin resistant for glucose disposal to subjects with diabetes mellitus ${ }^{16-20}$. Moreover, even in normolipidemic non-affected subjects of FCHL families insulin resistance has been found ${ }^{59}$, indicating a possible role of insulin resistance in the development of some features of $\mathrm{FCHL}$.

As pointed out before, an impaired insulin-mediated activation of LPL results in a reduced clearance of triglyceride-rich proteins. Additionally, insulin resistance has been associated with increased levels of small dense LDL particles, which has also often been abserved in FCHL. Furthermore, an impaired FFA suppression during hyperinsulinemic euglycemic clamp ${ }^{20,59,60}$ and after oral fat load ${ }^{61}$ has been observed in FCHL. Also, in vitro stimulation of adipose tissue derived from FCHL affected subjects, showed an impaired FFA suppression after stimulation with insulin ${ }^{57}$.

However, increased fasting plasma insulin concentrations may also be secondary to impaired postprandial FFA metabolism. Increased FFA-flux from visceral fat to the liver not only promotes VLDL production, but also gluconeogenesis. Increased production of glucose is a trigger to the pancreas to secrete insulin in order to maintain normoglycemia, and can thus result in increased fasting plasma insulin concentrations. Although the occurrence of diabetes mellitus is not enhanced in FCHL. kindred, increased prevalence of impaired glucose tolerance and higher insulin and glucose area under the oral glucose folerance curve have been observed.

Because of the remarkable resemblance of the metabolic profile observed in FCHL and the Insulin Resistance Syndrome (IRS), FCHL has been postulated as being part of IRS instead of being a solely dinical entity. At present, it is clear that IRS plays an important role in the clinical and biochemical expression of FCHL. However, whether IRS also plays a role in the development of FCHL or is merely a consequence of FCHL remains to be elucidated. Furthermore, the observed clinical and biochemical abnormalities in FCHL cannot be explained by IRS alone, because normolipidemic relatives have been reported to be insulin resistant as well ${ }^{59}$. 


\subsection{Genetic susceptibility}

Originally, it was thought that FCHL was a dominantly inherited hyperlipidemia closely associated with cardiovascular disease. However, subsequent research has not supported this cancept. One hypothesis is that affected families have an aligogenic hyperlipidemia, causing variable phenotypes among family members, in relation to environmental effects. Because of its complex phenotype, FCHL is likely to be a heterogeneous disorder, influenced by several susceptibility genes and environmental factors. Till now, no major genes have been located, but some modifier genes are known.

As pointed out above, mutations in apo B gene, LPL gene, HL gene and HSL gene have an effect on lipid and lipoprotein phenotype expression, but do not represent the major gene causing FCHL. One of the first proposed major candidate-regions causing FCHL was the apo Al-CIII-AlV gene cluster on chromosome $11^{62}$, that was further confirmed in other populations ${ }^{63,64}$. However, not all FCHL populations confirmed this finding ${ }^{65}$. A more detailed analysis revecled a specific high risk combination of haplotypes based on three polymorphic markers within this cluster: Xmnl, Mspl and Sstl, indicating that two different susceptibility loci for FCHL exist within this gene complex ${ }^{66}$. Furthermore, the Sstil locus was recently shown to be related to non-fatal CVD risk in FCHL subjects $^{22}$.

Recently, linkage studies in a large number of Finnish FCHL families revealed evidence of a major gene for $\mathrm{FCHL}$ on chromosome 1q21-q236\%. A study in another $\mathrm{FCHL}$ population confirmed ${ }^{68}$ this finding using a novel analytical strategy. However, different strategies in genetic analyses (affected-only vs. sibpair analyses), renders comparisons between the several studies difficult ${ }^{67,69}$. For instance, analyses of Dutch pedigrees using the Finnish affected-only strategy also revealed linkage to this chromosomal region (TWA de Bruin, P Pajukanta, FCHL workshop, ESCl meeting, 2-5 May 2001, Barcelona, Spain). A novel gene (Hyplip I) in $\mathrm{HCB} 19$ mice has been mapped to a portion of the mouse genome that is syntenic to the human chromosome $1 q 21-q 23$. Recently, the region on chromosome $1 \mathrm{q}$ has been narrowed down to $1 \mathrm{q} 21$ by fine-mapping the Hyplip 1 locus in the mouse and defining the borders of the region of conserved synteny between human and mouse. This region lies approximately within 5-10 $\mathrm{Mb}$ of the peak marker (D1S104) for linkage to $\mathrm{FCHL}^{70}$, which, however, also harbours several other interesting candidate genes (P Pajukanta, FCHL workshop, ESCl meeting, 2-5 May 2001, Barcelona, Spain).

A genome scan in Dutch FCHL families revealed another candidate modifier gene: lecithin:cholesterol acyltransferase $(L C A T)^{71}$, an enzyme involved in cholesterol transfer between lipoprotein particles ${ }^{48}$. Furthermore, candidate gene studies also have shown that PPAR $\gamma^{72}$, and tumor necrosis factor receptor superfamily member $1 B$ (TNFRSF 1B) ${ }^{73}$ have some effect on the $\mathrm{FCHL}$ phenotype, but seem not to be the primary cause of FCHL.

Despite all these major and important efforts, much work has to been done to truly clarify the genetic background of FCHL. Additional candidate gene studies 
should be performed since many candidates for both 'major' and 'modifier" effects remain to be examined. Furthermore, 'major' genes are likely to be heterogeneous. The potential overlap of genetic factors between FCHL, type 2 diabetes mellitus and ALP suggests that collaboration between the groups studying these traits will be beneficial.

\subsection{Conclusion}

Since its first description in 1973, major efforts have been taken to unravel the genetic and metabolic pathophysiology underlying FCHL. Currently, the increased free fatty acid flux from visceral ar subcutaneous adipose tissue to the liver is an important metabolic theory in FCHL, that explains - in part - the increased production of VLDL particles, and hence hyperlipidemia. Several modifier genes have been detected, which have especially an effect on the hyperlipidemic phenotype observed in FCHL. The recently published human genome map $^{74,75}$ may make it easier to fine-map and detect possible important genes underneath an interesting LOD-peak for FCHL. However, despite the knowledge of the chromosomal map of a gene, the exact role of many genes has to be established. Moreover, gene-gene and gene-environment interaction probably also will play a major role in many multi-genic diseases like $\mathrm{FCHL}$. It is likely that gene expression profile from affected organs of FCHL subjects will further increase our insight and understanding of FCHL at the cellular level ${ }^{\gamma \delta, 77}$. 


\section{References}

1. Goldstein JL, Schrot HG, Hazzard WR, Bierman EL, Matulsky AG. Hyperlipidaemia in Coronary Heart Disease. II Genefic analysis of lipid levels in 176 families and delineation of a new inherited disonder, combined hyperlipidaemia. Joumal of Clinical Investigation 1973,52:1544-1568.

2. Rase $H G$, Kranz P, Weinstock M, Juliano J, Haff Jl. Inheritance of combined hyperlipoproteinaemia: evidence for a new lipoprotein phenotype. American Journal of Medicine 1973;54:148-160.

3. Nikkilä EA, Aro A. Family study of serum lipids and apolipoproteins in coronary artery disease. Lancet 1973;78:954-959.

4. Brunzell JD, Schrott HG, Motulsky AG, Bierman EL. Myocardial intarction in the familial forms of hypentriglyceridemia. Metabolism 1976;25:313-320.

5. Genest Jr JJ, Martin MS, Melvamara JR, Ordlovas JM, Jenner J, Myers RH, Silberman SR, Wilson PW, Salem DN, Schoefer EJ. Familial lipoprotein disorders in patients with premature coronary artery disease. Circulation 1992;85:2025-2033.

6. Motulsky AG. Current concepts in genetics. The genetic hyperlipidemias. New England Journal of Medicine 1976;294:823-827.

7. Grundy SM, Chait A, Brunzell JD. Familial combined hyperlipidaemia workshop. Arteriosclerosis 1987;7:203-207.

8. Venkatesan S, Cullen P, Pacy P, Halliday D, Scott J. Stable isotopes show a direct relation between VLDL apoB overproduction and serum triglyceride levels and indicate a metabolically and biochemically coherent basis for familial combined hyperlipidemia. Asteriosclerosis Thrombasis and Vascular Biology 1993;13:1110. 1118

9. Castro Cabezas $M$, de Bruin TWA, de Valk HW, Shoulders CC, Jansen H, Erkelens DW. Impaired fatty acid metabolism in famifial combined hyperllipidemia. A mechanism associating hepatic apolipoprotein B overproduction and insulin resistance. Journal of Clinical Investigation 1993:92:160-168.

10. Kissebah AH, Alfarsi S, Evans DJ. Low density lipoprotein metabolism in familial combined hyperlipidemia. Mechanism of the multiple lipoprotein phenotypic expression. Arteriosclerosis 1984;4:614-624.

11. Hennekens $\mathrm{CH}$. Increasing burden of cardiovascular disease; current knowledge and future directions for research on risk factors. Circulation 1998;97:1095-1102.

12. Bredie SJ, Kiemeney LA, de Haon AF, Demacker PN, Stalenhoef AF. Inherited susceptibility determines the distribution of dense low-density lipoprotein subfraction protiles in familial combined hyperlipidemia. American Journal of Human Genefics $1996,58: 812-822$

13. Bredie SJ, Demacker PN, Stalenhoef AF. Metabolic and genetic aspects of familial combined hyperlipidaemia with emphasis on low-density lipoprotein heterogeneity. European Journal of Clinical Investigation 1997;27:802-8\%1.

14. Hakanson JE, Krauss RM, Albers JJ, Austin MA, Brunzell JD. LDL physical and chemical properties in familial combined hyperlipidemia. Arteriosclerosis Thrombosis Vascular Biology 1995; 15:452-459. 
15. Cabezas MC, de Bruin TWA, Jansen H, Kock LA, Kartlandt W, Erkelens DW. Impaired chylomicron remnant dearance in familial combined hyperlipidemia. Anteriosclerosis and Thrombosis 1993;13:804-814.

16. Bredie SJH, Tack CJJ, Smits P, Stalenhoef AFH. Nonmobese patients with fomilict combined hyperlipidemia are insulin resistant as compared with their non-affected relatives. Arteriosclerosis Thrombosis and Vascular Biology 1997; 17: 1465-1471.

17. Hunt SC, Wu LL, Hopkins PN, Stults BM, Kuida H, Ramirez ME, Lalouel JM, Williams RR. Apolipoprotein, low density lipoprotein subfraction, and insulin associations with fomilial combined hyperlipidemia. Study of Utah patients with familial dyslipidemic thypentension. Arteriosclerosis 1989;9:335-344.

18. Ascaso JF, Merchante A, Lorente RI, Real JT, Martinez VJ, Carmena R. A study of insulin resistance using the minimal model in nondiabetic familial combined hyperlipidemic patients. Metabolism 1998;47:508-513.

19. Ascaso JF, Lorente R, Merchante A, Real JT, Priego A, Carmena R. Insulin resistance in patients with familial combined hyperlipidemia and coronary artery disease. American Journal of Cardiology 1997;80:1484-1487.

20. Pihlajamaki J, Karjalainen L, Karhapaa P, Vauhkonen I, Laakso M. Impaired free fatty acid suppression during hyperinsulinemia is a characteristic finding in familial combined hyperlipidemia, but insulin resistance is observed only in hypentriglyceridemic patients. Arteriosclerosis Thrombosis and Vascular Biolagy 2000;20:164-170.

21. Austin MA, McKnight B, Edwards KL, Bradley CM, McNeely MJ, Psaty BM, Brunzell JD, Motrulsky AG. Cardiovascular disease mortality in familial forms of hypertriglyceridemia: A 20-year prospective study. Circulation 2000;101:27772782.

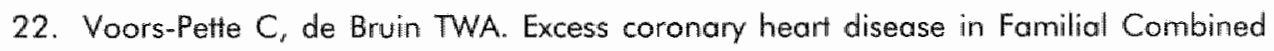
Hyperlipidemia, in relation to genetic factors and central obesity. Atherosclerosis $2001 ; 157: 481$-489.

23. Cuchel M, Schaefer EJ, Millar JS, Jones PJ, Dolnikowski GG, Vergani C, Lichtenstein AH. Lovastatin decreases de novo cholesterol synthesis and LDL Apo B-10O production rates in combined-hyperlipidemic males. Arteriosclerosis Thrombosis and Vascular Biology 1997;17:1910-1917.

24. Kwiterovich-Jr PO, Coresh J, Smith HH, Bachorik PS, Derby CA, Pearson TA. Comparison of the plasma levels of apolipoproteins B and A-1, and other risk factiors in men and women with premature coronary artiery disease. American Joumal of Cardiology 1992;69:1015-1021.

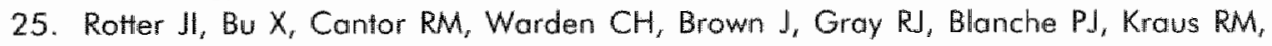
Lusis AJ. Multilocus genetic determinants of LDL particle size in coromary artery disease families. American Journal of Human Genetics 1996;58:585-594.

26. Austim MA, Wijsman E, Guo SW, Krauss RM, Brunzell JD, Deeb S. Lack of evidence for linkage between low-density lipoprotein subclass phenotypes and the apolipoprotein B locus in familial combined hyperlipidemia. Genetic Epidemiology $1991: 8: 287-297$.

27. Rauh G, Schuster H, Muller B, Schewe S, Keller C, Wolfram G, Zollner N. Genetic evidence from 7 families that the apolipoprotein $B$ gene is not involved in familial combined hyperlipidemia. Atherosclerosis 1990;83:81-87. 
28. Coresh J, Beaty TH, Kwiterowich-Jr PO, Antonarakis SE. Pedigree and sib-pair linkage cinalysis suggest the apolipoprotein B gene is not the major gene influencing plasma opolipoprotein B levels. American Journal of Human Genetics 1992,50:1038-1045.

29. van Beek AP, von Borlingen HH, de Ruijter Heijstek FC, Jansen H, Erkelens DW, Dallinga-Thie GM, de Bruin TWA. Preferential clearance of apoB-48-containing lipoproteins after heparin-induced lipolysis is madulated by lipoprotein lipase activity. Journal of Lipid Research 1998;39:322-332.

30. Babirak 5 , Brown B, Brunzell J. Familial combined hyperlipidemia and abnormal lipoprotein lipase. Arteriosclerosis and Thrombosis 1992;12:1176-1183.

31. Seed M, Mailly F, Vallance D, Doherty E, Winder A, Talmud P, Humphries SE. Lipoprotein lipase activity in patients with combined hyperlipidaemia. Clinical Investigation 1994;72:100-106.

32. Nevin DN, Brunzell JD, Deeb SS. The LPL gene in individuals with fomilial combined hyperlipidemia and decreased LPL activity. Arteriosclerosis and Thrombosis $1994: 14: 869 \times 873$

33. Gogne E, Genest J, Zhang $H$, Clarke LA, Hayden MR. Analysis of DNA changes in the LPL gene in patients with familial combined hyperlipidemia. Atteriosclerosis and Thrombosis 1994;"14:1250-1257.

34. Yang WS, Nevin DN, Iwasaki L, Peng R, Brown BG, Brunzell JD, Deeb SS. Regulatory mutations in the human lipopratein lipase gene in patients with familial combined hyperlipidemia and coronary artery disease. Journal of Lipid Research $1996 ; 37: 2627-2637$.

35. de Bruin TWA, Mailly F, van Barlingen HH, Fisher $R$, Castro Cabezas M, Talmud $P$, Dallinga-Thie GM, Humphries SE. Lipoprotein lipase gene mutations D $9 N$ and N2915 in four pedigrees with familial combined hyperlipidaemia. European Journal of Clinical investigation 1996;26:631-639.

36. Hoffer MJ, Bredie SJ, Boomsma DI, Reymer PW, Kastelein JJ, de Knijff $P_{i}$ Demacker PN. Stalenhoef AF, Havekes LM, Frants RR. The lipoprotein lipase (Asn291 -.> Ser) mutation is associated with elevaled lipid levels in families with familial combined hyperlipidaemia. Atherosclerasis 1996; 1 19:159-167.

37. Pajukanta $P$, Porkka KV, Antikainen M, Taskinen MR, Perola M, Murtomaki Repo $S_{\text {, }}$ Ehnholm S, Nuotio 1. Suurinkeroinen L, Lahdenkari AT, Syanen AC, Viikari JS, Ehnholm C. Peltonen L. No evidence of linkage between familial combined hyperlipidemia and genes encoding lipolytic enzymes in Finnish families. Arterioselerosis Thrombosis and Vascular Biology 1997;17:841-850.

38. Talmud PJ, Bujac SR, Hall S, Miller GJ, Humphries. SE. Substitution of asparagine for aspartic acid at residue 9 (D9N) of lipopratein lipase markedly augments risk of ischaemic heart disease in male simokers. Atherosclerosis 2000;149:75-81.

39. Zambon A, Austin MA, Brown BG. Hokanson JE, Brunzell JD. Effect of hepatic lipase on LDL in normal men and thase with coronary artery disease. Arteriasclerasis and Thrombosis 1993;13:147.153.

40. Allayee H, Dominguez KM, Aovizerat BE, Kraus RM, Rotter JI, Lu J, Cantor RM, de Bruin TWA, Lusis AJ. Contribution of the hepatic lipase gene to the atherogenic lipopratein phenotype in familial combined hyperlipidemia. Journal of Lipid Research
$2000,41: 245-252$.

41. Jansen H, Chu $G$, Ehnhalm C, Dallongeville J, Nicaud V, Talmud PJ. The T allele of the hepatic lipase promater varian $C-480 T$ is associated with increased fasting lipids 
and HDL and increased preprandial and postprandial LpCII:B : European Atherascllerosis Research Study (EARS) II. Atteriosclerosis Thrombosis and Vascular" Biology 1999:19:303-308.

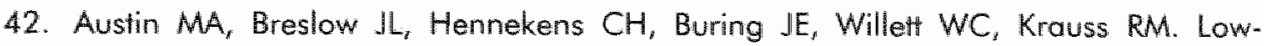
density lipoprotein subclass patterns and risk of myocardial infarction. Joumal of American Medical Association 1988;260:1917-1921.

43. Austin MA, Brunzell JD, Fitch WL, Krouss RM. Inheritance of low density lipoprotein subclass patterns in familial combined hyperlipidemia. Arteriosclerosis 1990; 10:520530 .

44. Jarvik GP, Brunzell JD, Austin MA, Krauss RM, Molulsky AG, Wijsman E, Genetic predictors of FCHL in four large pedigrees. Influence of ApoB level majar locus predicted genotype and LDL subclass phenotype. Arteriosclerosis and Thrombosis $1994 ; 14: 1687-1694$.

45. Allayee $H$, Aovizerat BE, Cantor RM, Dallinga-Thie GM, Kraus RM, Lanning CD, Rotter JI, Lusis AJ, de Bruin TWA. Families with familial combined hyperlipidemia and families enriched for coronary artery disease share genetic determinants for the atherogenic lipoprotein phenotype. American Journal of Human Genetics $1998 ; 63: 577-585$.

46. Castro Cabezas $M$, de Bruin TWA, Van-Linde-Sibenius TM, Kock LA, Jansen $H$, Erkelens DW. Lipopratein(a) plasma concentrations assaciated with lipallytic activities in eight kindreds with familial combined hyperlipidemia and normolipidemic subjects. Metabolism 1993;42:756-761.

47. Netea RT, Netea MG, Bredie SJ, Demacker PN, Hancu N, Thien T, Stalenhoef AF, Lipoprotein (a) concentrations in patients with familial combined hyperlipidemia and hypertension. Netherlands Journal of Medicine 1999;55:39-45.

48. Aovizerat BE, Allayee $H$, Bodnar J, Krass $K_{\text {, }}$, Peltonen L, de Bruin TWA, Rotter Jl, Lusis AJ. Novel genes for familial combined hyperlipidemia. Current Opinion in Lipidology 1999;10:113-122.

49. Pajukanta $P$, Terwilliger JD, Perala $M$, Hiekkalinna $T$, Nuotio I, Ellanen P, Parkkonen M, Hartiala J, Ylitalo K, Pihlajamaki J, Porkka K, Laakso M, Vikari d, Ehnholm $C$, Taskinen MR, Peltonen L. Genomewide scan for familial combined hyperlipidemia genes in finnish families, suggesting multiple susceptibilify laci influencing triglyceride, cholesterol, and apolipoprotein B levels. American Jounal of Humam Genetics 1999;64:1453-7:463.

50. Seidell JC, Cigolini $M$, Charzewska J, Ellsinger BM, Deslypere JP, Cruz A. Fat distribution in European men: a comparison of anthropometric measurements in relation to cardiovascular risk factors. International Journal of Obesity Related Metabolic Disorders 1992;16:17-22.

51. Jacobson MS, Yoon DJ, Frank GR. Serum leptin is elevated out of proportion to the body mass index in adolescent females with familial combined hyperlipidemia (FCH). Clinical Pediatrics Philadelphia 1999;38:49-53.

52. Haluzik M, Fiedler J, Nedvidkova J, Ceska R. Serum leptin concentrations in patients with combined hyperlipidemia: relationship to serum lipids and lipoproteins. Phiysiological Research 1999;48:363-368.

53. van der Kallen $\mathrm{CJH}$, Cantor RM, van Greevenbroek MMJ, Geurts JMW. Bouwnan FG, Aouizerat BE, Allayee H, Buurman WA, Lusis AJ, Rotter $J$, de Bruin TWA. Genome scan for adipasity in Dutch dyslipidemic families reveals novel quantitative 
trait loci for leptin, bady mass index and soluble tumor necrosis factor receptor superfamily A. International Joumal of Obesity 2000,24:1381-1391.

54. Sniderman AD, Walson C, Teng B, Franklin FA, Bachorik PS, Kwiterovich-Jr PO. Assaciation of hyperapobetalipoproteinemia with endogenous hypertriglyceridemia and atherosclerosis. Annals of Internal Medicine 1982;97:833-839.

55. wan der Kallen CJH, Voors-Pette C, Bouwman FG, LU JY, wan de Hulst RRWJ, Janssen MJ, Keulen ETP, Boecko WD, Rotter Jl, de Bruin TWA. Evidence of insulin resistant lipid metabolism in adipose fissue in familial combined hyperlipidemia, but not type 2 diabetes mellitus. Atherosclerosis 2001 ; submitted.

56. Reynisdattir 5, Eriksson M, Angelin B, Arner P. Impaired activation of adipocyte lipolysis in familial combined hyperlipidemia. Joumal of Clinical Investigation $1995 ; 95: 2161-2169$.

57. Pette C, Janssen MJ, van der Kallen CJH, de Bruin TWA. Specific insulin resistance of adipose tissue in familial combined hyperlipidemia. Circulation 1999;100:1-196 (Abstract).

58. Ylitalo $K_{x}$ Large V, Pajukanta $P_{s}$ Reynisdottir $S$, Parkka KVK, Vukkilainen J, Nuotio $I_{f}$ Taskinen MR, Amer P. Reduced hormone-sensitive lipase activity is not a major metabolic defect in Finnish FCHL families. Atherosclerosis 2000;153:373-381.

59. Karialainen L. Pihllajamaki J, Karhapaa P, Laakso M. Impaired insulin-stimulated glucose oxidation and free fatty acid suppression in patients with familial combined hyperlipidemia: a precursor defect for dyslipidemia? Anteriosclerosis Thrombosis and Vascular Biology 1998;18:1548-1553.

60. Aitman TJ, Godsland IF, Farren B, Crook D, Wang HJ, Scott J. Defects of insulin action on fatty acid and carbohydrate metabolism in familial combined hyperlipidemia. Arteriosclerosis Thrombosis and Vascular Biology 1997; 7:748-754.

61. Meijssen S, Cabezas MC, Twickler TB, Jansen H, Erkelens DW. In vivo evidence of defective pasiprandial and postabsorptive free fatty acid metabolism in famillial combined hyperlipidemia. Journal of Lipid Research 2000;41:1096-1102.

62. Wojciechowski AP, Farrall M, Cullen P, Wilson TM, Buyliss JD, Farren B, Griffin BA, Caslake MJ, Packand CJ, Shepherd AJ. Familial combined hyperlipidaemia linked to the opolipoprotein Al.CII-AIV gene cluster on chromosome 11q23-q24. Nature $1991,349: 161-164$

63. Dallinga-Thie GM, van Linde-Sibenius Trip $M$, Rotter JI, Lusis AJ, de Bruin TWA. Apolipoprotein Al/CIII/AIV gene cluster in familial combined hyperlipidemia: effects on LDL-cholesterol and apolipoproteins B and C-lll. Journal of Lipid Research $1996,37: 136-147$.

64. Coon H. Myers RH, Borecki IB, Arnett DK, Hunt SC, Province MA, Diousse L, Leppert MF. Replication of linkage of familial combined hyperlipidemia to chromosome $1 q$ with additional heterogeneous effect of apolipoprotein A-U/C-III-IV locus - The NHLBI Family Heart Study. Arteriosclerasis Thrombasis and Vascular Biology $2000: 20: 2275-2280$. 
65. Wijsman EM, Brunzell JD, Jarvik GP, Austin MA, Motulsky AG, Deeb SS. Evidence against linkage of familial combined hyperlipidemia to the apolipoprotein AI-CIIH-AIM gene complex. Arteriosclerasis Thrombosis and Vascular Bialagy 1998;18:215-226.

66. Dallinga-Thie GM, van Linde-Sibenius Trip M, Rotter Jl, Cantor RM, Bu X, Lusis AJ, de Bruin TWA. Complex genetic contribution of the apoAll-Clll-AlV gene cluster to familial combined hyperlipidemia: identification of different susceptibility haplotypes. Journal of Clinical Investigation 1997:99:953-961.

67. Pajukanta P, Nuatio I, Tenwilliger JD, Porkka KV, Ylitalo K, Pihlajamaki J, Suomalainen AJ, Sywanen AC, Lehtimaki $T$, Viikari $J S_{i}$ Laakso M, Taskinen MR, Ehnholm $C_{r}$ Peltonen L. Linkage of familial combined hyperlipidaemia to chromosome 1q21-q23. Nature Genetics 1998;18:369-373.

68. Pei W, Baron H, Muller MB, Myksoh B, Knoblauch H, Al Yahycee SA, Hui R, Wu X,

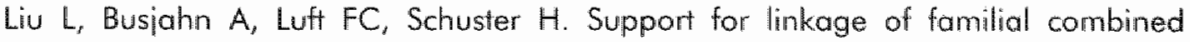
hyperlipidemia to chromosome $1 q 27-q 23$ in Chinese and German families. Clinical Genetics 2000;57:29-34.

69. Aovizerat BE, Allayee $H$, Cantor RM, Pavis RC, Lanning CD, Lien PZ, Dallinga-Thie GM, de Bruin TWA, Rotter JI, Lusis AJ. A genome scan for familial combined hyperlipidemia reveals evidence of linkage with a lacus an chromosome 11 . American Journal of Human Genetics 1999;65:397-412.

70. Pajukanta P, Bodnar JS, Sallinem R, Chu M, Ainaksinen T, Xiao QN, Castellani LW, Sheth SS, Wesman M, Palotie A, Sinsheimer JS, Demant P, Lusis AJ, Peltonen L. Fine mapping of Hyplipl and the human homolog, a potential locus for FCHL. Mammalian Genome 2001;12:238-245.

71. Aouizerat BE, Allayee $H$, Cantor RM, Dallinga-Thie GM, Lanning CD, de Bruin TWA, Lusis AJ, Rotter Jl. Linkage of a candidate gene locus to familial combined hyperlipidemia: lecithin:cholesterol acyltransferase on 16q. Arteriosclerosis Thrombosis and Vascular Biology 1999:19:2730-2736.

72. Pihlajamaki J, Miettinen R, Valwe R, Karjalainen L, Mykkanen L, Kuuisisto J, Deeb S, Auwerx J, Laakso M. The Pro12Ala substitution in the peroxisome proliferator activated receptor gamma 2 is associated with an insulin-sensitive phenotype in families with familial combined hyperlipidemia and in nondiabetic elderly subjects with dyslipidemia. Atherasclerosis 2000;151:567-574.

73. Geurts JMW, Janssen RGJH, van Greevenbroek MMJ, van der Kallen CJH, Cantor RM, Bu XD, Aquizerat BE, Allayee $H$, Rotter Jl, de Bruin TWA. Identification of TNFRSFIB as a novel madifier gene in familial combined hyperlipidemia. Human Molecular Genetics 2000;9:2067-2074.

74. Human genome project 2001. Science 2001;291:1195-1200.

75. Lander ES, Linton LM, Birren B. Initial sequencing and anallysis of the human genome. Nature 2001;409:860-921.

76. Eurlings PMH, Geurts JMW, van der Kallen CJH, de Bruin TWA. Genetic dissection of familial combined hyperlipidaemia. European Journal of Clinical Investigation $2001 ; 31: 20: 88$ (Abstract).

77. Eurlings PMH, wan der Kallen CJH, Geurts JMW, van Greevenbroek MMJ, de Bruin TWA. Genetic dissection of familial combined hyperlipidemia. Molecular Genetics and Metabolism 2001, in press. 
52 


\section{Chapter 4}

\section{Familial Dyslipidemic}

Hypertension Syndrome: further delineation in Familial Combined Hyperlipidemia, and the role of abdominal fat mass 


\section{Abstract}

Familial Combined Hyperlipidemia (FCHL) is the most frequent genelic lipid abnormality in humans, with a 5- to 10-fold increased risk of early myocardial infarction. FCHL has been proposed as the leading cause of dyslipidemia in Familial Dysilipidemic Hypertension $(\mathrm{FDH})$. It was the objective of this study to quantify and analyse the simultaneaus occurrence of hypertension and hyperlipidemia in FCHL families. We assessed blood pressure and hyperlipidemia in 27 families with FCHL (235 relatives and 140 spouses, aged 30 to 60 years\}. Hypertension was defined as a blood pressure more than 140/90 $\mathrm{mm} H \mathrm{~g}$, or the use of antihypertensive medication. Multiple backward linear regression analysis was used to derive a bialogical formula describing blood pressure in FCHL families. One-third of 27 FCHL-families were diognosed with FDH. Sixty-four of 235 $(27.2 \%)$ relatives had dyslipidemic hypertension (DH), compared to 20 of $140(14.3 \%)$ spouses $(p=0.005) ;$ odds ratio $=2.25(95 \%$ confidence interval 1.29-3.91). Multiple linear regression analysis showed that age, FCHL-status and waist-circumference significantly contributed to systolic blood pressure in females. In conclusion, in FCHL we defined age, waist-circumference and hyperlipidemia as predictors of systolic blood pressure. This study indicates that visceral adipose tissue strongly contributes to the high prevalence of $\mathrm{DH}$ in FCHL families. Reduction of viscerall fat should be tested as a potential therapeutic intervention for hyperlipidemia and hypertension in FCHL individuals. 


\section{Introduction}

Hyperlipidemia, hypertension, diabetes mellitus, smoking, and a positive family history of cardiovascular disease are established major risk factors for the development of premature atherosclerosis and subsequent cardiovascular events. Multiple combinations of these cardiovascular risk factors will lead to an exponentially increased risk of early coronary artery disease $(C A D)^{1,2}$. Hyperlipidemia, hypertension and a positive family history of CAD combined occur as a separate entity: Familial Dyslipidemic Hypertension (FDH), which has been delineated in a large survey on the genetics of essential hypertension in Utah, USA ${ }^{3}$. Approximately $12 \%$ of all adults in families with essential hypertension also expressed dyslipidemia ${ }^{3}$. Although no formal study was done at that time and early coronary artery events had not been recorded, Familial Combined Hyperlipidemia $(\mathrm{FCHL}$ ) was proposed to be the most frequent cause of the observed $12 \%$ dyslipidemic cases ${ }^{3}$.

FCHL is, by far, the most common genetic dyslipidemia in humans, with a prevalence of 0.5 to $1.0 \%$ in the general population ${ }^{4.7}$. Ten percent of survivors of early onset coronary artery disease have been reported to be affected with $\mathrm{FCHL}$, resulting in a high relative risk ratio of 10 with regard to early $C A D^{4,5}$. It is very likely that the presence of both hyperlipidemia and hypertension in FCHL families contribute to such high risk of early CAD. It is the objective of this study to quantify, for the first time, the simultaneous occurrence of hypertension and combined hyperlipidemia in FCHL families and to evaluate a common pathogenic ancestry for FDH and FCHL.

\section{Subjects and methods}

Twenty-seven unrelated Caucasian FCHL index patients (probands) were identified at our Lipid Clinic. FCHL probands met each of the following criteria: first, a primary hyperlipidemia including fasting total plasma cholesterol (TC) $>6.5 \mathrm{mmol} / \mathrm{L}(250 \mathrm{mg} / \mathrm{dL}$ ) and/or fasting plasma triglyceride (TG) concentration $>2.3 \mathrm{mmol} / \mathrm{L}(200 \mathrm{mg} / \mathrm{dL})$; second, at least one first-degree relative with a different hyperlipidemic phenotype (Fredrickson Classification Ila, Ilb or IV); third, a positive family history of premature cardiovascular disease (CVD). Premature CVD was defined as the occurrence of a myocardial infarction (MI) or cerebrovascular disease before the age of $60 \mathrm{y}$ in at least one first degree relative of the proband, or the proband him-/herself. Secondary causes of hyperlipidemia (renal or hepatic insufficiency, hypothyroidism and medication), presence of the apo E2/E2 genotype, and subjects with tendon xanthomas or a diagnosis matching familial hyper-cholesterolemia were excluded.

In total, during the period 1991 to $1997,95 \%$ of living relatives over 18 years of age have been collected, $(n=470)$ to confirm the diagnosis of FCHL and in the 
framework of metabolic and genetic studies ${ }^{8}$. The structure of these pedigrees has been published earlier ${ }^{8}$. In the repont by Williams et $a^{3}$, Familial Dyslipidemic Hypertension (FDH) was diagnosed as follows: first, hypertension before the age of $60 y$; second, another first degree relative before age $60 y$ with hypertension; and third, dyslipidemia ${ }^{3}$. In the present study hypertension has been defined as either systolic blood pressure (SBP) $>140 \mathrm{mmHg}$ and/or diastolic blood pressure (DBP) $>90 \mathrm{mmHg}$, or the current use of antihypentensive medication ${ }^{9.10}$. Dyslipidemic Hypertension (DH) was diagnosed according to classical criteria when a subject was both hyperlipidemic and hypertensive ${ }^{3}$. Because of the upper age cut-off in Williams' report (age $60 \mathrm{y})^{3}$, our present study group contained all $\mathrm{FCHL}$ relatives and spouses between 30 and 60 years of age, thus including $235 \mathrm{FCHL}$-relatives and 140 spouses. In the present analysis, subjects younger than 30 years were not included because of a low penetrance of the DH phenotype in that age group $(5 / 127=3.9 \%)$. Hypertensive subjects had to exhibit a TC $>6.5 \mathrm{mmol} / \mathrm{L}(250 \mathrm{mg} / \mathrm{dL})$ and/or a fasting plasma TG concentration $>2.3 \mathrm{mmol} / \mathrm{L}(200 \mathrm{mg} / \mathrm{dL})$ before they were included as $\mathrm{DH}$ individual. FCHL-relatives were divided into a hyperlipidemic $(n=121)$ and normolipidemic $(n=114)$ group.

\section{Measurements}

Clinical measurements were performed at the clinical research unit in the morning $\left(08^{00}-10^{00}\right)$ after an overnight fast $(12-14 \mathrm{~h})$. Subjects had refrained from smoking and had not drunk coffee in the morning. Participants also had abstained from alcohol for at least 72 hours. A medical history was obtained from all participating subjects and a standard questionnaire was filled out. All patients were weighed in underwear (Meltler electronic scale E1200, Greifensee, Switzerland), the height was determined by stabilometer and the body mass index (BMI) was subsequently calculated as weight in kilograms / (height in meters $)^{2}$. The waist was measured at the level of the umbilicus, the hip circumference was measured at the level of the trochanter major and the waist to hip ratio (WHR) was calculated. Both waist-circumference and hip-circumference were measured with the subject in standing position.

Blood pressure was measured twice with a mercury sphygmomanometer in a standardised fashion, with the subject in sitting position after 10 minutes of rest. Cuff size was adjusted to the circumference of the arm, and the arm was placed with the cuff at heart-level. Systolic (SBP) and diastolic blood (DBP) pressures were defined according to Korotkoff sounds 1 and $V^{9}$. With SBP and DBP, the mean of two measurements was used in the analyses. Mean arterial pressure (MAP) was defined as DBP + 1/3(SBP -. DBP). Pulse pressure (PP) was calculated as SBP minus DBP. The study protocol was approved by the Human Investigations Review Committee and performed according to the Helsinki Declaration. All subjects gave written informed consent.

\section{Laboratory methods}

Any lipid lowering medication had been withdrawn during two weeks before blood samples were collected. After an overnight fast (12-14 h) venous blood 
was collected in pre-cooled EDTA $(1-\mathrm{mg} / \mathrm{ml})$ Vacutainer tubes for measurements of lipids, lipoproteins, glucose and insulin. Total cholesterol and fasting triglyceride concentrations were measured in duplicate by a commercially available colorimetric assay (Monotest Cholesterol kit, Boehringer Mannheim \#1442350 and GPO-PAP, Boehringer Mannheim, \#701912, respectively). HDL. cholesterol (HDL-C) was determined after phosphotungstate- $\mathrm{MgCl} 2$ precipitation of whole plasma. Fasting plasma LDL-cholesterol (LDL-C) was calculated according to the Friedewald formula: $L D L-C=T C-H D L C-(T G \times 0.45)^{11}$, if plasma TG concentration was below $4.5 \mathrm{mmol} / \mathrm{L}(390 \mathrm{mg} / \mathrm{dL})$. Otherwise LDL.C was measured in the density 1.019 to 1.063 fractions, prepared by equilibrium ultracentrifugation. Nonesterified fatty acids (NEFA) were measured in plasma samples by an enzymatic colorimetric method (Wako Chemicals $\mathrm{GmbH}$, Neuss, Germany).

Insulin was measured by competitive radioimmunaassay with the polyclonal insulin antibody Caris 46, insulin tracer labelled with ${ }^{125}$ (IM. 166, Radiochemical Centre, Amersham, England), and insulin standards (WHO: first international reference preparation 66/304). Plasma apolipoprotein B (apo B) and apolipoprotein A-1 (apo A-1) were determined by commercially available immunonephelometric assays, using calibrated standards according to the International Federation for Clinical Chemistry (Behringwerke, Marburg, Germany). Apolipoprotein C-III (apo C-III) was measured using a commercially available single radial immunodiffusion assay (Daiichi Chemicals, Tokyo, Japan) according to manufacturer instructions, as described ${ }^{12,13}$.

Statistical analyses

All values are expressed as mean \pm standard deviation. Log transformed values for fasting insulin and TG concentration were used in statistical analyses because of non-normal distribution; values are non-logarithmically listed in the tables for practical reasons. Differences between FCHL relatives and the spouse group were calculated using an independent sample T-test; one way ANOVA with Bonferroni correction was used for comparisans between hyperlipidemic relatives, normolipidemic relatives and the spouse group. Age and BMI were entered as independent variables in a multiple linear regression analysis between two groups.

Prevalence of DH and FDH in the study groups was compared using $\chi^{2}$-test. An odds ratio for the occurrence of $\mathrm{DH}$ was calculated'4. Differences in the prevalence of $\mathrm{DH}$ over age-category were compared using $\chi^{2}$-test for a combined age-DH variable. To test which variables have an independent influence on blood pressure values, the effects of a variable, adjusted for the effects of the other independent variables, was analysed by backward stepwise multiple linear regression analyses with either SBP, DBP or MAP as dependent variable ${ }^{14}$. FCHL status was entered as a dummy variable. Although the number of individuals per family differed, a backward stepwise multiple linear regression analyses showed no significant contribution of one of the families to our results. In all statistical analyses, the statistical package SPSS 8.0 was used. 


\section{Results}

The characterisfics of the subjects studied are presented in Table 4.1.

Table 4.1 Characteristics of FCHL relatives from $27 \mathrm{FCHL}$ families and 140 married-in spouses, age 30-59 y.

\begin{tabular}{|c|c|c|}
\hline & $F C H L$ & Spouses \\
\hline Number & 235 & 140 \\
\hline$M / F$ & $127 / 708$ & $55 / 85$ \\
\hline$\%$ on cntihypertensive medication & 7.7 & 4.3 \\
\hline Age $(y)$ & $41.0 \pm 7.9^{\circ}$ & $43.4 \pm 8.2$ \\
\hline $\left.\mathrm{BM} / \mathrm{kg} / \mathrm{m}^{2}\right)$ & $25.3 \pm 3.7$ & $25.4 \pm 3.6$ \\
\hline WHR & $0.87 \pm 0.09^{*}$ & $0.84 \pm 0.09$ \\
\hline Systolic Blood Pressure (mmitg) & $127.0 \pm 14.91$ & $123.0 \pm 15.2$ \\
\hline Diastalic Blood Pressure (mmHg) & $85.4 \pm 10.7$ & $83.4 \pm 10.7$ \\
\hline Mean Arterial Pressure (mmHg) & $99.3 \pm 11.2^{4}$ & $96.6 \pm 11.5$ \\
\hline Pulse Pressure (mmHg) & $41.7 \pm 10.6$ & $39.5 \pm 10.0$ \\
\hline $\mathrm{TC}(\mathrm{mmol} / \mathrm{L})$ & $6.2 \pm 1.8^{\circ}$ & $5.6 \pm 1.0$ \\
\hline TG ( $\mathrm{mmol} / \mathrm{L})$ & $2.4 \pm 5.5^{\circ}$ & $1.6 \pm 0.8$ \\
\hline HDL-C (mmol/s) & $1.17 \pm 0.33^{\sharp}$ & $1.25 \pm 0.34$ \\
\hline LDL_C ( $\mathrm{mmol} / \mathrm{L})$ & $4.02 \pm 1.18^{\circ}$ & $3.67 \pm 0.96$ \\
\hline Apo B $(g / L)$ & $1.14 \pm 0.34^{\circ}$ & $1.01 \pm 0.28$ \\
\hline Glucose (mimol/L) & $4.8 \pm 0.7$ & $4.8 \pm 0.7$ \\
\hline Insulin $(\mu \mathrm{U} / \mathrm{mL})$ & $7.7 \pm 6.8$ & $7.5 \pm 7.9$ \\
\hline
\end{tabular}

$\mathrm{BMI}=$ body mass index, WHR $=$ waist to hip ratio, $T C=$ total chollesteral $(\mathrm{for} \mathrm{mg} / \mathrm{dL}$ divide by 0.0259 , $\mathrm{TG}=$ plasma triglyceride (for $\mathrm{mg} / \mathrm{dL}$ divide by 0.0113 ), $\mathrm{HDL}-\mathrm{C}=$ high-density lipoprotein cholesterol, LDL-C $=$ low-density lipoprotein cholesterol, glucose $=$ for $\mathrm{mg} / \mathrm{dL}$ divide by 0.0555 , insulin $=$ for $\mathrm{pmol} / \mathrm{L}$ multiply with 6.945 .

* $=p<0.01, t=p<0.05$

Systolic blood pressure (SBP) and mean arterial pressure (MAP) were higher in $\mathbb{F C H L}$ relatives compared to spouses $(127.0 \pm 14.9 \mathrm{vs} .123 .0 \pm 15.2 \mathrm{mmHg}$, $(p<0.05)$ and $99.3 \pm 11.2$ vs. $96.6 \pm 11.5 \mathrm{mmHg}_{r}(p<0.05)$, respectively). The pulse pressure (PP) showed a trend towards a significant difference between FCHL relatives and spouses $(p=0.052)$. FCHL family members were significantly younger than the spouses, with significantly higher TC, TG, LDL-C, and apo B concentrations and WHR, and significantly lower HDL-C levels. No differences between FCHL relatives and spouses were observed in plasma glucose or insulin concentrations or in the use of antihypertensive medication: in $7.7 \%$ of $\mathrm{FCHL}$ relatives versus $4.3 \%$ of spouses.

Table 4.2 lists the prevalence of Familial Dyslipidemic Hypertension (FDH) and dyslipidemic hypertension (DH) in each of the 27 studied FCHL pedigrees. Nine of twenty-seven FCHL families (33.3\%) were diagnosed with FDH. 
Table 4.2 Prewalence of FDH and DH in 27 FCHL-families and 140 married-in spouses; age cut-off $30-60 y$.

\begin{tabular}{|c|c|c|c|c|}
\hline $\begin{array}{l}\text { FCHL Family } \\
\text { No. }\end{array}$ & $\begin{array}{l}\text { Presence } \\
\text { of FDH }\end{array}$ & $\begin{array}{c}\text { DH (affected/ } \\
\text { n relatives) }\end{array}$ & $\begin{array}{c}\% \\
\text { with } \mathrm{DH}\end{array}$ & $\begin{array}{l}\text { Odds ratio } \\
195 \% \mathrm{Cl}\end{array}$ \\
\hline 1 & Yes & $10 / 54$ & 18.5 & \\
\hline 2 & Yes & $4 / 16$ & 25.0 & \\
\hline 3 & $\mathrm{No}^{\circ}$ & $1 / 5$ & 20.0 & \\
\hline 4 & $\mathrm{No}^{\circ}$ & $1 / 12$ & 8.3 & \\
\hline 5 & $\mathrm{No}^{\circ}$ & $1 / 4$ & 25.0 & \\
\hline 6 & $\mathrm{No}^{\circ}$ & $1 / 3$ & 33.3 & \\
\hline 7 & $\mathrm{No}^{\circ}$ & $1 / 4$ & 25.0 & \\
\hline 8 & $\mathrm{No}^{\circ}$ & $1 / 8$ & 12.5 & \\
\hline 9 & $\mathrm{No}$ & $0 / 1$ & 0 & \\
\hline 10 & $\mathrm{Na}$ & $0 / 6$ & 0 & \\
\hline 11 & Yes & $11 / 19$ & 57.9 & \\
\hline 12 & Yes & $4 / 10$ & 40.0 & \\
\hline 13 & Yes & $3 / 8$ & 37.5 & \\
\hline 14 & Yes & $5 / 13$ & 38.5 & \\
\hline 15 & $\mathrm{No}^{\circ}$ & $1 / 7$ & 14.3 & \\
\hline 16 & Yes & $7 / 19$ & 36.8 & \\
\hline 17 & No & $0 / 1$ & 0 & \\
\hline 18 & Yesi & $5 / 12$ & 41.7 & \\
\hline 19 & Yes & $2 / 6$ & 33.3 & \\
\hline 20 & No & $0 / 4$ & 0 & \\
\hline 21 & $\mathrm{No}^{\circ}$ & $1 / 2$ & 50.0 & \\
\hline 22 & $\mathrm{No}^{\circ}$ & $1 / 4$ & 25.0 & \\
\hline 23 & $\mathrm{No}^{\circ}$ & $1 / 7$ & 14.3 & \\
\hline 24 & $\mathrm{No}^{\circ}$ & $1 / 4$ & 25.0 & \\
\hline 25 & $\mathrm{No}^{\circ}$ & $1 / 2$ & 50.0 & \\
\hline 26 & No & $0 / 1$ & 0 & \\
\hline \multirow[t]{4}{*}{27} & No & $0 / 3$ & 0 & \\
\hline & $\begin{array}{c}9 / 27(33.3 \%) \\
\text { families }\end{array}$ & $\begin{array}{c}64 / 235 \\
\text { FCHL relatives" }\end{array}$ & $27.2 \%$ & \\
\hline & & $20 / 140$ spouses & $14.3 \%$ & \\
\hline & & & & $2.25(1.29-3.91)$ \\
\hline
\end{tabular}

$\mathrm{FDH}=$ Familial Dyslipidemic Hypertension, $\mathrm{DH}=$ Dyslipidemic Hypertension, $\mathrm{n}=$ total number, $a=$ at least 2 affected relatives required to diagnose $F D H, O R=$ Odds Ratio, $\mathrm{Cl}$ $=$ confidence interwal.

$*=p<0.01 \mathrm{FCH}$-relative vs. Spouses

Because of the age-cut off $(30-60 y)$, several families became smaller in size $(<7$ individuals) or even nuclear. This may have underestimated the diagnosis of FDH. Sixty-four out of $235(27.2 \%)$ relatives, aged $30.60 \%$, were diagnosed with dyslipidemic hypertension, compared to twenty out of 140 (14.3\%) spouses, $(p=0.005)$. This statistically highly significant difference resulted in a significant odds ratio of $2.25(95 \%$ confidence interval, 1.29-3.91) of dyslipidemic hypertension in FCHL relatives. The incidence of essential hypertension, without 
dyslipidemia, in normolipidemic relatives $(33$ of $114 ; 28.9 \%)$ was comparable to the incidence in normolipidemic spouses $(23$ of $99 ; 23.2 \%), p=0.36$; NS.

The percentages of FCHL relatives and spouses with dyslipidemic hypertension in each 10-y age-category are depicted in Figure 4.1. A significantly steeper increase with age is shown for the $\mathrm{FCHL}$ relatives compared with that observed in the spouse control group, ( $<<0.001$ for frend). At age $40 y$ and over, dyslipidemic hypertension was at least two times as frequent among FCHL relatives as in spouses (Figure 4.1 ).

After this qualitative analysis we evaluated quantitative aspects of blood pressure in men and women separately. Twenty-for subjects on antihypertensive medication were now excluded from these analyses $(n=11 \mathrm{FCHL}$ men, $n=7$ FCHL women, $n=2$ spouse men and $n=4$ spouse women). In women, hyperlipidemic relatives had significantly higher age- and BMl-adjusted SBP, DBP and MAP than spouses (SBP, $129.0 \pm 16.9$ vs. $120.8 \pm 14.9 \mathrm{mmHg}(\mathrm{p}<0.01)$; DBP, $87.0 \pm 10.1$ vs. $81.4 \pm 9.1 \mathrm{mmHg}(p<0.01)$ and MAP, $101.0 \pm 11.3$ vs. $94.5 \pm 10.4 \mathrm{mmHg}(p<0.01)$, respectively) (Table 4.3). These differences were not observed in hyperlipidemic men. After adjustment for differences in age and BMI, normolipidemic relatives exhibited a significantly higher SBP than spouses (122.2 \pm 12.9 vs. $120.8 \pm 14.9 \mathrm{mmHg}, p<0.05$ ). Hyperlipidemic relatives had again higher DBP and MAP than normolipidemic relatives $(87.0 \pm 10.1$ vs. 81.0 $\pm 9.2 \mathrm{mmHg}(p<0.05)$, and $101.0 \pm 11.3$ vs. $94.7 \pm 10.0 \mathrm{mmHg}(p<0.05)$, respectively). (Table 4.3).

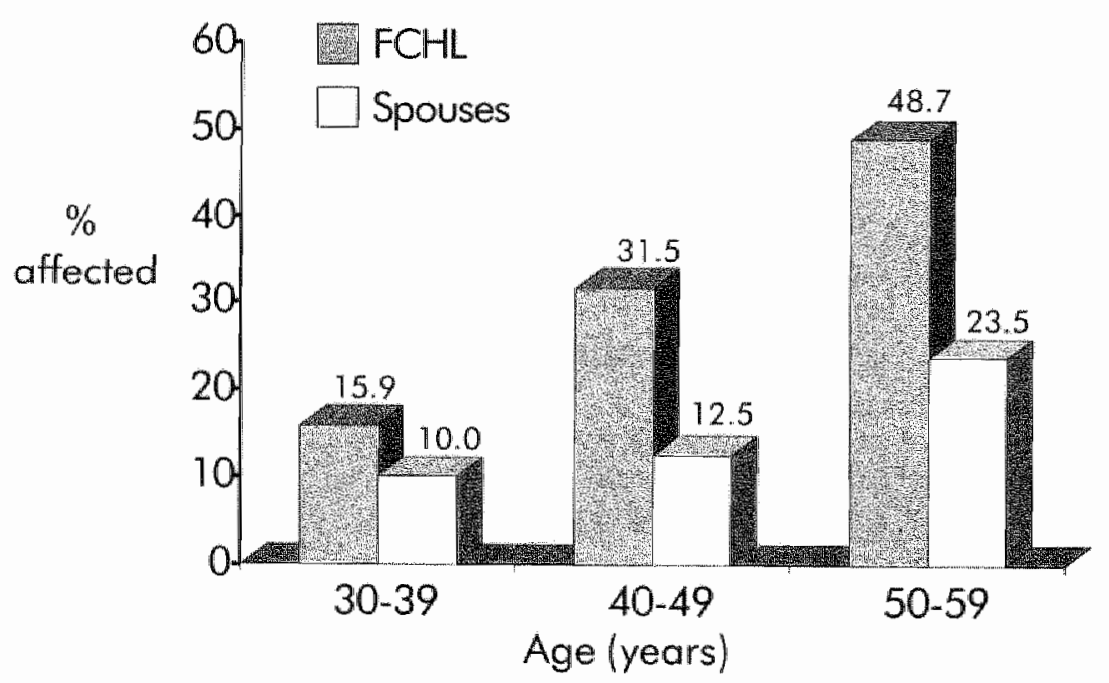

Figure 4.1 Percent Dysllipidemic Hypertension per 10 y age-category in FCHL relatives and married in spouses ( $p<0.001$ for trend FCHL relatives versus spouses). Numbers in study: FCHL age 30-39, $n=107$; age 40-49, $n=89$; age 50$59, \mathrm{n}=39 ;$ spouses age 30-39, $\mathrm{n}=50$; age $40-49, \mathrm{n}=56 ; 50-59, \mathrm{n}=$ 34. 
Table 4.3 Blaod pressure and anthropometric values in women age 30-59, without antihypertensive medication

\begin{tabular}{lccc} 
& $\begin{array}{c}\text { Normolipidemic } \\
\text { relatives }(\mathrm{n}=62)\end{array}$ & $\begin{array}{c}\text { Hyperlipidemic } \\
\text { relatives }(\mathrm{n}=38)\end{array}$ & $\begin{array}{c}\text { Spouses } \\
(\mathrm{n}=81)\end{array}$ \\
\hline Age $($ years $)$ & $38.1 \pm 6.9$ & $42.2 \pm 8.3$ & $42.9 \pm 7.9$ \\
BMl $(\mathrm{kg} / \mathrm{m} 2)$ & $23.2 \pm 2.9$ & $25.4 \pm 3.8$ & $24.7 \pm 3.4$ \\
WHR & $0.80 \pm 0.07$ & $0.81 \pm 0.08$ & $0.80 \pm 0.08$ \\
Wais $(\mathrm{cm})$ & $80.1 \pm 9.4$ & $85.7 \pm 10.7$ & $83.0 \pm 10.9$ \\
SBP $(\mathrm{mmHg})$ & $122.2 \pm 12.9 \pm$ & $129.0 \pm 16.9^{*}$ & $120.8 \pm 14.9$ \\
DBP $(\mathrm{mmHg})$ & $81.0 \pm 9.2$ & $87.0 \pm 10.1^{*}+$ & $81.4 \pm 9.1$ \\
MAP $(\mathrm{mmHg})$ & $94.7 \pm 10.0$ & $101.0 \pm 11.3^{*}+$ & $94.5 \pm 10.4$ \\
PP $(\mathrm{mmHg})$ & $41.2 \pm 7.8 \pm$ & $42.0 \pm 12.5$ & $40.6 \pm 9.9$ \\
\hline
\end{tabular}

$B M I=$ body mass index, $W H R=$ waist to hip ratio, $S B P=$ systolic blood pressure, $\mathrm{DBP}=$ diastolic bload pressure, $\mathrm{MAP}=$ mean arterial pressure, $\mathrm{PP}=$ pulse pressure. ${ }^{*}=\mathrm{HL}$ vs. Spouses, $p<0.01 i^{\dagger}=H L$ vs. $\mathrm{NL}_{i} p<0.05 ;^{*}=\mathrm{NL}$ vs. Spouses, $p<0.05$

In women, a multiple linear regression analysis showed that age, FCHL status and waist-circumference significantly contributed to SBP and MAP (Table 4.4). The analysis with DBP as dependent variable showed that age and FCHL status were significant contributors (Table 4.5), and waist-circumference was excluded at the last step of the regression analysis only. The andyses used age, BMI, WHR, waist-circumference, TC, logTG, HDL-C, NEFA, Apo-A1, Apo-B, Apo-CIII, glucose, (log)insulin and FCHL status as independent variables. Exclusion of the variable FCHL stalus did not result in an improved model for SBP nor DBP $\left(r^{2}=0.208\right.$ for SBP and $r^{2}=0.086$ for DBP, respectively), although tatal cholesterol was now identified as a contributing factor.

Because waist-circumference was identified as independent variable contributing to blood pressure in women, we analysed the total group of 178 women, including those on medication. Twenty-one out of eighty $(26.3 \%)$ women with a waist-circumference greater then $85.0 \mathrm{~cm}$ were diagnosed with dyslipidemic hypertension, compared to nine out of $98(9.2 \%)$ women with a waistcircumference less then $85.0 \mathrm{~cm}(\mathrm{p}=0.004,2 \times 2$ table $)$. 
Table 4.4 Results of backward stepwise regression analysis with either Systolic Blood Pressure or Mean Arterial Pressure as dependent wariable.

Systolic Blood Pressure

\begin{tabular}{lccccc}
\hline Variable & $\beta$ & $\beta$ SE & Stand. $\beta$ & $P$ & Model $r^{2}$ \\
\hline & & & & & $0.217^{*}$ \\
Intercept & 66.717 & 10.281 & & $<0.001$ & \\
Age & 0.674 & 0.150 & 0.359 & $<0.001$ & \\
Affected FCHL & 7.279 & 3.138 & 0.787 & $<0.05$ & \\
Waist & 0.311 & 0.109 & 0.224 & $<0.01$ & \\
\hline
\end{tabular}

Mean Arterial Pressure

\begin{tabular}{lccccc}
\hline Variable & $\beta$ & $\beta$ SE & Stand. $\beta$ & $P$ & Model $r^{2}$ \\
\hline & & & & & $0.157^{*}$ \\
Intercept & 66.262 & 7.379 & & $<0.001$ & \\
Agle & 0.362 & 0.110 & 0.266 & $<0.001$ & \\
Affected FCHL & 5.422 & 2.247 & 0.193 & $<0.05$ & \\
Waist & 0.171 & 0.082 & 0.170 & $<0.05$ & \\
\hline
\end{tabular}

$\beta$ SE: $\beta$ standard error; stand $\beta$ : standardised $\beta ;$ affected $\mathrm{FCHL}=$ hyperlipidemic FCHL status; : $p<0.001$

Table 4.5 Results of backward stepwise regression analysis with Diastolic Blood Pressure as dependent variable

Dicastolic Blood Pressure

\begin{tabular}{lccccc}
\hline Variable & $\beta$ & $\beta$ SE & Stand. $\beta$ & $P$ & ${\text { Model } r^{2}}^{*}$ \\
\hline Intercept & 71.097 & 4.232 & & & $0.091^{*}$ \\
Age & 0.263 & 0.101 & 0.214 & $<0.01$ & \\
Affected FCHL & 5.723 & 2.093 & 0.224 & $<0.01$ & \\
\hline
\end{tabular}

$\beta$ SE: $\beta$ standard error; stand $\beta$; standardised $\beta$; affected $F C H L=$ hyperlipidemic $F C H L$ status; ${ }^{*} p<0.001$

\section{Discussion}

In the present study, one-third of FCHL families was diagnosed with Familial Dyslipidemic Hypertension (FDH) and $27 \%$ of FCHL relatives had dyslipidemic hypertension $(\mathrm{DH})$. This prevalence is far in excess of the $12 \%$ population prevalence described by Williams et $\mathrm{al}^{3}$ as well as the $14.3 \%$ prevalence in spouses in the present study. Quantitative analyses revealed a statistically significant 2.25 higher probability of developing $\mathrm{DH}$ in $\mathrm{FCHL}$ relatives compared to their spouses. The over-expression of dyslipidemic hypertension in FCHL relatives increased with age, as observed in the 30 to $60 y$ age interval, and was 
dependent on waist-circumference, which is a novel finding. The frequent occurrence of FDH in Dutch FCHL families corresponds well with the prediction of Williams et $\mathrm{al}^{3}$ that FCHL would represent the most common type of hyperlipidemia in FDH families, present in $15 \%$ of siblings ${ }^{15-17}$. The National Heart, Lung and Blood Institute (NHLBI) twin study reported that subjects with dyslipidemic hypertension have a coronary mortality rate that is approximately four times greater than their other twin halves, who shared only lipid abnormalities, or hypertension ${ }^{18}$. This figure is in complete agreement with the 5 10 fold higher risk of CAD in FCHL families. The frequent presence of hypertension in affected FCHL relatives does help to explain the hitherto less well understood accurrence of cerebrovascular accidents in FCHL families?. The simultaneous accurrence of FDH and FCHL suggests a common mechanism involved in the expression, or even the pathogenesis, of these disorders, apparently related to a genetic hyperresponse to abdominal fat.

Estimates of the heritability of systolic blood pressure (SBP) in population-based studies revealed a figure of $17 \%$ and with diastolic blood pressure of $12 \%{ }^{19}$. Our model derived for systolic blood pressure in women explained $21.7 \%$ of the variability, which is in good agreement with these estimates. In addition to age, waist-circumference and affected FCHL status contributed to the expression of SBP and mean arterial pressure in women.

However, in men we could not detect any difference in blood pressure variables between $\mathrm{FCHL}$ relatives and spouses. $\mathrm{FCHL}$ is expressed more frequently in men $(60.6 \%)$ than in women $(40.7 \%)$ in Dutch FCHL families. One explanation is that women are partly protected from $\mathrm{FCHL}$, and that women may suffer from a more severe form of FCHL (dyslipidemia and hypertension) when it develops. Another possibility to explain this men / women difference is an increase in background risk factors for hypertension in male spouses compared to female spouses. In that case, a smaller difference in average blood pressure wariables between the group of FCHL men and the group of male spouses is expected, and a smaller difference is more difficult to detect given the sample size.

The Framingham Offspring Study contributed statistical evidence that systolic blood pressure is associated with dyslipidemia through a pathogenic link with obesity ${ }^{20}$. It was shown that hyperinsulinemia did not represent the pathogenic link between hypertension and dyslipidemia, but that genetic or environmentinduced abnormalities of adipose tissue are required for dyslipidemic subjects to become hypertensive ${ }^{20}$. In the present study, waist-circumference, a measure of abdominal obesity and visceral fat, was identified as the (abesity) link between clinical expression of dyslipidemia and systolic hypertension in FCHL, in agreement with the above-mentioned Framingham mode ${ }^{20}$. Other studies have also shown a relationship between obesity, dyslipidemia and hypertension ${ }^{21,22}$.

Increased Free Fatty Acid flux (FFA) from visceral fat to the liver, resulting in hyperactivity of the sympathetic nervous system, has been proposed as an important mechanism in the pathogenesis of obesity-related hypertension ${ }^{23.24}$. Moreover, an increased FFA-flux impairs the function of the hypothalamuspifuitary-adrenall axis, resulting in increased cortisol secretion and sodium retention, both contributing to hypertension ${ }^{25,26}$. Increased FFA-flux from visceral fat directly to the liver can also contribute to the hypersecretion of triglyceride-rich 
very low-density lipoproteins from the liver ${ }^{27}$, a hallmark of FCHL. Increased VLDL secretion and impaired elimination ${ }^{12,28}$ result in increased plasma cancentrations of atherogenic lipoprotein remnants, that can also provide a link between dyslipidemia and hypertension. Impaired nitric oxide-dependent vasodilatation in FCHL subjects has been associated with the plasma concentration of atherogenic triglyceride-rich remnant lipoproteins ${ }^{13,29}$. Therefore, remnants may contribute to the development of premature otherosclerosis and expression of hypertension.

The present study not only ties FDH and FCHL together as specific hypertensive entities, but also suggests that a common mechanism is responsible for the pathogenesis of dyslipidemia as well as hypertension in FCHL. The mechanism could be FFA-flux from visceral adipose tissue, or an indirect mechanism inducing increased adipose fissue mass, or through lipoprotein abnormalities and insulin resistance. In support of this line of reasoning, we have identified in a recently published genome-wide $\operatorname{scan}^{8}$ a locus on chromosome 4 , containing the alpha-adducin A gene, that showed a highly significant LOD score of 4.0 with systolic blood pressure and free fatty acids in the sarne FCHL families ${ }^{30}$. The alpho-adducin A gene (ADD1) has been implicated as the cause of hypertension in a rat model ${ }^{31}$.

In conclusion, in FCHL we identified age, waist-circumference and hyperlipidemia as predictors of systolic blood pressure. Further genetic and metabolic studies are awaited, as this may have future implications for pathogenesis and treatment $t^{9,10,32}$. The present study indicates that visceral adipose tissue strongly contributes to the high prevalence of dyslipidemic hypertension in FCHL families. Visceral fat, measured indirectly as waistcircumference, may represent the common pathogenic denominator in FCHL and FDH. Reduction of visceral fat versus treatment of hyperlipidemia should be tested as potential therapeutic interventions of the hypertension in FCHL individuals. 


\section{References}

1. Turner RC, Millns H, Nell HA, Stratton M, Manley SE, Matthews DR. Holman RR. Risk factors for coronary artery disease in mon-insulin dependent diabetes mellifus: United Kingdom Prospective Diabetes Study (UKPDS: 23). British Medical Journal 1998;316:823-828.

2. Anderson KM, Odell PM, Wilson PWF, Kannel WB. Cardiovascular disease risk profiles. American Heart Journall 1991;121:293-298.

3. Williams RR, Hunt SC, Hopkins PN, Stults BM, WU LL, Hasstedt SJ, Burlow GK, Stephenson SH, Lalovel JM, Kuida H. Familial Dyslipidemic Hypertensian. Evidence from 58 Utah families for a syndrome present in approximately $12 \%$ of patients with essential hypertension. Joumal of the American Medical Association $1988,259: 3579-3586$

4. Goldstein JL, SchroH HG, Hazzard WR, Bierman EL, Motulsiky AG. Hyperlipidaemia in Coronary Heart Disease. Ill Genetic analysis of lipid levels in 176 familles and delineation of a new inherited disorder, combined hyperlipidaemia. Journal of Clinical Investigation 1973;52:154441568.

5. Rose HG, Kranz P, Weinstock M, Juliano J, Haft Jl. Inheritance of combined hyperlipoproteinaemia: ewidence for a new lipoprotein phenotype. American Jaurnal of Medicine 1973;54:148-160.

6. Nikkilä EA, Aro A. Family study of serum lipids and apolipoproteins in coronary artery disease. Lancet 1973;78:954-959.

7. Castro Caberas $M$, de Bruin TWA, Erkelens. DW. Familial combined hyperlipidaemia: 1973-1991. Netherlands Journal of Medicine 1992;40:83-95.

8. Aovizerat $B E$, Allayee $H$, Cantor RM, Davis $R C$, Lanning $C D$, Wen $P Z$, Dallinga-Thie GM, de Bruin TWA, Rotter $J_{r}$ Lusis AJ. A genome scan for familial combined hyperlipidemia reveals evidence of linkage with a locus on chromosome 11. American Joumal of Human Genetics 1999;65:397-412.

9. Joint National Committee on Prevention, Detection, Evaluation, and Treatment of High Blood Pressure: The sixth report of the Joint National Committee on prevention, detection, evaluation, and treatment of high blood pressure. Archives of Internal Medicine 1997; 157:2413-2446.

10. 1999 World Heath Organization-International Society of Hypertension: Guidelines for the Management of Hypertension. Guidelines Subcommittee. Jaurnal of Hypertension 1999:17:151-183.

11. Friedewald WT, Levy RI, Fredrickson DS. Estimation of the concentration of lowdensity lipoprotein cholesterol in plasma, without the use of the preparative utracentrifuge. Clinical Chemistry 1972;18:499-502.

12. Castro Cabezas $M$, de Bruin TWA, de Valk HW, Shoulders CC, Jansen H, Erkelens DW. Impaired fatty acid metabolism in familial combined hyperlipidemia. A mechanism associating hepatic apolipoprotein B overproduction and insulin resistance. Journal of Clinical Investigation 1993;92:160-168. 
13. Siroes $E_{y}$ de Bruin TWA, de Valk $H$, Erkelens DW, Banga JD, van Rinn H, Koomans $H$, Rabelink T. NO activity in familial combined hyperlipidemia: potential role of cholesterol reminants. Cardiovascular Research 1997;36:445-452.

14. Ingelfinger JA, Mosteller F, Thibodeau LA, Ware JH. Biostatistics in dinical medicine. New York, USA: McGrow-Hill, Inc, 1994

15. Willians RR, Hopkins PN, Hunt SC, Wu LL, Hasstedt SJ, Lalovel JM, Ash KO, Stults $B M$, Kuida $H$. Population-based frequency of dyslipidemia syndromes in coronaryprone families in Utah. Archives of linternal Medicine 1990; 150:582-588.

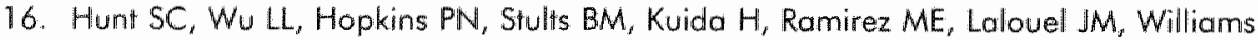
RR. Apolipoprotein, low density lipoprotein subfraction, and insulin associations with familial combined hyperlipidemia. Study of Utah patients with familial dyslipidemic hypertension. Arteriosclerosis 1989;9:335-344.

17. Williarns RR, Hunt SC, Hopkins PN, Wu LL, Hassted SJ, Berry TD, Barlow GK, Sitults BM, Schumacher MC, Ludwig EH, Elbein SC, Wilson DE, Lifton RP, Lalovel JM. Genetic basis of familial dyslipidemia and hypertension: 15-year results from Utah. American Journal of Hypertension 1993;6:3195-327S.

18. Selby JV, Newman B, Quiroga J, Christian JC, Austin MA, Fabsizz RR. Concondance for dyslipidemic hypertension in malle twins. Journal of the American Medical Association 1991,265:2079-2084.

19. Schork $\mathbb{N} J_{x}$ Weder $A B$, Trevisan $M$, Laurenzi M. The contribution of pleiotropy to blood pressure and body-mass index variation: the Gubbio Study. American Journal of Human Genetics 1994;54:361-373.

20. Meigs JB, D'Agostino SRB, Wilson PW, Cupples LA, Nathan DM, Singer DE. Rilsk variable dustering in the insulin resistance syndrome. The Framingham Offspring Study. Diabetes 1997;46:1594-1600.

21. Dyer AR, Ellioft $P$, Shipley $M$, Stamler $\mathbb{R}$, Stamler J. Body mass index and assaciations of sodium and potassium with blood pressure in INTERSALT. Hypertension $1994 ; 23: 729-736$.

22. Mark AL, Correia M, Morgan DA, Shaffer RA, Haynes WG. State-of-the-art-lecture: Obesity-induced hypertension: new concepts from the emerging biology of obesity. Hypertension 1999;33:537-541.

23. Grekin RJ, Dumont CJ, Vollmer AP, Watts SW, Webb RC. Mechanisms in the pressor effects of hepatic portal venous fatty acid infusion. American Journal of Physiology $1997: 273: R 324-R 330$

24. Reaven GM, Lithell $H$, Landsberg L. Hypertension and associated metabolic abnormalities - the role of insulin resistance and the sympathoadrenal system. New England Journal of Medicine 1996,334:374-381.

25. Rosmond R, Dallman MF, Biorntorp P. Stress-related cortisol secretion in men: relationships with abdominal obesity and endocrine, metabolic and hemadynamic abnomalities. Journal of Clinical Endocrinology and Metabolism 1998;83:1853. 1859 .

26. Kelly JJ, Mangas G, Williamson PM, Whitworth JA. Cortisol and hypentension. Clinical and Experimental Pharmacology and Physiology 1998;25:\$51-S56.

27. Riches FM, Watts GF, Huo J, Stewart GR, Naoumova RP, Barrett PHR. Reduction in viscerall adipase tissue is associated with improwement in apalipoprotein B-100 metabolism in obese men. Journal of Clinical Endocrinology and Metabolism $1999 ; 84: 2854-2861$. 
28. Cabezas MC, de Bruin TWA, Jansen H, Kock LA, Kartlandt W, Erkelens DW. Impaired chylomicron remnant clearance in familial combined hyperlipidemia. Arteriasclerosis and Thrombosis 1993;13:804-814.

29. Bredie SJH, Tack CJJ, Smits P, Stalenhoef AFH. Non-obese patients with familial combined hyperlipidemia are insulin resistant as compared with their nonmaffected relatives. Arteriosclerosis Thrombosis and Vascular Biology 1997;17:1465-1471.

30. Alloyee H, de Bruin TWA, Cantor RM, Aovizerat BE, Lusis AJ, Rotter Jl. Genome scan in Dutch dyslipidemic families reveals novel blood pressure loci. American Journal of Human Genetics 999;65:A16 (abstract)

31. Bianchi $G$, Tripodi $G$, Casari $G$, Salardi $S$, Barber BR, Garcia R, Leonie P, Torielli L. Cusi D, Ferrandi M, Pinna LA, Baralle FE, Ferrari $P$. Two point mutations within the adducin genes are involved in blood pressure variation. Proceedings of the National Academy of Sciences of USA 1994;91:3999-4003.

32. Lasser NL, Grandits G, Caggiula AW, Cutler JA, Grimm RHJ, Kuller LH, Sherwin RW, Stamler J. Effects of antihypertensive therapy on plasma lipids and lipoproteins in the Multiple Risk Factor Interwention Trial. American Journal of Medicine 1984;76:52-66. 
68 


\section{Abstract}

The objective of the present study was to determine whether FCHL subjects had prolonged heant rate corrected QT (QTC) times relative to spouse controls and to investigate the potential relationship of QTc with hyperlipidemia and surrogate markers of the insulin resistance syndrome.

The QT interval was measured in all leads from a standard 12 -lead electrocardiogram in 76 FCHL-affected subjects and 92 spouses. All individuals were free of previous myocardial infarction, type 2 diabetes or cardiovascular medication. QTc interwal was significantly prolonged in FCHL-affected women, but not in men, compored to spouse controls; the adds ratio of QTe $>420 \mathrm{msec}$ was $4.93(95 \%$ confidence interval, 1.22 . 20.03). Plasma triglyceride. HDL-cholesterol, fasting insulin and calculated insulin resistance (HOMA) were significantly correlated $(p<0.05)$ with QTC. Regression analyses revealed that plasma insulin, systolic blaod pressure, HDL-cholesteral, body mass index, and free fiatty acids were independent predictors of QTC.

In conclusion, in FCHL, prolonged QTc was specifically found in hyperlipidemic FCHL women and associated with components of the insulin resistance syndrome. QTC prolongation either relates to the genetic susceptibility to FCHL in womem, or represents an adaptation mechanism to insulin resistance. QTc prolongation may add to the risk of coronary artery disease in FCHL. 


\section{Chapter 5}

\section{QT-interval (QTc) is}

prolonged in Familial

\section{Combined}

Hyperlipidemia: association with Insulin Resistance

ETP Keulen, K Rijkers, I Lutgens, JMJP van Lin, NC Schaper, TWA de Bruin

Submitted for publication 


\section{Introduction}

An association has been observed beween the duration of the heart rate corrected QT-interwal (QTC) and sudden death, both in patients with a myocardial infarction and patients who had a diagnostic 24-hour electrocardiagraphy ${ }^{1-4}$. Moreover, prolonged duration of QTC raises the risk of coronary heart disease related death in the general population ${ }^{5-8}$. This greater risk has been attributed to an imbalance of sympathetic innervation at the level of left and right ganglia stellata", predominant sympathetic aver parasympathetic activity $^{10,13}$, or myacardial membrane defects ${ }^{12,13}$, each separately or in combination leading to electrical instability in situations of high sympathetic activity. Recently, a new observation was made that, in an elderly male population (age $>70$ years), QTc was positively associated with plasma insulin and glucose concentrations ${ }^{14}$. Therefore, QTC prolongation was suggested as an additional feature of the insulin resistance syndrome. A prolonged QTC interval should be distinguished from the long QT syndrome. This genetic syndrome is caused by multiple monogenetic defects and defined by QTc intervals langer than 440 msec among family members.

Familial Combined Hyperlipidemia (FCHL) is the most common genetic dyslipidemia in humans, with a prevalence of $0.5-1.0 \%$ in the general population ${ }^{15,16}$. Ten percent of survivors of myocardial infarction before the age of 60 years have been reported to be affected with $\mathrm{FCHL}$, resulting in a high relative risk ratio of about 10 for early coronary artery disease in index cases ${ }^{15}$. Recently, two reports addressed the seriously increased risk of fattal and non-fatal coronary artery disease in the relatives of $\mathrm{FCHL}$ probands and found odds ratios of 1.7 and 5.1, respectively ${ }^{7.18}$. Patients with FCHL are characterised by an averproduction of apolipoprotein B and very low-density lipoproteins ${ }^{19,20}$ in combination with a relative impairment of lipopratein catabalism ${ }^{21}$. Furthermore, FCHL affected patients are frequently insulin resistant ${ }^{22}$, and dyslipidemic hypentension has been reported as well ${ }^{23}$. However, these classical cardiovascular risk factors alone can not fully explain the high cardiovascular risk in FCHL ${ }^{18}$. Because QTc prolongation is associated with increased risk of coronary heart disease death and has been proposed as additional feature of the insulin resistance syndrome, QTe prolongation may also occur in FCHL.

It is the objective of the present study to determine whether FCHL subjects have prolonged QTc times relative to spouse controls and to investigate the potential relationship of QTc with hyperlipidemia and surrogate markers of the insulin resilstance syndrome. 


\section{Subjects and methods}

In rotal, in the period of 1997 - 1999, 308 subjects from 27 Caucasian FCHL families attended our laboratory to confirm the diagnosis of FCHL in their family. In the framework of metabolic and genetic studies, a standard resting 12-lead electracardiogram was made in 105 hyperlipidemic relatives and 103 spouses, using a Marquette 12 SL ECG (GE Marquette Medical Systems, Milwaukee, WI, USA).

Hyperlipidemic subjects were characterised by a primary hyperlipidemia, defined as fasting total plasma cholesterol $>6.5 \mathrm{mmol} / \mathrm{L}(250 \mathrm{mg} / \mathrm{dL})$ or fasting plasma triglyceride concentration $>2.0 \mathrm{mmol} / \mathrm{L}(180 \mathrm{mg} / \mathrm{dL})$. Because a prolonged QTinterval can result from a myocardial infarction, subjects with a previous myocardial infarction (11 FCHL, 3 spouses) have been excluded. Furthermare, subjects with o bundle branch block (1 FCHL), subjects using $\beta$-blockers $(9 \mathrm{FCHL}$, 4 spouses) ${ }^{24}$, or subjects with type 2 diabetes mellitus ( 7 FCHL, 3 spouses) ${ }^{25}$ were excluded from the analysis, as these conditions are known to potentially prolong the QT-interval.

QT intervals were automatically measured in all 12 leads of the electrocardiogram. The beginning of the QT-interval was defined as the first deflection of the QRS complex, and the end as return of the $T$ wave to the isoelectric line. QTc interval was callculated with a modified Bazett formula, using heart rate instead of RR interval for adjustment. For this reason subjects with sinus arrhythmia (1 FCHL, I spouse) were also excluded from the analysis. The remaining study population consisted of $76 \mathrm{FCHL}$ affected subjects and 92 spouses. The study protocol was approved by the Human Investigations Review Committee and performed according to the Helsinki Declaration. All subjects gave written informed consent.

\section{Measurements}

The measurements were performed in the morning $(8.00-11.00)$ after an overnight fast $(12-14 \mathrm{~h})$. Subjects had refrained from smoking and had not drunk coffee or tea in the morning. Subjects had also abstained from alcohol for at least 72 hours. A medical history was obtained from all participating subjects and a standardised questionnaire was filled out. All patients were weighed in underwear (EKS), height was determined by stadiometer and the body mass index was subsequently calculated as weight in kilograms / (height in meters) ${ }^{2}$. The waist-circumference was measured at the level of the umbilicus, the hipcircumference was measured at the level of the trochanter major, and the waist to hip ratio was calculated. Both waist-circumference and hip-circumference were measured with the subject in standing position.

Systolic and diastolic blood pressures were measured twice, with the Omron 705CP (OMRON Health Care GmbH, Hamburg, Germany), in a standardised fashion. Subjects were in a sitting position after 10 minutes of rest. Cuff size was 
adjusted to the circumference of the arm, and the arm was placed with the cuff at heart-level. The mean of two measurements was used in the analyses.

\section{Laboratory methods}

Any lipid lowering medication had been withdrawn for two weeks before fasting blood samples were collected. After completion of all physical measurements, venous blood was collected in pre-caoled EDTA $(1-\mathrm{mg} / \mathrm{ml})$ Vacutainer tubes for measurements of lipids, apolipoproteins, glucose, and insulin. Total cholesterol and fasting triglyceride concentrations were measured in duplicate by a commercially available colorimetric assay (Monotest Cholesterol kit, Boehringer Mannheim \#1442350 and GPO-PAP, Boehringer Mannheim, \#701912, respectively). High-density Lipoprotein cholesterol (HDL-C) was determined after phosphotungstate- $\mathrm{MgCl} 2$ precipitation of whole plasma. Fasting plasma lowdensity lipoprotein cholesterol (LDL-C) was calculated according to the Friedewald formula: LDL-C = Total Cholesterol - HDL-C $-(T G \times 0.45)^{26}$, if plasma triglyceride concentration was below $390 \mathrm{mg} / \mathrm{dL}(4.5 \mathrm{mmol} / \mathrm{L})$. Otherwise LDL-C was measured in the density 1.019-1.063 fractions, prepared after equilibrium ultracentrifugation ${ }^{26}$. Free fatty acids were measured in plasma samples by an enzymatic colorimetric method (Wako Chemicals $\mathrm{GmbH}$, Neuss, Germany).

Fasting blood glucose was measured immediately on a YSI 2300 monitor (Yellow Spring Instruments, USA). Fasting insulin concentration was determined using an Elisa (Mercodia AB, Uppsala, Sweden), with a cross-reactivity to pro-insulin $<0.01 \%$. Surrogate insulin resistance was calculated as the proposed formula of the homeostasis model assessment (HOMA): Resistance = fasting insulin $/(7 \times$ $22.5 \times \varepsilon^{\text {-ln gluccse) }}$, which formula can be simplified as (fasting insulin $x$ fasting blood glucose $) /(7 \times 22.5)^{27}$. This surrogate marker of insulin resistance shows an association of -0.82 with insulin sensitivity determined by hyperinsulinemic euglycemic clamp ${ }^{28}$.

Plasma apolipoprotein B and apolipoprotein A-1 were determined by commercially available immunonephelometric assays, using callibrated standards according to the International Federation for Clinical Chemistry (Behringwerke, Marburg, Germanyl.

\section{Statistical analyses}

All values are expressed as mean \pm standard deviation. Log transformed values for fasting insulin and triglyceride concentrations were used in statistical analyses because of non-normal distribution; values are non-logarithmically listed in the Table 5.1 and Figure 5.1 for practical reasons. Differences between FCHLaffected subjects and spouse controls were calculated using linear regression analyses with age as co-variable. Prevalence of a QTc interval greater than 420 msec 5,6 or $440 \mathrm{msec}$ in either study group, $\mathrm{FCHL}$ or spouses, was compared by age-adjusted logistic regression analysis. The subsequent odds ratio was calculated ${ }^{29}$.

Age-corrected Pearson correlation coefficients were determined for the relationship between continuous QTc variable and surrogate insulin resistance 
indices. Moreover, age- and body mass index-corrected univariate analysis of variance was used to test whether tertile categories ( $n=28$ or 29 subjects in each) of fasting plasma triglyceride concentration, HDL-cholesterol, fasting plasma insulin and HOMA were significantly assaciated with QTc. One way ANOVA with Bonferroni correction was used for comparisons between the terfile cotegories. To test whether variables had an independent effect on the QTc interval, the effects of such a variable, adjusted for other independent variables, was analysed by backward stepwise multiple linear regression analyses with QTc as dependent variable ${ }^{29}$. FCHL affected status was entered as an independent variable. Although in the present study group several individuals per family were present, a backward stepwise multiple limear regression analyses showed no significant contribution of one of the families to our results. In all statistical analyses, the statistical package SPSS 8.0 (SPSS Inc. Chicago, III., USA) was used.

Table 5.1 Characteristics of 76 hyperlipidemic FCHL relatives and 92 married-in spouses.

\begin{tabular}{|c|c|c|c|c|}
\hline & FCHL women & Control women & FCHL men & Control men \\
\hline Number & 41 & 46 & 35 & 46 \\
\hline Age (years) & $49.3 \pm 14.2^{*}$ & $42.9 \pm 10.2$ & $43.3 \pm 11.8$ & $47.2 \pm 12.1$ \\
\hline $\mathrm{TC}(\mathrm{mm}$ ol/L) & $6.7 \pm 1.3 \ddagger$ & $5.2 \pm 1.0$ & $6.9 \pm 1.7 \pm$ & $5.2 \pm 0.9$ \\
\hline $\mathrm{HDL}-\mathrm{C}(\mathrm{mmol} / \mathrm{L})$ & $0.98 \pm 0.24 t$ & $1.13 \pm 0.24$ & $0.81 \pm 0.21 *$ & $0.91 \pm 0.18$ \\
\hline TG (mmol/L) & $2.0 \pm 0.9 \neq$ & $1.1 \pm 0.4$ & $3.0 \pm 2.4 \pm$ & $1.3 \pm 0.8$ \\
\hline Apo B $(g / L)$ & $1.43 \pm 0.34 t$ & $0.98 \pm 0.24$ & $1.37 \pm 0.35$ & $1.07 \pm 0.20$ \\
\hline $\mathrm{FFA}(\mathrm{mmol} / \mathrm{L})$ & $0.53 \pm 0.22$ & $0.51 \pm 0.21$ & $0.42 \pm 0.15^{\top}$ & $0.38 \pm 0.18$ \\
\hline Glucose (mimol/L) & $5.0 \pm 0.5$ & $4.7 \pm 0.5$ & $4.9 \pm 0.7$ & $5.0 \pm 0.5$ \\
\hline Insulin (pmol/L) & $66.7 \pm 40.67$ & $40.2 \pm 26.5$ & $71.8 \pm 73.7^{*}$ & $45.4 \pm 26.5$ \\
\hline HOMA & $2.17 \pm 1.484$ & $1.22 \pm 0.79$ & $2.27 \pm 2.29$ & $1.48 \pm 0.95$ \\
\hline $\mathrm{BM}(\mathrm{kg} / \mathrm{m} 2)$ & $27.5+4.7 t$ & $24.0 \pm 3.7$ & $26.1 \pm 3.2$ & $26.7 \pm 3.1$ \\
\hline WHR & $0.90 \pm 0.09 \neq$ & $0.83+0.07$ & $0.95 \pm 0.06$ & $0.94 \pm 0.06$ \\
\hline SBP $(\mathrm{mmHg})$ & $144.7 \pm 27.9+$ & $123.1 \pm 16.9$ & $140.5 \pm 8.9$ & $136.9=15.3$ \\
\hline $\mathrm{DBP}(\mathrm{mmHg})$ & $89.1 \pm 15.7+$ & $79.3 \pm 9.1$ & $89.6 \pm 10.9$ & $88.0 \pm 11.5$ \\
\hline
\end{tabular}

Apo $\mathrm{B}=$ apolipoprotein $\mathrm{B}, \mathrm{BMI}=$ Body Mass Index, DBP = Diastolic Blood Pressure, FFA: Free Fatty Acids, Glucose: for $\mathrm{mg} / \mathrm{dL}$, divide by $0.0555, \mathrm{HDL} \cdot \mathrm{C}=$ High Density Lipoprotein Cholesterol. HOMA = calculated surrogate marker of insulin resistance, Insulin: for $\mu U / \mathrm{mL}$, divide by 6.945, SBP = Systolic Blood Pressure, TC = Total Cholesterol (for $\mathrm{mg} / \mathrm{dL}$, divide by 0.0259 ), TG = plasma triglyceride (for $\mathrm{mg} / \mathrm{dL}$, divide by $0.0113 \mathrm{~J}, \mathrm{WHR}=$ Woist-Hip ratio ${ }^{*}=$ FCHL ws. spouses, $p<0.05 i^{\dagger}=$ FCHL vs. spouses, $p<0.01 ;=$ FCHL vs. spouses, $p<0.001$

\section{Results}

Characteristics of the subjects studied are presented in Table 5.1. FCHL women were significantly older and had a significantly higher body mass index, waist to hip ratio and systolic and diastolic blood pressures compared to female spouses. Male and female FCHL subjects had significantly higher total cholesterol, fasting plasma triglyceride, and apolipoprotein B concentrations and a lower HDLcholesterol level than spouses did. In addition, FCHL women had significantly higher fasting plasma insulin levels (Fl: $66.7 \pm 40.6$ vs. $40.2 \pm 26.5 \mathrm{pmol} / \mathrm{L}$; 
$p<0.001)$ and higher calculated insulin resistance (HOMA: $2.17 \pm 1.48$ vs. 1.22 $\pm 0.79 ; p<0.001)$ than female controls. Fasting insulin levels were significantly higher in FCHL men relative to male controls $(71.8 \pm 73.7$ vs. $45.4 \pm 26.5$ $\mathrm{pmol} / \mathrm{L}, \mathrm{p}<0.05)$, as was observed in women, but the difference in calculated insulin resistance (HOMA) was not statistically significant. These abnormalities confirm earlier abnormalities observed in FCHL subjects.

QTc was corrected for age using linear regression analysis because of the significant age difference between the female populations under study, and the reported age-dependency of QTc ${ }^{30}$. Age-corrected QTc in FCHL women was significantly prolonged compared to spouses (difference of $7.8 \mathrm{msec}$, agecorrected $p<0.01$ ) (Table 5.2). In FCHL women, 10 out of $41(24.4 \%$ ) had a QTC-interval greater than 420 msec compared to 3 out of $46(6.5 \%)$ female spouses, $(p<0.05)$. This resulted in a highly significant odds ratio of $4.93(95 \%$ confidence interval, 1.22-20.03) of QTc $>420$ msec in FCHL affected females (Table 5.3). With respect to a QTc cut-off value of $440 \mathrm{msec}$, no significant difference $(p=0.10)$ was found between FCHL women $(3 / 4 \pi ; 7.3 \%)$ and female spouses $(0 / 46 ; 0 \%)$. In FCHL men, a significantly increased heart rate compared to male spouses was observed $(p<0.05)$, but after correction for heart rate and age, no differences in QTc interval were detected.

Earlier reports suggested that QTc might be part of an insulin resistant state. Subsequently, the potential relationship of QTe with components of the insulin resistance syndrome, and hyperlipidemia, were analysed in women. Men were not included in the analyses.

Table 5.2 Electrocardiogram heart rate and heart rate adjusted QT-interval, in FCHL affected subjects and spouses ( $\mathrm{p}$-values shown after adjustment for age).

\begin{tabular}{lcccc} 
& FCHL women & Control women & FCHL men & Control men \\
\hline Number & 41 & 46 & 35 & 46 \\
HR $($ beats $/$ min) & $66.9 \pm 9.0$ & $62.8 \pm 11.0$ & $62.0 \pm 7.8$ & $58.0 \pm 9.0^{*}$ \\
QTC $(\mathrm{msec})$ & $414.2 \pm 15.8+$ & $406.6 \pm 9.5$ & $403.6 \pm 10.1$ & $404.6 \pm 14.4$ \\
\hline
\end{tabular}

$H R=$ heart rate, $\mathrm{QTC}=$ heart rate corrected $\mathrm{QT}$ winterval; mean $\pm S D$;

* FCHL vs. spouses, age-adjusted $p<0.05$; $\dagger=$ FCHL vs. spouses, age-adjusted $p<0.01$;

Table 5.3 Prevalence of heart rate corrected QT-interval (QTc) greater than $420 \mathrm{msec}$

\begin{tabular}{lccc}
\hline & FCHL & Spouses & Odds ratio $(95 \% \mathrm{Cl})$ \\
\hline Women & $10 / 41(24.4 \%)^{*}$ & $3 / 46(6.5 \%)$ & $4.92(1.22-20.03)$ \\
Men & $3 / 35(8.6 \%)$ & $5 / 46(10.9 \%)$ & NS \\
\hline
\end{tabular}

$\mathrm{Cl}=$ confidence interval, $\mathrm{NS}=$ nan significant; $*$ FCHL ws. spouses, age-adjusted $p<0.05$

Age-adjusted Pearson correlations between QTC, lipid values and surrogate markers of insulin resistance, all treated as continuous variables, are depicted in Table 5.4. In women, a significantly positive correlation between QTC and log transformed triglyceride concentration, log transformed fasting insulin and HOMA were observed. A significantly negative correlation was found between 
QTc and HDL-cholesterol. To visualise these correlations, tertile categories ( $n=29$ subjects in each) of log triglyceride, HDL-cholesterol, log insulin and HOMA were identified. As shown in Figure 5.1, with longer duration of QTc, adjusted for age and $\mathrm{BMI}$, higher triglyceride, insulin and HOMA and lower HDL-cholesterol were found.

Table 5.4 Age-adjusted Pearson correlation coefficients between heart rate carrected QT-interval (QTc), plasma lipids and surrogate markers of insulin resistance variables in women $(n=87)$.

\begin{tabular}{lcc}
\hline & QTc & p-value \\
\hline BMI & -0.16 & $0.15, \mathrm{NS}$ \\
WHR & 0.18 & $0.11, \mathrm{NS}$ \\
Log TG & 0.25 & $<0.05$ \\
HDLC & -0.29 & $<0.01$ \\
FFA & -0.01 & $0.96, \mathrm{NS}$ \\
Log insulin & 0.30 & $<0.01$ \\
HOMA & 0.26 & $<0.05$ \\
\hline
\end{tabular}

$B M I=$ body mass index, $W H R=$ waist to hip ratio, $T G=$ fasting plasma triglyceride, HDL-C = high-density lipoprotein cholesterol, FFA = free fatty acids, HOMA = calculated surrogate marker of insulin resistance, NS = non-significant.

Next, multiple backward linear regression analysis was used to evaluate whether one of these metabolic factors was the most dominant in predicting a prolonged QTc. This analysis suggested that insulin was the most important metabolic indicator of prolonged QTc, apart from systolic blood pressure, and that HDLcholesterol was protective (Table 5.5). Age was no contributar. The analysis used age, body mass index, waist-hip ratio, systolic and diastolic blood pressures, fotal cholesterol, HDL-cholesterol, glucose, log insullin, free fatty acids, glycerol, apolipoprotein B, apolipoprotein A1, FCHL affected status, and heart rate ${ }^{8}$ as independent variables.

Table 5.5 Results of backward stepwise regression analysis with heart rate corrected QTinterval (QTC) as dependent variable.

QTe

\begin{tabular}{lccccc}
\hline Variable & $\beta$ & $\beta$ SE & Stand $\beta$ & $p$ & Model $r 2$ \\
\hline Intercept & 396.427 & 12.692 & & & $0.282^{*}$ \\
Loginsulin & 16.614 & 6.216 & 0.393 & $<0.001$ & \\
SBP & 0.196 & 0.052 & 0.411 & $<0.001$ & \\
HDL. C & -11.155 & 5.535 & -0.235 & $<0.05$ & \\
BMI & -0.869 & 0.355 & -0.354 & $<0.05$ & \\
FFA & -12.627 & 5.822 & -0.233 & $<0.05$ & \\
\hline
\end{tabular}

$\mathrm{SBP}=$ systolic blood pressure, $\mathrm{HDL}-\mathrm{C}=$ high-density lipoprotein cholesterol, $\mathrm{BMI}=$ body mass index, FFA = free fatty acids $\beta$ SE: $\beta$ standard error; stand $\beta$ : standardised $\beta$; $*=0<0.001$ 

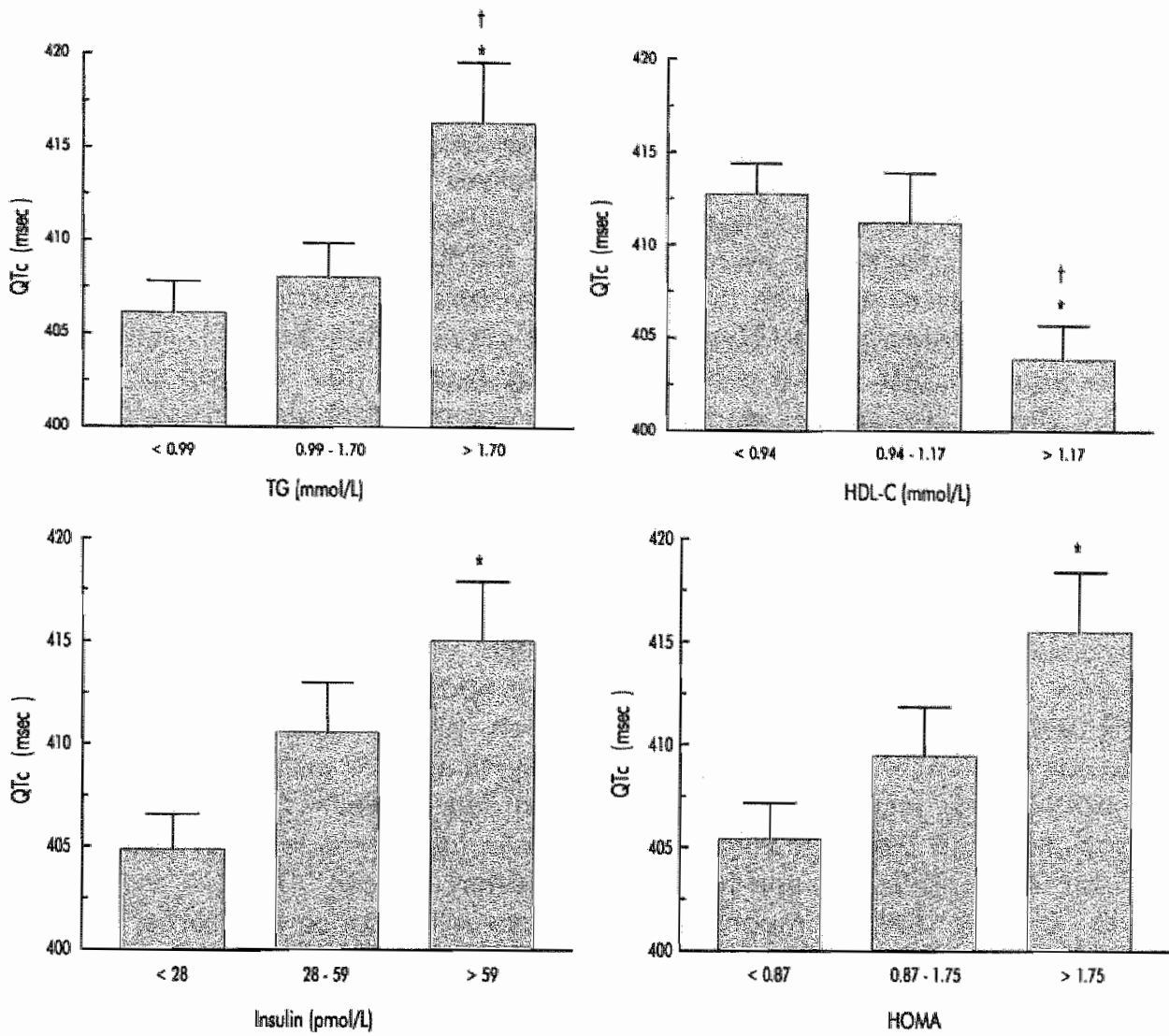

Figure 5.1 QTc values in tertile categories ( $n=29$ for each) in women of: $A$, fasting plasma triglyeride (TG); $B$, plasma HDL-cholesterd: $C_{\text {s }}$ plasma Insulin; $D$, HOMA value (see Methods; a higher HOMA value indicates less insulin sensitivity; ref 27,28 )

* = age and BMl-adjusted $p<0.02$, third ws. first tertile; $t=$ age and BMI adjusted $p<0.05$, third ws. second tertile.

\section{Discussion}

Women with FCHL showed a prolonged, age-adjusted, QTc duration compared to healthy female spouses. Quantitative analyses revealed a statistically significant 4.93 higher probability (odds ratio) of having a QTc greater than 420 msec in FCHL women relative to healthy women. A QTC greater than $440 \mathrm{msec}$ is considered directly clinically relevant, especially in the framework of long QT syndrome. We identified 3 of $41 \mathrm{FCHL}$ women, but no female spouses, with a QTc $>440 \mathrm{msec}$, and 10 of these 41 women had a QTc $>420 \mathrm{msec}$. It should be emphasised that even moderate QTc prolongation (QTc between 420-440 msec) has been associated with increased mortality during a 15 years follow-up 
study in a healthy Dutch population ${ }^{5}$. In addition, an increased QTc interval has been associated with an increased risk of sudden cardiac death in Caucasians s.5. $^{3.5}$ *as well as in American Indians ${ }^{31}$. The data show that FCHL predisposes to prolonged QTC, specifically in women. In male subjects we could not detect any difference in QTc interval between FCHL relatives and spouses. One possibility is that FCHL-cffected men with an increased QTc interval already suffered from cardiovascular disease or even died. The $6 \mathrm{FCHL}$ men who had been excluded from the analyses because of previous myocardial infarction did show some evidence of an increased QTc interval (median QTc $411.5 \mathrm{msec}$ ), compared to male spouses (QTc $404.6 \mathrm{msec}$ ) and FCHL men without a previous M! (QTC 403.6 msec); (Table 5.2). A second explanation is that women have delayed expression of $\mathrm{FCHL}$ and suffer from subsequent cardiovascular events at a higher age. Therefore, FCHL women may have had more time to develop an increased number of cardiovascular risk factors and insulin resistance that promotes a prolongation of the QTc interval. Recently, a stronger relationship between QTc interval and subclinical atherosclerosis, as assessed by intima media thickness, was reported in female nondiabetic subjects without clinical coronary artery disease than in men ${ }^{32}$. QTc interval was proposed as indicator of subclinical atherasclerosis ${ }^{32}$. Therefore, in FCHL women, prolonged duration of QTc can increase the risk of sudden cardiac death by ventricular arrhythmia, but may be associated with increased atherosclerotic burden as well. FCHL is known for its associated high risk of developing cardiovascular events, with an odds ratio of 1.7 for fatal and 5.1 for non-fatal coronary artery disease ${ }^{17,18}$.

In the present study, components of the insulin resistance syndrome, including higher plasma insulin, high triglyceride levels, low HDL-cholesterol and systolic blood pressure, all well-known metabolic risk indicators of cardiovascular mortality, were associated with a prolongation of the QTc interval. These relationships were previously described in healthy men ${ }^{14}$. Moreover, regression analyses revealed that fasting plasma insulin, systolic blood pressure and low HDL-cholesterol contributed independently to prolonged QTC. Increased left ventricular mass, secondary to hypertension, can also lead to QTC prolongation ${ }^{33,34}$. However, none of our subjects had signs of established left ventricular hypertrophy on electrocardiogram.

Body mass index and free fatty acids were not significantly correlated with QTC in univariate analysis, in agreement with findings in a middle aged Finnish population $^{34}$. Conversely, higher plasma levels of HDL-cholesterol and lower insulin concentrations were associated with protection against QTc interval prolongation.

It has been shown that FCHL affected subjects are as insulin resistant as subjects with type 2 diabetes mellitus, as measured by hyperinsulinemic euglycemic clamp ${ }^{35}$. Insulin resistance and concomitant hyperinsulinemia are known to increase sympathetic activity, and this increased sympathetic activity may be a dominant factor leading to QTc prolongation ${ }^{36}$. The presently found positive association between the QTC interval and blood pressure may be related to an unfavourable balance in sympathetic and parasympathetic activity ${ }^{10}$. The elevated risk of cardiovascular death associated with QTC prolongation has been attributed to ventricular electrical instability as a consequence of sympathetic 
stimulation unopposed by vagal activity ${ }^{10,11}$ or myocardial membrane defects ${ }^{12,13}$. In fact, higher systolic and diastolic blood pressures and a trend towards an increased heart rate in FCHL women can be interpreted as signs of increased activity of the sympathetic nerve system, but this was not measured directly in the present study.

The present findings point to the metabolic origin of a prolonged QTc interval by deficient intracellular energy substrate utilisation. This concept requires further sludy.

In conclusion, the duration of QTe is prolonged in women with FCHL and a specific association with components of the insulin resistance syndrome: hyperinsulinemia, systolic blood pressure and low HDL-cholesterol, was found. In theory, QTC prolongation may relate to the genetic susceptibility to $\mathrm{FCHL}$, but the findings suggest an adaptation mechanism to insulin resistance, more pronounced in women. Future studies will need to address the roll of QTC duration in female mortality in type 2 diabetes, hypertension and familial combined hyperlipidemia. 


\section{References}

1. Peters RW, Byington RP, Barker A, Yusuf S. Prognostic value of prolonged ventricular repolarization following myocardial infarction: the BHAT experience. The BHAT Study Group. Journal of Clinical Epimiolagy 1990;43:167-172.

2. Algra A, Tijssen JG, Roelandt JR, Pool J, Lubsen J. QT interval variables from 24 hour electrocardiography and the two year risk of sudden death. British Heart Journal $1993 ; 70: 43-48$

3. Algra A, Tijssen JG, Roelandt JR, Paol J, Lubsen J. QTC prolangation measured by standard 12-lead electracardiography is an independent risk factor for sudden death due to cardiac arrest. Circulation 1991;83:1888-1894.

4. A.hnve S. QT interval pralongation in acute myocardial infarction. European Heant Journal 1985;6 Suppl D:85-95.

5. Schouten EG, Dekker JM, Meppelink P, Kok FJ Vandenbroucke JP, Pool J. QT interval prolongation predicts cardiavascular mortality in an apparently healthy population. Circulation 1991,84:1516-1523.

6. Dekker JM, Schouten EG, Klootwiik P, Pool J, Kromhout D. Association between QT interval and coronary heart disease in middle-aged and elderly men. The Zutphen Study. Circulation 1994;90;779-785.

7. de Bruyne M, Hoes AW, Kors JA, Hofman A, wan Bemmel JH, Grobbee DE. Prolonged QT interval predicts cardiac and all-cause mortality in the elderly. The Rotterdam Study. European Heart Journal 1999;20:278-284.

8. Elming $H$, Holm E, Jun L, Torp Pedersen $C$, Kober $L$, Kircshoff $M$, Malik M, Camm J. The prognostic value of the QT interval and QT interval dispersion in all-cause and cardiac mortality and morbidity in a population of Danish citizens. European Heart Journal 1998;19:1391-1400.

9. Schwartz PJ, Snebolld NG. Brown AM. Effects of unilateral cardiac sympathetic denervation on the ventricular fibrillation threshold. American Journal of Cardialogy $1976,37: 1034-1040$.

10. Ben DJ, Zipes DP. Differential response to right and left arteria subclaviae stimulation of early afterdepolarizations and ventricular tachycardia induced by cesium in dogs. Circulation 1988;78:1241-1250.

11. Takahashi $N$, llo $M$, Ishida $S$, Fujino $T$, Saikawa $T$, Arita $M$. Effects of vagal stimulation on cesium-induced early afterdepolarizations and ventricular arrhythmias in rabbits. Circulation 1992;86:1987-1992.

12. Vincent $\mathrm{GM}$, Timothy $\mathrm{KW}$, Leppent $M$, Keating $M$. The spectrum of symptoms and QT intervals in carriers of the gene for the long-QT syndrome. New England Journal of Medicine 1992;327:846-852.

13. Zipes DP. The long QT interval syndrome. A Rosetta stone for sympathetic related ventricular tachyarrhythmias. Circulation 1992;84:1414-1419.

14. Dekker JM, Feskens EJ, Schouten EG, Klootwijk P, Pool J, Kromhout D. QTe duration is associated with levels of insulin and glucose intolerance. The Zutphen Elderly Study. Diabetes 1996:45:376-380. 
15. Goldstein JL, Schrot HG, Hazzard WR, Bierman EL, Motulsky AG. Hyperlipidaemia in Coronary Heart Disease. II Genetic analysis of lipid levels in 176 families and delineation of a new inherited disorder, combined hyperlipidaemia. Jounal of Clinical Investigation 1973,52:1544-1568.

16. Castro Cabezas $M$, de Bruin TWA, Erkellens DW. Familial combined hyperlipidaemia: 1973-1991. Netherlands Journal of Medicine 1992;40:83-95.

17. Austin MA, McKnight B, Edwards KL, Bradley CM, McNeely MJ, Psaty BM, Brunzell JD, Motulsky AG. Cardiovascular disease martality in familial forms of hypertriglyceridemia: A 20-year prospective study. Circulation 2000;101:2777. 2782 .

18. Voors-Pette $C$, de Bruin TWA. Excess coronary heart disease in Familial Combined Hyperlipidemia, in relation to genetic factors and central obesity. Atherosclerosis $2001 ; 157: 481-489$.

19. Venkatesan S, Cullen P, Pacy P, Halliday D, Scott J. Stable isotopes show a direct relation between $V L D L$ apoB overproduction and serum triglyceride levels and indicate a metabolically and biochemically coherent basis for familial combined hyperlipidemia. Arteriosclerosis Thrombosis and Vascular Biology 1993;13:11101118.

20. Castra Cabezas $M$, de Bruin TWA, de Valk HW, Shoulders CC, Jansen H, Erkelens DW. Impaired fatty acid metabalism in familial combined hyperlipidemia. A mechanism associating hepatic apolipopratein $B$ overproduction and insullin resistance. Journal of Clinical Investigation 1993;92:160-168.

21. Cabezas MC, de Bruin TWA, Jansen H, Kack LA, Kortlandt W, Erkelens DW. Impaired chylomicron remnant clearance in familial combined hyperlipidemica. Arteriosclerosis and Thrombosis 1993;13:804-814.

22. Bredie $S J H$, Tack CJJ, Smits $P$, Stalenhoef AFH. Non-obese patients with familial combined hyperlipidemia are insulin resistant as compared with their non-affected relatives. Arteriosclerosis Thrombosis and Vascular Bialogy 1997;17:1465-1471.

23. Keulen ETP, Voor-Pette $C_{r}$ de Bruin TWA. Familial Dyslipidaemic Hypertension Syndrome: further delineation in Familial Combined Hyperlipidaemia, and the role of abdominal fat mass. American Journal of Hypertension 2001; 14:357-363.

24. Ackerman MJ. The long QT syndrome: ion channel diseases of the heart. Mayo Clinical Procedings 1998;73:250-269.

25. Bellavere F, Ferri $M_{*}$ Guarini L, Bax $G$, Piccali $A_{*}$ Cardone C. Fedele D. Prolonged QT period in diabetic autonomic neuropathy: a possible role in sudden cardiac death? British Heart Journal 1988;59:379-383.

26. Friedewald WT, Levy RI, Fredrickson DS. Estimation of the concentration of lowdensity lipoprotein cholesterol in plasma, without the use of the preparative ultracentrifuge. Clinical Chemistry 1972;18:499-502.

27. Matthews DR, Hosker JP, Rudenski AS, Naylor BA, Treacher DF, Turner RC. Homeostasis model assessment: insulin resistance and beta-cell function from fasting plasma glucose and insulin concentrations in man. Diabetologia 1985;28:412-419.

28. Bonora $E$, Targher $G$, Alberiche $M$, Bonadonna RC, Saggiani F, Zenere MB, Monaumi T. Muggeo M. Homeostasis madel assessment clasely mirrors the glucose clamp technique in the assessment of insulin sensitivity: studies in subjects with various degrees of glucose tolerance and insulin sensitivity. Diabetes Care 2000;23:57-63. 
29. Ingelfinger JA, Mosteller F, Thibodeau LA, Wore JH. Biostatistics in clinical medicine. New York, USA: MCGraw-Hill, Inc, 1994.

30. de Bruyne MC, Hoes AW, Kors JA, Dekker JM, Hofman A, van Bemmel JH, Grobbee DE, Feskens EJ, Schouten EG, Klootwijk P, Pool J, Kromhout D, Meppelink P, Kok FJ, Vandenbroucke JP. Prolonged QT interval: a tricky diagnosis? American Jaumal of Cardiology 1997,80:1300-1304.

31. Okin PM, Devereux RB, Howard BV, Fabsitz RR, Lee ET, Welty TK. Assessment of QT interval and QT dispersion for prediction of all-cause and cardiovascular mortality in American Indians: The Strong Heart Study. Circulation 2000;101:67-66.

32. Festa A, D'Agostino R, Rautaharju P, O'Leary DH, Rewers M, Mylkkanen L, Haffner SM. Is QT interval a marker of subclinical atherasclerasis in nondiabetic subjects? The insulin resistance atherosclerosis study (IRAS). Stroke 1999;30:1566-1571.

33. Cavallaro $V$, Petretta $M$, Betocchi $S$, Salvatore $C$, Morgano $G$, Bianchi $V$, Breglio $R$, Bonaduce $D$. Effects of sustained training on left ventricular structure and function in rop level rowers. European Heart Jaurnal 1993;14:898-903.

34. Karjalainen J, Reunanen A, Ristola P, Vitasalo M. QT interval as a cardiac risk factor in a middle aged population. Heart 1997;77:543-548.

35. Pette $C$, Janssen $M-J$, van der Kallen $C J H$, de Bruin TWA. Specific insulin resistance of adipose tissue in familial combined hyperlipidemia. Circulation 1999;100:1 196 (absitract).

36. Rowe لW, Young JB, Minaker KL, Stevens AL, Pallotta J, Landsberg L. Effect of insulin and glucose infusions on sympathetic nervous system activity in normal man. Diabetes $1981,30: 2119: 225$. 


\section{Chapter 6}

Pro-coagulant endothelium in Familial Combined Hyperlipidemia

ETP Keulen, K Hamulyak, TWA de Bruin Submitted for publication 


\section{Abstract}

The approximately 10-fold increased risk of early cardiovascular disease in Familial Combined Hyperlipidemia (FCHL) is nof fully explained by classical risk factors such as hyperlipidemia, insulin resistance and hypertension. Abnormal hemostatic properties of endothelium are potentially relevant to the development of clinical cardiovascular disease in FCHL. In this study we report that PAI-1 and WWf are elevated in FCHL subjects, indicating a pro-coagulant state. Surrogate markers of insulin resistance explained $50 \%$ of the variation in plasma PAI.1 levels. The significantly 1.8-fold higher levels of PAI-1 in FCHL represent one of the most dramatic biochemical abnormalities reported in this disorder. 


\section{Introduction}

Major functions of the vascular endothelium are NO production and regulation of hemostasis, i.e. coagulation and fibrinolysis. The NO-production regulates, in part, vasodilatation and proliferation of cells in the vascular wall. In subjects with Familial Combined Hyperlipidemia (FCHL) impaired endothelial derived NOdependent vasodilatation has been reported', and this abnormality can be almost completely reversed by antihyperlipidemic therapy. In FCHL, classical risk factors, including hyperlipidemia, insulin resistance and hypertension, contribute to the 10-fold elevated risk of early cardiovascular disease, but do not explain all of the observed cardiovascular risk. Abnormal hemostatic properties of endothelium can be important in the occurrence of cardiovascular events in $\mathrm{FCHL}$, as described in other insulin resistant states such as type 2 diabetes mellitus. As far as we know, abnormal hemostatic properties of endothelium have not yet been studied in FCHL.

Endothelium produces pro-coagulant and anti-coagulant substances (procoagulant: von Willebrand factor (VWf); anti-coagulant: tissue factor pathway inhibitor (TFPI) and thrombomodulin) and components of the fibrinolytic system that promote or inhibit fibrinolysis (tissue type plasminogen activator (t-PA) and plasminogen activator inhibitor 1 (PAl-1), respectively).

In this study we report on an apparent pro-coagulant state of the endothelium in $\mathrm{FCHL}$, as shown by elevated plasma PAI- 1 and $\mathrm{WWF}$ concentrations. Surrogate markers of insulin resistance explained $50 \%$ of the variation in PAI- 1 levels in FCHL, a disorder characterised by insulin resistant, dyslipidemia and hypertension.

\section{Subjects and methods}

In the framework of metabolic and genetic studies, venous blood was collected from 70 hyperlipidemic FCHL subjects (fasting plasma total cholesterol (TC) $>6.5$ $\mathrm{mmol} / \mathrm{L}$ and/or fasting plasma triglyceride (TG) concentration $>2.0 \mathrm{mmol} / \mathrm{L}$ ) and 57 healthy married-in spouses. Fourteen FCHL-affected subjects identified with a previous cardiovascular history (CVD) had their event at least 6 months prior to the blood callection. The study protocol was approved by the Human Investigations Review Committee and performed according to the Helsinki Declaration. All subjects gave written informed consent.

All measurements were performed in the morning $(8.00-11.00 \mathrm{~h})$ after an overnight fast (12-14h). Subjects had refrained from smoking and abstained from coffee or tea. Lipid lowering medication had been withdrawn for two weeks prior to the study. Venous blood was collected in pre-cooled tubes containing $3.25 \%$ sodium citrate (dilution 1:10) for measurements of WWf, TFPl, soluble thrombomodulin and PAI-1, using commercially available assays. Blood collected in the Biopool ${ }^{\infty}$ stabilyte ${ }^{T M}$ devices was used to measure t-PA levels, 
using a commercially available assay. Other measurements were described previously ${ }^{2}$.

\section{Statistical analyses}

All values are expressed as mean \pm standard deviation, except as median and range for PAl-1. An independent sample t-test was used to determine differences between the two groups. BMI was used as covariant in t-PA and PAI-1 analyses. For technical reasons, t-PA levels were only available in $49 \mathrm{FCHL}$ affected subjects and 51 healthy controls. Log transformed fasting insulin and TG concentrations were used in statistical analyses because of non-normal distribution. The statistical package SPSS 8.0 was used.

\section{Results}

FCHL subjects exhibited their characteristic phenotype with significantly higher $\mathrm{BMI}$, waist-circumference, systolic and diastolic blood pressures, total cholesterol (TC) concentration, fasting plasma triglyceride (TG) and insulin levels than controls (Table 6.1).

Table 6.1 Characteristics of 70 hyperlipidemic FCHL relatives and 57 healthy control subjects.

\begin{tabular}{|c|c|c|}
\hline & FCHL $(n=70)$ & Healthy controls $(n=57)$ \\
\hline Age (years) & $47.3 \pm 12.1$ & $45.5 \pm 12.5$ \\
\hline $\mathrm{TC}(\mathrm{mmol} / \mathrm{L})$ & $6.9 \pm 1.4 \neq$ & $5.1 \pm 0.8$ \\
\hline HDL-C (mmol/ll.) & $0.88 \pm 0.267$ & $1.06 \pm 0.27$ \\
\hline $\mathrm{TG}(\mathrm{mmol} / \mathrm{L})$ & $3.1 \pm 2.67$ & $1.0 \pm 0.4$ \\
\hline Apo B $(g / L)$ & $1.4 \pm 0.34$ & $1.0 \pm 0.2$ \\
\hline Glucose (mmol/L) & $5.2 \pm 0.8$ & $4.9 \pm 0.5$ \\
\hline Insulin $(\mu U / \mathrm{mL})$ & $10.0=8.5$ & $4.6 \pm 3.3$ \\
\hline $\mathrm{BMH}(\mathrm{kg} / \mathrm{m} 2)$ & $27.4 \pm 3.9+$ & $25.3 \pm 3.8$ \\
\hline Waist-circumference $(\mathrm{cm})$ & $95.3 \pm 10.7 *$ & $87.8 \pm 13.1$ \\
\hline $\operatorname{SBP}(\mathrm{mmH} \lg )$ & $140.3 \pm 18.8+$ & $129.7 \pm 20.2$ \\
\hline $\mathrm{DBP}(\mathrm{mmHg})$ & $88.2=10.6+$ & $82.5 \pm 11.8$ \\
\hline
\end{tabular}

$T C=$ Total Cholesterol (for $\mathrm{mg} / \mathrm{dL}$, divide by 0.0259 ), HDL-C $=$ High Density Lipoprotein Cholesterol, $T G=$ plasma triglyceride (for $\mathrm{mg} / \mathrm{dL}$, divide by 0.0113 ), $A$ po $B=$ apolipoprotein $\mathrm{B}$, glucose: for $\mathrm{mg} / \mathrm{dL}$, divide by 0.0555 , insulin: for pmol/mL, multiply by 6.945, BMI = Body Mass Index, SBP $=$ Systolic Blood Pressure, $\mathrm{DBP}=$ Diastolic Blood Pressure; $t=$ FCHL vs. healthy controls, $p<0.01 ; \ddagger=F C H L$ vs. healthy controls, $p<0.001$

Notably, FCHL subjects showed significantly higher PAI- 1 levels and higher t-PA levels than healthy controls (PAl-1: $18(3-38)$ vs. $10(1-29) \mathrm{U} / \mathrm{mL} ; p<0.001$, and t.PA: $10.8 \pm 3.8$ vs. $7.5 \pm 3.9 \mathrm{ng} / \mathrm{mL} ; \mathrm{p}<0.001$ ) (Table 6.2). Furthermore, wwf was significantly higher in FCHL subjects compared to healthy controls $(110.0 \pm$ 
$35.4 \%$ vs. $94.3 \pm 36.8 \%, p<0.05$ ) (Table 6.2 ) Exclusion of 14 FCHL subjects with previous CVD did not alter these results, nor the statistical significance.

Multivariate backward regression analyses, with the variables listed in Table 6.1, revealed that $50.5 \%$ of PAl-1 levels were explained by logTG, log insulin, glucose and apolipoprotein B, all FCHL traits (Table 6.3). Of these factors, especially hypertriglyceridemia and hyperinsulinemia were identified as the strongest contributors to the association with PAl-1.

Table 6.2 Endothelium derived factors of the coagulant and fibrinalytic system in 70 FCHL affected subjects and 57 healthy married-in spouses.

\begin{tabular}{lcc} 
& FCHL $(n=70)$ & Healthy controls $(n=57)$ \\
\hline PAl-1 $(\mathrm{U} / \mathrm{mL})$ & $18(3-38) \pm$ & $10(1-29)$ \\
t.PA $(\mathrm{ng} / \mathrm{mL})$ & $10.8 \pm 3.8 \neq$ & $7.5 \pm 3.9$ \\
WWf $(\%)$ & $110.0 \pm 35.4^{*}$ & $94.3 \pm 36.8$ \\
TFPI $(\mathrm{ng} / \mathrm{mL})$ & $47.1 \pm 11.6$ & $43.0 \pm 11.7$ \\
S. Thrombomodulin $(\mathrm{ng} / \mathrm{mL})$ & $31.8 \pm 7.5$ & $30.1 \pm 9.2$ \\
\hline
\end{tabular}

PAl-1 = Plasminogen Activator Inhibitor 1 (median and range), $\mathrm{t}-\mathrm{PA}=$ tissue derived Plasminogen Activator, $\mathrm{VWf}=$ von Willebrand factor, TFPI $=$ truncated Tissue Factor Pathway Inhibitor, S. Thrombomadulin = soluble thrombomadulin. ${ }^{*}=\mathrm{FCHL}$ vs. spouses, $p<0.05 ; t=$ FCHL vs. spouses, $p<0.01 ; \ddagger=F C H L$ vs. spouses, $p<0.001$

Table 6.3 Results of backward stepwise regression analysis with PAI-1 as dependent variable.

PAl - 1

\begin{tabular}{lcllll}
\hline Variable & $\beta$ & $\beta$ SE & Stand. $\beta$ & $P$ & Model r2 \\
\hline & & & & & $0.505^{*}$ \\
Intercept & -4.853 & 4.887 & & & \\
Log TG & 13.267 & 2.68 & 0.430 & $<0.001$ & \\
Log Insulin & 6.260 & 2.541 & 0.218 & $<0.05$ & \\
Glucose & 1.751 & 0.898 & 0.135 & 0.054 & \\
Apo B & 3.605 & 2.097 & 0.131 & 0.088 & \\
\hline
\end{tabular}

$\beta$ SE: $\beta$ standard error; stand $\beta$ : standardised $\beta ; \log T G=\log$ triglyceride; apo $B=$ apolipoprotein $B ; * ; p<0.001$

\section{Discussion}

In the present study, FCHL affected subjects had higher PAI- 1 and WWf levels, indicating a pro-coagulant, anti-fibrinolytic state of the endothelium. PAI-1 and WWf have shown to be independent risk factors of cardiovascular disease $e^{3,4}$. Therefore, it is plausible that increased PAI- 1 and $v W F$ expression can contribute to the 10-fold higher risk of CVD in FCHL. Increased PAl-1 and WWf concentrations have been shown to reflect endothelial dysfunction, in agreement with other evidence in FCHL'. High PAI-1 levels have been found in subjects with 
insulin resistance and hypertension, two clinical features that are frequently observed in FCHL. In the present study, components of the insulin resistance syndrome explained $50.5 \%$ of the variation in PAI-1 levels, especially hypertriglyceridemic and hyperinsulinemia. This finding offers possibilities to lower PAl- 1 levels by treating the contributing abnormalities, hypertriglyceridemia and hyperinsullinemia. Recently, we reported on the role of tumor necrosis factor $\alpha\left(T N F a\right.$ ) and TNF receptor 2 (TNFRSF2b) in $\mathrm{FCHL}^{2}$. It has been shown that TNFa-induced PAl-1 expression in vascular endothelial cells as well as PAl-1 secretion from human adipocytes was inhibited by thiazolidinediones, offering another potential treatment modality in $\mathrm{FCHL}^{5}$.

In conclusion, the significantly elevated (1.8-fold higher) levels of PAI- 1 in FCHL indicate an anti-fibrinolytic state of the endothelium, that is dependent on insulin resistance, and potentially contributes to the risk of premature cardiovascular disease. Because FCHL is best described as insulin resistant hyperlipidemia and hypertension, further studies to the contribution of PAI-1 to risk of cardiovascular disease, and the potential treatment of elevated PAI-1 and VWf levels are warranted. 


\section{References}

1. Stroes $E$, de Bruin TWA, Valk de $H$, Erkelens DW, Banga JD, van Riin $H$, Koomans H, Rabelink T. NO actiwity in familial combined hyperlipidemia: potential role of cholesterol remnants. Cardiovascular Research 1997; 36:445-452.

2. Geurts $I M W$, Janssen RGJH, wan Greevenbroek MMJ, van der Kallen CJH, Cantor RM, Bu XD, Aouizerat BE, Allayee H, Rotter Jl, de Bruin TWA. Identification of TNFRSFIB as a novel modifier gene in familial combined hyperlipidemia. Human Molecular Genetics 2000; 9:2067-2074.

3. Hamsten A, de Faire U, Walldius $G$, Dahlen $G$, Szamosi A, Landou $C$, Blomback $M$, Wiman B. Plasminagen activator inhibitor in plasma: risk factor for recurrent myocardial infarction. Lancet 1987; 2:3-9.

4. Thogersen AM, Jansson JH, Boman K, Nilsson TK, Weinehall $L$, Huhtasaari $F$, Hallmans $G$. high plasminogen activator inhibitor and tissue plasminogen activator levels in plasma precede a first acute myocardial infarction in both men and women: evidence for the fibrinalytic system as an independent primary risk factor. Circulation $1998 ; 98: 2241-2247$

5. Kato K, Satoh H, Endo Y, Yamada D, Midorikawa S, Sato W, Mizuno K, Fujita T, Tsuhamoto $K$, Watanabe $T$. Thiazolidinediones down-regulate plasminogen activatior inhibitor type 1 expression in human vascular endothelial cells: A possible role for PPARgamma in endathelial function. Biochemical and Biophysical Research Communications $1999 ; 258: 431-435$. 



\section{Chapter 7}

Reduced structural and functional skin capillaries in Familial Combined Hyperlipidemia: association with increased remnant-like lipoprotein cholesterol levels

ETP Keulen, NC Schaper, AJHM Houben, JMJP van Lin, I Lutgens, K Rijkers, GM Dallinga-Thie, TWA de Bruin

Submitted for publication 


\section{Abstract}

We defermined whether abnormalities in basal (BC) and post-occlusive $(P O C)$ number of capillariss are present in Familial Combined Hyperlipidemia (FCHL), and investigated the relationship of POC with plasma lipids, remnant-like lipaprotein particles (RLP-C), blood pressure, and surrogate markers of insulin resistance.

Fiffy age-matched subjects: 23 (12 men) hyperlipidemic, normotensive FCHL subjects and 27 (14 men) healthy controls participated in this study. Capillary density was measured just above the finger nailfold, before and after 4 minutes of arterial occlusion. BC and POC were significantly lower in FCHL men compared to thealthy men, $113.7 \pm 15.1 \mathrm{ws}$. $132.0 \pm 18.0(p=0.02)$ and $123 \pm 19.1$ vs. $142.3 \pm 18.3(p=0.03)$, respectively. POC was inversely correlated with total cholesterol $(r=-0.61, p<0.005), \log T G(r=-0.52$, $p<0.05)$, $\log R L P-C(r=-0.51, p<0.05)$ and $\log$-insulin $(r=-0.48, p<0.05)$. Multivariate analyses revealed that logRLP-C was the only significant independent, contributor to POC.

In conclusion, in FCHL men a reduction in struetural and functional skin capillaries was abserved, and associated with increased atherogenic lipoprotein levels. This loss of capillary surface may be implicated in the pathophysiology of FCHL or can pesult from adaptation to the hyperlipidemia in FCHL. 


\section{Introduction}

Familial Combined Hyperlipidemia (FCHL), the most common genetic dyslipidemia in humans, affects $0.5 \%-2 \%$ of the population and occurs in 10 . $20 \%$ of premature myocardial infarction survivors ${ }^{1.2}$. Recently, two reports showed that FCHL relatives also have a markedly increased risk of fatal and nonfatal coronary artery disease (CAD), with odds ratios of 1.7 and 5.1, respectively $y^{3,4}$. In addition to genetic factors, metabolic cardiovascular risk factors serve as an explanation for this high risk of $\mathrm{CAD}^{1,4}$. FCHL is a metabolic, hyperlipidemic syndrome associated with apolipoprotein B overproduction ${ }^{5,6}$, relatively impaired lipoprotein elimination ${ }^{6,7}$, impaired insulin stimulated glucose uptake $^{8,9}$, and central obesity ${ }^{10}$. Moreover, the prevalence of dyslipidemic hypertension in $\mathrm{FCHL}$ is increased two-fold ${ }^{10}$.

A common feature of $\mathrm{FCHL}$, hypertension and type 2 diabetes is impaired $\mathrm{NO}$ -

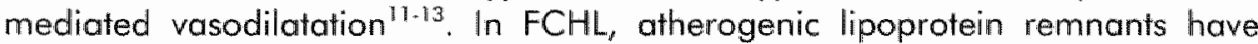
been causally linked to impaired endothelial-derived vasodilatation, because this abnormality partly normalised following antihyperlipidemic treatment that resulted in reduced lipoprotein remnant concentrations ${ }^{11}$. Furthermore, increased levels of remnant particles have been associated with the presence and progression of cardiovascular disease and play an important role in the macrovascular atherogenic process. Increased levels of atherogenic remnant particles have also been demonstrated as part of the insulin resistance syndrome ${ }^{14}$. Recently, a new methodology has been described to measure remnant-like lipoprotein particles by immunoaffinity columns ${ }^{15.18}$. This methodology facilitates studies of larger groups and can therefore help to shed light on the interaction between atherogenic lipoproteins and the endothelium, or circulation parameters, in subjects at risk of atherosclerasis, such as in FCHL.

In subjects with hypertension or type 2 diabetes, several abnormalities in the microvasculature have been reported ${ }^{19.25}$. A reduction in the density of capillaries, also known as rarefaction, is often observed in hypertensive patients $^{19.23}$ and, moreover, in subjects at risk of developing hypertension ${ }^{26}$. Another abnormality in microvasculature function, impaired capillary recruitment, has been proposed as a link between elevated blood pressure and insulin resistance, in hypertensive ${ }^{27}$ and normotensive subjects ${ }^{28}$. However, no reduction in capillary density and no association between capillary density and blood pressure values have been demonstrated in subjects with type 2 diabetes or impaired glucose tolerance ${ }^{29}$, who are both known to be insulin resistant. As a result, the possible relationship between insulin resistance and microvascular abnormalities is not clear. Moreover, the possible role of plasma lipids, lipoproteins and remnant particles in microvascular abnormalities have not yet been taken into account in the above mentioned studies. Furthermore, little is known about microvasculature in hyperlipidemic diseases. It was the aim of the present study to determine whether abnormalities in capillary structure and function are present in FCHL. The abnormalifies found in capillary density were subsequently evaluated for their potential association with plasma lipids and 
remnant-like lipoprotein porticles, blood pressure values, and surrogate markers of insulin resistance.

\section{Subjects and methods}

Fifty age matched subjects participated in the present study: 23 (12 men) hyperlipidemic, normotensive FCHL subjects and $27(1.4 \mathrm{men})$ healthy controls. Hyperlipidemic subjects were characterised by a primary hyperlipidemia, defined as fasting plasma total cholesteral (TC) $>6.5 \mathrm{mmol} / \mathrm{L}(250 \mathrm{mg} / \mathrm{dL})$ and/or fasting plasma triglyceride (TG) concentration $>2.3 \mathrm{mmol} / \mathrm{L}(200 \mathrm{mg} / \mathrm{dL})$, as described before ${ }^{10}$. Nome of our subjects had established cardiovascular disease on clinical examination or ECG. Subjects using cardiovascular medication, or salicylates and NSAID's, as well as subjects with a newly diagnosed hypertension las defined in the present study as blood pressure $>160 / 95$ on three consecutive visits) were excluded from this study. The study protocol was approved by the Human Investigations Review Committee and performed according to the Helsinki Declaration. All subjects gave written informed consent.

\section{Measurements}

The measurements were performed in the morning $(8.00-11.00)$ after an overnight fast $(12-14 \mathrm{~h})$. Subjects had refrained from smoking and had not drunk colfee or tea in the morning. Subjects had also abstained from alcohol for at least 72 hours. A medical history was obtained from all participating subjects and a standardised questionnaire was filled out. All patients were weighed in underwear, the height was determined by stadiometer and the bady mass index (BMI) was subsequently calculated as weight in kilograms / (height in meters) ${ }^{2}$. The waist-circumference was measured at the level of the umbilicus, the hipcircumference was measured at the level of the trachanter major and the waist to hip ratio (WHR) wos calculated. Both waisi-circumference and hip-circumference were measured with the subject in standing position.

Systolic (SBP) and diastalic (DBP) blood pressures were measured twice, with the Omron 705CP (OMRON Health Care GmbH, Hamburg, Germany) in a standardised fashion, with the subject in sitting position after 10 minutes of rest. Cuff size was adjusted to the circumference of the arm, and the arm was placed with the cuff at heart-level. The mean of two measurements was used in the statistical analyses.

\section{Evaluation of microcirculation}

After an acclimatisation perilod of at least 20 minutes in a quiet, temperaturecontrolled $\left(25.5 \pm 0.5^{\circ} \mathrm{C}\right)$ room, sufficient to result in a stabel skin temperature, the microvascular measurements were performed. The subject was seated in upright position with the right hand in fixed position at heart level. Perfused skin capillaries were measured approximatiely $6 \mathrm{~mm}$ proximal to the nail fold of the dorsum of the right $4^{\text {th }}$ finger, using capillary microscopy equipped with a $4 x$ 
objective. Only the tip of the capillary loop was visible in the above mentioned area. A drop of oil was applied to the skin to diminish scattering, and improve skin transparency. In the resting phase, three microscopic images $\left(1,6 \mathrm{~mm}^{2}\right)$ were videotaped (Panasonic) during 10 seconds for off-line analysis. The mean of these three images was used for baseline number of capillaries (BC). Subsequently, a wrist-cuff was inflated for four minutes at suprasystalic level to obtain arterial occlusion. Immediately after deflation of the wrist-cuff, two microscopic fields were measured for 8 seconds to obtain total post-occlusive number of capillaries (POC). The two post-occlusive fields overlapped the three baseline fields measured and all erythrocyte perfused capillaries were counted from a free-framed reproduction of the videotape and from the running videotape when it was uncertain whether a capillary was present or not. The mean of two fields was used in the analyses. Post-ocelusive hyperaemic capillary recruitment $(C R)$ was defined as $[(P O C$ minus $B C] / B C] \times 100 \%$. The day-to-day coefficient of variation was $8 \%$, as determined in ten subjects on two occasions.

Thermoregulatory skin perfusion was simultaneously determined with microscopy, using laser-Doppler fluxmetry (LDF, Periflux PF3, Perimed, Sweden), with the standard probe PF308, filter setting: $12 \mathrm{kHz}$ ('wide band') and time constant: $0.2 \mathrm{~s}$. The probe was placed at the dorsum of the middle phalanx of the right $3 \mathrm{rd}$ finger. This probe remained in the same position during the experiment. Flux values are expressed as arbitrary, but calibrated, perfusion units (PU). Perfusion units are determined by red blood cell concentration and red blood cell velocity. During the resting microscopy measurements of the capillaries, basal flux (LDBF) was measured as the mean flux during the last two minutes before the arterial occlusion. During the post-occlusive reactive hyperaemia, peak flux (LDPF), delta peak flux (delPF = peak flux minus resting flux), percent post-occlusive reactive hyperaemia (LDPRH) ([delPF / LDBF] $x$ $100 \%$ ), time to peak flux following release of occlusion and time to $50 \%$ recovery, were determined. All flux data are presented with the corresponding biological zero subtracted. The biological zero was defined as the mean laserDoppler flux at the end of the arterial occlusion periad. The day-to-day coefficient of variation of LDPRH was $16 \%$, as determined in ten subjects on two accasions. During these measurements skin temperature was measured continuously by an electronic thermometer (Hewlett Packard, USA).

\section{Laboratory methods}

Any lipid lowering medication had been withdrawn for two weeks before blood samples were collected. After all measurement of microvasculature were performed, fasting venous blood was collected in pre-cooled EDTA (1 - mg/m/) Vacutainer tubes for measurements of lipids, lipoproteins, glucose and insulin. Total cholesterol (TC) and fasting triglyceride (TG) concentrations were measured in duplicate by a commercially available colorimetric assay (Monotest Cholesteral kit, Boehringer Mannheim \#1442350 and GPO-PAP, Boehringer Mannheim, \#701912, respectively). HDL-cholesterol (HDL-C) was determined after phosphotungstate- $\mathrm{MgCl} 2$ precipitation of whole plasma. Fasting plasma LDLcholesterol (LDL-C) was calculated according to the Friedewald formula: 
LDL-C $=$ TC-HDL-C-(TG $\times 0.45)^{3}$, if plasma TG concentration was below 4.5 $\mathrm{mmol} / \mathrm{L}(390 \mathrm{mg} / \mathrm{dL})$. If plasma TG was above $4.5 \mathrm{mmol} / \mathrm{L}$, LDL-chal was measured in the density $1.019-1.063$ fractions, prepared after equilibrium ultracentrifugation. Nonesterified fatty acids (NEFA) were measured in plasma samples by an enzymatic colorimetric method (Wako Chemicals $\mathrm{GmbH}$, Neuss, Germany).

The Remnant-like Lipoprotein Particles (RLP) fraction was prepared by use of an immunoseparation technique described by several laboratories ${ }^{15,16}$. Briefly, $5 \mu \mathrm{L}$ of plasma was added to $300 \mu \mathrm{L}$ of mixed immunoaffinity gel suspension containing monoclonal anti-human apoA $1(\mathrm{H}-12)$ and anti-human apoB-100 (JlH) antibodies (Japan Immunoresearch Laboratories). The reaction mixture was gently shaken for 120 minutes at room temperature. After the supernatant was left standing for 15 minutes, $200 \mu \mathrm{L}$ was withdrawn for the assay of RLP cholesterol. Cholesterol in the RLP fraction (coefficient of variation $<3 \%$ ) was measured by an enzymatic assay with the use of an automatic chemistry analyser (Cobas Mira autoanalyser, ABX). In this RLP fraction, both cholesterol-containing apoB-48 chylomicron remnants and apoE-enriched apoB-100 $\beta-V L D L$, and intermediatte density lipoprotein (IDL) lipoproteins are detected ${ }^{17}$. Both species of atherogenic remnants cannot bind to the anti-apoB monoclonal that is presumed to recognise an apoB epitope which is absent in apoB 48 , and made inaccessible on apoB 100 by apoE.

Glucose (FBG) was measured immediately on a YSI 2300 monitor (Yellow Spring Instruments, USA). Fasting insulin concentration (FI) was determined using an Elisa (Mercodia AB, Uppsala, Sweden), with a cross-reactivity with pro-insulin $<0.01 \%$. Insulin resistance was calculated with the HOMA formula: Resistance $=$ $\mathrm{FI} /\left(7 \times 22.5 \times \varepsilon^{-\ln \mathrm{FGG}}\right)$, which can be simplified as $\langle\mathrm{FI} \times \mathrm{FBG}) /(7 \times 22.5)^{32}$. Plasma apolipoprotein B (apo B) and apolipoprotein A-1 (apo A-1) were determined by commercially available immunonephelometric assays, using calibrated standards according to the International Federation for Clinical Chemistry (Behringwerke, Marburg, Germany).

\section{Statistical analyses}

All values are expressed as mean \pm standard deviation. Log transformed values for TG, RLP-C, insulin concentrations and HOMA were used in statistical analyses because of non-normal distribution; values are non-logarithmically listed in the tables for practical reasons. Differences between FCHL relatives and healthy controls were calculated using an independent sample T-test for all measurements. The Mann-Whitney-U test was used to calculate difference in laser Doppler derived parameters between FCHL relatives and healthy controls because of non-normal distribution; data are therefore given as median and range. Because a statistically significant difference existed in several microvascular parameters "delta number of capillaries, capillary recruitment and laser Doppler post-occlusive reactive hyperaemia) between healthy men and healthy women, all analyses were executed by gender. Pearson correlation coefficients were determined for the relationship between basal $(\mathrm{BC})$ and postocclusive (POC) number of capillaries and lipid levels, surrogate markers of 
insulin resistance, and blood pressure values. The independent contribution of different variables to BC and POC was assessed by multiple hinewr regression analysis $^{39}$. Variables with a Pearson correlation coefficient $<0.1$ and Vartance Inflation Factor (VIF) below 10 were entered into the mutivariate analyses. Statistical analyses were done with the SPSS statistical package (SPSS inc., Chicago, III., USA).

\section{Results}

The characteristics of the subjects studied are presented in Table 7.1. In both sexes, FCHL subjects had significantly higher waist to hip ratio (WHR), fosting total cholesterol concentration (TC), friglyceride levels (TG) and apo B concentrations than healthy subjects.

Table 7.1 Characteristics of the study population: 23 FCHL subjects and 27 healthy controls

\begin{tabular}{|c|c|c|c|c|}
\hline & FCHL men & Control men & FCHL women & Control women \\
\hline Number & 12 & 14 & 11 & 13 \\
\hline Age (years) & $41.3 \pm 11.8$ & $44.3 \pm 8.3$ & $46.2 \pm 11.3$ & $47.3 \pm 6.5$ \\
\hline BNI $\left(\mathrm{kg} / \mathrm{m}^{2}\right)$ & $27.7 \pm 2.7$ & $26.2 \pm 3.4$ & $26.5 \pm 3.1$ & $23.5 \pm 2.5$ \\
\hline WHR & $0.97 \pm 0.06^{*}$ & $0.92 \pm 0.07$ & $0.87 \pm 0.07^{*}$ & $0.81 \pm 0.06$ \\
\hline $\mathrm{SBP}(\mathrm{mmHg})$ & $130.7 \pm 10.9$ & $127.3 \pm 10.8$ & $140 \pm 16.5 t$ & $116.5=111.6$ \\
\hline $\mathrm{DBP}(\mathrm{mmHg})$ & $80.4 \pm 8.5$ & $83.5 \pm 7.4$ & $88.6 \pm 7.6 t$ & $76.2 \pm 6.6$ \\
\hline TC (mmol/L) & $7.4 \pm 1.6 \dagger$ & $5.3 \pm 0.6$ & $7.4 \pm 1.1 \dagger$ & $5.0 \pm 1.0$ \\
\hline $\mathrm{HDL}-\mathrm{C}(\mathrm{mmol} / \mathrm{L})$ & $0.77 \pm 0.23^{*}$ & $1.00 \pm 0.20$ & $1.16 \pm 0.19$ & $1.02 \pm 0.21$ \\
\hline$T G(\mathrm{mmol} / \mathrm{L})$ & $5.4 \pm 5.2 t$ & $1.2 \pm 0.4$ & $2.1 \pm 1.7^{*}$ & $1.1 \pm 0.4$ \\
\hline RLP-C (mmol/L) & $1.54 \pm 1.84 \uparrow$ & $0.24 \pm 0.05$ & $0.44 \pm 0.42 \dagger$ & $0.17 \pm 0.04$ \\
\hline Apo B $(g / L)$ & $1.4 \pm 0.4 \uparrow$ & $1.0 \pm 0.2$ & $1.4 \pm 0.2 \dagger$ & $1.0 \pm 0.2$ \\
\hline Glucose (mmol/L) & $5.0 \pm 0.9$ & $4.9 \pm 0.5$ & $5.3 \pm 0.5 *$ & $4.8 \pm 0.5$ \\
\hline Insullin (pmol/L) & $74.2 \pm 46.6 t$ & $32.2 \pm 14.8$ & $66.2 \pm 43.7$ & $41.2 \pm 29.6$ \\
\hline HOMA & $2.5 \pm 1.71$ & $1.0 \pm 0.6$ & $2.2 \pm 1.5^{*}$ & $1.3 \pm 0.9$ \\
\hline
\end{tabular}

$B M 1=$ body mass index, $W H R=$ waist to hip ratio, $S B P=$ systolic blood pressure, $D B P=$ diastalic blood pressure, $\mathrm{TC}=$ total cholesterol for $\mathrm{mg} / \mathrm{dL}$ divide by 0.0259$), \mathrm{HDL}-\mathrm{C}=$ high-density lipoprotein chollesteral, $T G=$ plasma triglyceride for $\mathrm{mg} / \mathrm{dL}$ divide by 0.01 13). Apo $B=$ apolipoprotein $B, R L P C=$ remnant-like lipoprotein particles cholesterol, insulin $=$ for $\mu \mathrm{U} / \mathrm{mL}$ divide by $6.945, \mathrm{HOMA}=$ calculated measure for insulin sensitivity;

* = FCHL $v s$, healthy controls, $p<0.05 ; t=F C H L$ vs. healthy controls, $p<0.01$;

In the fasting state, FCHL men had a 6 -fold higher remnant-like lipoprotein cholesteral (RLP-C) concentration than control men, whereas the RLP.C concentrations was only 2 -fold higher in $\mathrm{FCHL}$ women compared to control women (Table 7.1). FCHL women had a significantly higher BMI compared to healthy women. Systolic (SBP) and diastolic (DBP) blood pressures were also higher in FCHL women than in control women $(140.0 \pm 16.5$ vs. $116.5 \pm 11.6$ $\mathrm{mmHg}, \mathrm{p}<0.01$ and $88.6 \pm 7.6$ vs. $76.2 \pm 6.6 \mathrm{mmHg}, \mathrm{p}<0.01$, respectively). 
Calculated insulin resistance (HOMA) was higher in FCHL men and FCHL women than in contral subjects (men: $2.5 \pm 1.7$ vs. $1.0 \pm 0.6, p<0.01$ and in women: $2.2 \pm 1.5$ vs. $1.3 \pm 0.9, p<0.05$ ) (Table 7.1 ).

\section{Capillary density}

The results of the microscopic analyses of skin capillary density are depicted in Table 7.2. For technical reasons, no data on capillary density were available in two FCHL men, two control men and one FCHL woman. The basal number of capillaries (BC) was significantly lower in FCHL men compared to healthy men, $113.7 \pm 15.1$ vs. $132.0 \pm 18.0(p=0.02)$. Moreover, the post-occlusive number of capillaries (POC) was significantly reduced in $\mathrm{FCHL}$ men relative to healthy controls, $123.0 \pm 19.1$ vs. $142.3 \pm 18.3(p=0.03)$. In contrast between FCHL women and healthy women no differences in $B C$ or $P O C$ were observed $(p>0.1$ for both).

Table 7.2 Capillary Density (CD) indices per $1.6 \mathrm{~mm}^{2}$ in FCHL subjects and heatthy contrals, under baseline and post-occlusive condition.

\begin{tabular}{lcccc}
\hline CD-indices & FCHL men & Controi men & FCHL women & Control women \\
\hline Number & 10 & 12 & 10 & 13 \\
$B C(n)$ & $113.7 \pm 15.1^{*}$ & $132.0 \pm 18.0$ & $142.4 \pm 29.9$ & $129.3 \pm 18.1$ \\
$P O C(\mathrm{n})$ & $123.0 \pm 19.1^{*}$ & $142.3 \pm 18.3$ & $160.3 \pm 31.8$ & $150.1 \pm 22.0$ \\
$\delta C(\mathrm{n})$ & $9.3 \pm 9.0$ & $10.3 \pm 6.9 \pm$ & $17.9 \pm 8.7$ & $20.8 \pm 8.1$ \\
$C R(\%)$ & $8.0 \pm 8.0$ & $8.0 \pm 5.6 *$ & $13.1 \pm 8.1$ & $16.1 \pm 6.3$ \\
\hline
\end{tabular}

$\mathrm{BC}=$ basal number of capillaries, $\mathrm{POC}=$ past-occlusive number of capillaries, $\delta \mathrm{C}=$ $\mathrm{POC}-\mathrm{BC}, \mathrm{CR}=$ copillary recruitment;

$*=\mathrm{FCHL}$ vs. healthy controls, $p<0.05 ; *=$ control men vs. control women, $p<0.01$

Subsequently, we studied whether FCHL specific factors explained the difference in $\mathrm{BC}$ and $\mathrm{POC}$. In men ( $\mathrm{n}=22 ; \mathrm{FCHL}$ plus control men), $\mathrm{BC}$ was significant inversely correlated with TC $r=-0.58 ; p<0.01), \log T G(r=-0.47 ; p<0.05)$ and log RLP.C $(r=-0.46, p<0.05)$ (Table 7.3). Furthermore, in these 22 men, POC was inversely correlated with TC $(r=-0.61 ; p<0.005), \log T G(r=-0.52 ; p<0.05)$, $\log$ RLP-C $(r=-0.51 ; p<0.05)$ and log insulin $(r=-0.48 ; p<0.05)$ (Table 7.3). No significant correlations with blood pressure indices or other variables were observed. In women, no significant correlations were observed. 
Table 7.3 Pearson correlation coefficients between Capillary Density (CD) indices (BC and $\mathrm{POCl}$, and plasma lipids, surrogate markers of insulin resistance and blood pressure variables in men $(n=22)$.

\begin{tabular}{lcccc}
\hline & BC & p-value & POC & p-value \\
\hline TC & -0.578 & $<0.01$ & -0.608 & $<0.005$ \\
Log TG & -0.466 & $<0.05$ & -0.517 & $<0.05$ \\
Log RLP & -0.461 & $<0.05$ & -0.513 & $<0.05$ \\
Log insulin & -0.374 & $0.10, N 5$ & -0.480 & $<0.05$ \\
HOMA & $\ldots-$ & $\ldots$ & -0.384 & $0.09, \mathrm{NS}$ \\
SBP & $\ldots$ & $\ldots$ & $-\ldots$ & $\ldots$ \\
DBP & -- & -- & - & $\ldots$ \\
\hline
\end{tabular}

TC $=$ total cholesterol, $T G=$ plasma triglyceride, RLP-C = remnant-like lipoprotein particles cholesterol, $\mathrm{HOMA}=$ calculated measure for insulin sensitivity; $\mathrm{SBP}=$ systolic blood pressure, $\mathrm{DBP}=$ diastolic blood pressure, $\mathrm{BC}=$ basal number of capillaries, $\mathrm{POC}$ $=$ post-occlusive number of capillaries, $-\cdots=$ NS $=$ not significant.

Subsequently, the data were evaluated to identify the most important single contributing factor(s) to the lower number of basal and post-occlusive capillaries. In men, stepwise backward multivariate regression analyses (Table 7.4) showed that plasma total cholesterol significantly contributed to a lower basal number of capillaries. The variable log RLP.C was excluded at the last step of the regression analysis only. With respect to the lower post-occlusive number of capillaries, the analysis revealed that log RLP.C was the only significant contributing variable.

Table 7.4 Results of backward stepwise multivariate regression analysis in men $(n=22)$ with either basal number of capillaries $(\mathrm{BC})$ or post-occlusive number of capillaries (POC) as dependent variables.

$\mathrm{BC}$

\begin{tabular}{llllll}
\hline Variable & $\beta$ & $\beta S E$ & Stand. $\beta$ & $p$ & $r 2$ \\
\hline & & & & & $0.253^{*}$ \\
Intercept & 169.4 & 16.4 & & $<0.001$ & \\
TC & -7.347 & 2.636 & -0.539 & $<0.05$ & \\
\hline
\end{tabular}

POC

\begin{tabular}{llllll}
\hline Variable & $\beta$ & $\beta$ SE & Stand. B & $P$ & $r 2$ \\
\hline & & & & & $0.277 \neq$ \\
Intercept & 123.2 & 5.5 & & $<0.001$ & \\
Log RLP.C & -26.5 & 9.0 & -0.560 & $<0.01$ & \\
\hline
\end{tabular}

B SE: $\beta$ standard error; stand $\beta$ : standardised $\beta ;$ RLP.C $=$ Remnant-like Lipoprotein Particle cholesterol; $*=p<0.05, f=p<0.01$. 


\section{Laser Doppler fluxmetry}

No differences were observed in basal laser Doppler flux (LDBF) between FCHL and healthy subjects: FCHL men ws. healthy men: $10.0(2-27.5)$ perfusion units (PU, see methods) ws. $8.5(2.5-67.0)$ PU $(p>0.4)$; and FCHL women vs. healthy women: $13.5(5.0-23.0)$ PU vs. $16.5(6.0-69.0)$ PU $(p>0.2)$. Post-occlusive reactive hyperaemia (LDPRH) was higher in FCHL women compared to the healthy femalles: $537(239-800) \%$ vs. $327(39-565) \%(p<0.05)$. In FCHL men, LDPRH was not different from healthy controls: $577(138-2500) \%$ vs. $632(61-2000) \%(p>0.6)$. In men and women, the time to peak and time to $50 \%$ recovery were not different between FCHL and healthy subjects.

\section{Discussion}

In the present study, FCHL men had a reduced number of basal and postocclusive capillaries compared to healthy control men. This is in line with a structural or anatomical loss of capillaries described in subjects with hypertension $^{21}$. In FCHL men, total cholesterol and atherogenic remnant-like lipoprotein particles, but not bload pressure values or surrogate markers of insulin resistance, were associated with the abserved impaired capillary density. Subjects with FCHL are characterised by an overproduction of apolipoprotein B containing lipoproteins, which results in increased Very-Low-Density Lipoproteins ${ }^{5}$, Low-Density Lipoprotein $(L D L)^{34}$, and presence of small dense LDL particles, all carriers of cholesterol-esters. Furthermore, in FCHL a relative impairment of lipoprotein catabolism has been documented, that contributes to increased lipoprotein remnant concentrations ${ }^{7}$, as confirmed in this study. In the fasting state, FCHL men had a 6-fold higher remnant-like lipoprotein cholesterol (RLP.C) concentration than control men, whereas RLP-C concentrations were only 2 -fold higher in FCHL women compared to control women. This observation is a plausible explanation for the observed reduction in post-occlusive number of capillaries in FCHL men, associated with high RLP-C in univariate and multivariate analyses. Additional explanations for the reduction in POC are that FCHL subjects are insulin resistant ${ }^{8,9}$ and hypertensive ${ }^{10}$. Several of these metabolic abnormalities might play an additional role in the observed loss of capillaries in $\mathrm{FCHL}$, by yet unknown mechanisms.

A reduced number of skin capillaries has been observed previously in patients with essential hypertension and normotensive relatives ${ }^{1,21,23}$. However, in the present study no correlations between blood pressure values and capillary density have been observed. Furthermore, no differences in capillary density were found between FCHL women and control women, despite significantly higher blood pressures in FCHL women than controls.

Impaired capillary recruitment has been proposed as a link between elevated blood pressure and insulin resistance, both in hypertensive ${ }^{27}$ and normotensive subjects $^{29}$. However, no relationship between surrogate markers of insulin resistance and capillary density or capillary recruitment were observed in the present study, although elevated blood pressure and insulin resistance are part of 
FCHL, and are dearly present in our study population. Moreover, no reductions in capillary density, or a link between capillary density and blood pressure, have been observed in insulin resistant subjects with type 2 diabetes or impaired glucose tolerance ${ }^{29}$.

In the present study, lipid wariables were inversely associated with basal and post-occlusive number of capillaries, and hence explained a significant part - up to $25 \%$ - of the capillary loss observed in FCHL men. The obserwation that the reduction in capillary density is specifically found in FCHL men, characterised by 6-fold higher RLP.C concentrations, but not in FCHL women, suggests a mechanism joining both abservations. Atherogenic lipoprotein remnants have also been causally linked to impaired endothelial-derived vasodilatation in $\mathrm{FCHL}^{\prime \prime}$. To our knowledge, up till now, there is no known mechanism that explains how hyperlipidemia results in a reduced number of copillaries, for instance as a consequence of adaptation. It is conceivable that hyperlipidemia affects the activity of transicription factors or the cell cycle, subsequently affecting devellopment and growth of endothelial cells and hence capillaries in FCHL. Such mechanisms may be similar to the putative, abnormal adipocyte differentiation in type 2 diabetes ${ }^{35}$. In hypertensive subjects, reduced skin capillary density is associated with a reduction in muscle and adipose tissue capillaries ${ }^{23}$. If such an association is also present in FCHL, it may have important metabolic implications and affect risk of cardiovascular events. Loss of diffusion surface can potentially impair clearance of circulating lipoproteins, such as RLP-C. Loss of endothelial surface may result in reduced lipoprotein lipase activity, reported in approximately ane-third of FCHL-affected subjects ${ }^{36}$, further aggravating the metabolic lipid abnormalities in FCHL and the risk of cardiovascular events.

The increase in past-occlusive laser Doppler hyperaemia in FCHL women was an unexpected finding. Earlier studies found impaired hyperaemia in subjects with type 2 diabetes $^{24}$ and impaired glucose tolerance ${ }^{25}$, and it was suggested that this reduced maximal vasodilatation could be a hallmark of insulin resistance. The present data are clearly not in line with this hypothesis, despite the observed insulin resistance, calculated as high HOMA values, in FCHL women. The increased hyperaemia in FCHL women is at present difficult to explain. It should be noted however, that the increased hyperaemic response in FCHL women was associated with normal capillary density, but that in FCHL men, the normal hyperaemic response was associated with reduced capillary density. As skin laser Doppler flux is determined by both capillary and shunt blood flow, these data suggest that arteriovenous shunt blood flow is increased in FCHL.

In canclusion, in FCHL men a loss of structural and functional skin capillaries was observed, probably leading to a reduction in capillary endothelial surface, and shown to be associated with increased atherogenic lipoprotein levels. Whether this reduction in surface of structural and functional capillaries cam be implicated in the pathophysiology of FCHL and its high risk of cardiovascular events, or is the result of adaptation to hyperlipidemia in $\mathrm{FCHL}$, remains to be elucidated. 


\section{References}

1. Goldstein UL SH, Hazzard WR, Bierman EL, Motulsky AG. Hyperlipidemia in Coronary Heart Disease. II Genetic analysis of lipid levels in 176 families and delineation of a new inherited disorder, combined hyperlipidemia, Journal of Clinical Investigation 1973,52:1544-1568.

2. Mikkilä EA, Aro A. Family study of serum lipids and apolipoproteins in coronary artery disease. Lancet 1973;78:954-959.

3. Austin MA, Mcknight B, Edwards KL, Bradley CM, McNeely MJ, Psaly BM, Brunzell JD, Motulsky AG. Cardiovascular disease mortality in familial forms of hypertriglyceridemia: A 20-year prospective study. Circulation 2000;101:27772782 .

4. Voars-Pette $C$, de Bruin TWA. Excess coronary heart disease in Familial Combined Hyperlipidemia, in relation to genetic factors and central obesity. Atherosclerosis $2001 ; 157: 481-489$.

5. Wenkatesan S, Cullen P, Pacy P, Halliday D, Scott J. Stable isotopes show a direct relation between VLDL apoB owerproduction and serum friglyceride levels and indicate a metabolically and biochemically coherent basis for familial combined hyperlipidemia. Anteriosclerosis Thrombosis and Vascular Biology 1993;13:11101118.

6. Castro Cabezas M, de Bruin TWA, Valk de HW, Shoulders CC, Jansen H, Erkelens DW. Impaired fatty acid metabolism in familial combined hyperlipidemia. A mechanism associating hepatic apolipoprotein B averproduction and insulin resistance. Journal of Clinical Investigation 1993;92:160-168.

7. Cabezas MC, de Bruin TWA, Jansen H, Kock LA, Kortlandt W, Erkelens DW. Impaired chylamicron remnant clearance in familial combined hyperlipidemia. Arteriosclerosis and Thrombosis 1993;13:804-814.

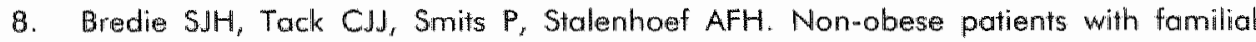
combined hyperlipidemia are insulin resistant as compared with their non-affected relatives. Arteriosclerosis Thrombosis and Vascular Biology 1997;17:1465-1471.

9. Hunt SC, Wu LL, Hopkins PN, Stults BM, Kuida H, Ramirex ME, Lalouel JM, Williams RR. Apolipoprotein, low densify lipoprotein subfraction, and insulin associations with familial combined hyperlipidemia. Study of Utah patients with familial dyslipidemic hypertension. Arteriosclerosis 1989:9:335-344.

10. Keulen ETP, Voors Pette C, de Bruin TWA. Familial Dyslipidaemic Hypertension Syndrome: further delineation in Familial Combined Hyperlipidaemia, and the role of abdominal fat mass. American Journal of Hypertension 2001; 14(4): $357-363$.

11. Stroes E, de Bruin TWA, de Valk H, Erkelens DW, Banga JD, wan Riin H, Hoomans $H$, Rabellink T. NO activity in familial combined hyperlipidemia: potentiall role of chollesteroll remnants. Cardiovascular Research 1997;36:445-452.

12. Cordillo C, Kilcoyne CM, Quyumi AA, Cannon RO, Panza JA. Selective defect in nitric oxide synthesis may explain the impaired endothelium-dependent vasadilation in patients with essential hypertension. Circulation 1998;97:851-856. 
13. Williams SB, Cusco JA, Rodidy MA, Johnstone MT, Creager MA. Impaired nitric oxidew mediated vasodilation in patients with nor-insulin-dependent diabetes mellitus. Journal of the American College of Cardiology 1996;27:567-574.

14. Timar $O$, Sestier $F$, Levy $E$. Metabolic syndrame $X$ : a review. Canadian Joumal of Cardiology 2000;16:779-789.

15. Nakajima K, Saito T, Tamura A, Suzuki M, Nakano T, Adachi M, Tanaka A, Tada N, Nakamura $H_{*}$ Campos $E$. Cholesterol in remnant-like lipoproteins in human serum using monodonal anti apo B-100 and anti apo A-l inmunoaffinity mixed gels. Clinica Chimica Acta, International Joumal of Clinical Chemistry 1993;223:53-71.

16. Campos E, Nakajima K, Tanaka A, Havel RJ. Properties of an apalipoprotein Eenriched fraction of triglyceride rich lipoproteins isolated from human blood plasma with a monoclonal antibody to apolipoprotein B-100. Journal of Lipid Research $1992,33: 369-380$.

17. Leary ET, Wang T, Biaker DJ Cilla DD, Zhong J, Wannich GR, Nakajima K, Havel RJ. Evaluation of an immunoseparation methad for quanfitative measurement of remnant-like particle-cholesteral in serum and plasma. Clinical Chemistry $1998 ; 44: 2490-2498$.

18. Schreuder P, Twickler T, Wang T, Nakajima K, Erkelens DW, Dallinga-Thie G. Isolation of remnant particles by immunoseparation: a new approach for investigation of postprandial lipoprotein metabolism in normolipidemic subjects. Atherosclerosis 2001;157:145-151.

19. Prasad A, Dunnill GS, Mortimer PS, MacGregor GA. Capillary rarefaction in the forearm skin in essential hypertension. Journal of Hypertension 1995;13:265-268.

20. Houben AJ, Canoy MC, Paling HA, Derhaag PI, de Leeuw PW. Quantitative analysis of retinal vascular changes in essential and renovascular hypertension. Journal of Hypertension 1995;13:1729-1733.

21. Antonios TF, Singer DR, Markandu ND, Mortimer PS, MacGregar GA. Structural skin capillary rarefaction in essential hypertension. Hypertension 1999;33:998-1001.

22. Antonios TF, Singer DR, Markandu ND, Mortimer PS, MacGregor GA. Rarefaction of skin capillaries in borderline essential hypertension suggests an early structural abnormality. Hypertension 1999;34:655-658.

23. Shore AC, Tooke JE. Microvascular function in human essential hypertension. Journal of Hypertension 1994:12:717-728.

24. Tur $E$, Yosipowitch $G$, Bar OY. Skin reactive hyperemina in diabetic patients. A study by laser Doppler flowmetry. Diabeles Care 1991;14:958-962.

25. Jaap AJ, Hammersley MS, Shore AC, Tooke JE. Reduced microvascular hyperaemia in subjects at risk of developing type 2 (non-insulin-dependent) diabetes mellitus. Diabetologia 1994;37:214-216.

26. Noon JP, Walker BR, Webb DJ, Share AC, Holton DW, Edwards HV, Watt GC. Impaired microwascular dillatation and capillary rarefaction in young adults with a predisposition to high bload pressure. Journal of Clinical Investigation $1997 ; 99: 1873-1879$.

27. Serne EH, Gans ROB, ter Moaten JC, ter Wee PM, Donker AM, Stehouwer CDA. Capillary recruitment is impaired in essential hypertension and relates to insulin's metabolic and vascular actions. Cardiovascular Research 2001;49:161-168. 
28. Serne EH, Stehouwer CDA, ter Maaten JC, ter Wee PM, Rauwerda JA, Donker AM, Gans ROB. Microvascular function relates to insulin sensifivily and blood pressure in normal subjects. Circulation 1999;99:896-902.

29. Joap AJ, Shone AC, Stockman AJ, Tooke JE. Skin capillary density in subjects with impaired glucose tolerance and patients with type 2 diabetes. Diabetic Medicine 1996:13:160-164.

30. Houben Al, Krekels MM, Schaper NC, Fuss LM, Rodriguez SA, de Leeuw PW. Microvascular effects of atrial natriuretic peptide (ANP) in man: studies during high and low salt diet. Cardiovascular Research 1998;39:442-450.

31. Friedewald WT, Lery RI, Fredrickson DS. Estimation of the concentration of lowdensity lipoprotein cholesterol in plasma, without the use of the preparative ultracentrifuge. Clinical Chemistry 1972;18:499m502.

32. Matthews DR, Hosker JP, Rudenski AS, Naylor BA, Treacher DF, Turner RC. Homeastasis model assessment: insulin resistance and beta-cell function from fasting plasma glucose and insulin concentrations in man. Diabetologia 1985;28:412-419.

33. Ingelfinger $J A$, Mosteller $F$, Thibodeau LA, Ware JH. Biostatistics in clinical medicine. New York, USA: McGraw-Hill, Inc, 1994.

34. Kissebah AH, Alfarsi S, Evans DJ. Low density lipoprotein metabolism in familial combined hyperlipidemia. Mechanism of the multiple lipoprotein phenotypic expression. Anteriosclerosis 1984;4:614-624.

35. Danforth $E$. Fallure of adipacyte differentiation causes type 11 diabetes mellitus? Nature Genetics 2000;26:13,

36. Babirak $S$, Brown $B$, Brunzell J. Familial combined hyperlipidemia and abnormal lipoprotein lipase. Arteriasclerosis and Thrombosis 1992:12:1176-1183. 


\section{Chapter 8}

Increased intima media thickness in Familial

Combined

Hyperlipidemia:

association with

apolipoprotein B

ETP Keulen, M Kruijshoop, NC Schaper, AGP Hoeks, TWA de Bruin

Accepted for publication in:

Arteriasclerosis Thrombosis and Vascular Biology 


\section{Abstract}

The aim of the present study was to quantify intima media thickness (IMT) in Familial Cambined Hyperlipidemia (FCHL) and to evaluate the relationship of IMT with lipids and apolipoproteins, bload pressure values and surrogiate markers of insulin resistance.

IMT was measured by ulfrasound at the left and right common carotid artery in $46 \mathrm{FCHL}$ affected subjects, free of clinical manifestations of atherasclerosis, and 55 age- and gender matched healthy controls. FCHL affected subjects had significantly increased IMT compared to healthy confrols, with a difference of $57 \mu \mathrm{m}$ (age- and gender-corrected $p<0.01$ ): Significantly positive, age- and gender-corrected, univariate correlations were observed between IMT and total cholesterol non-HDL cholesterol, fasting plasma triglyceride, apolipoprotein B, fasting insulin, calculated insulin resistance (HOMA), body mass index $(B M)$ and waist-circumference. Multwariate regression analyses revealed that oge, gender, apolipoprotein B and BMI were significant and independent predictors of IMT, explaining $50 \%$ of the observed variation $(p<0.001)$.

The increased IMT observed in FCHL corresponds to approximately 7 years of physiological IMT increase in excess of the average IMT in age and gender matched controls. The present findings show the important confribution of lipoprotein particles, marked by increased apolipopratein B concentrations, to the dewelopment of increased IMT in FCHL. The increased IMT in FCHL affected subjects is in agreement with the known high risk of cardiowascular disease in FCHL. 


\section{Introduction}

Familial Combined Hyperlipidemia (FCHL), the most common genetic dyslipidemia in humans, affects $0.5 \%-2 \%$ of the population and $10 \%-20 \%$ of premature myocardial infaretion survivars exhibit $\mathrm{FCHL}^{1.3}$. Recently, two reponts showed that $\mathrm{FCHL}$ relatives also have a markedly increased risk of fatal and non. fatal coronary artery disease (CAD), with odds ratios of 1.7 and 5.1 . respectively ${ }^{4,5}$. However, these clinical sequelae are usuclly preceded by silent atherosclerotic changes in the vessel wall. Ultrasound measurement of intima media thickness (IMT) in the carotid wall is currently used as marker of silent atherosclerosis. Cross-sectional studies have shown an association between carotid IMT and various cardiovascular risk factors ${ }^{6.8}$ and the prevalence of CAD $\$$. Moreover, carotid IMT has been validated as a predictor of future CAD in prospective studies, independent of other cardiovascular risk factors ${ }^{11,12}$.

FCHL is a hyperlipidemic, metabolic syndrome associated with apolipoprotein B overproduction ${ }^{13}$, relatively impaired lipoprotein elimination ${ }^{14}$, impaired insulin stimulated glucose uptake ${ }^{15}$, and central obesity ${ }^{16}$. Moreover, the prevalence of dyslipidemic hypertension in FCHL families is increased two-fold ${ }^{16}$. Clearly, the aggregate of these abnormalities results in an unfavourable, atherogenic risk profile in FCHL and increases the risk of enhanced atherosclerosis and subsequent cardiovascular events.

It is the objective of the present study to assess the amount of silent atherosclerosis, by ultrasound carotid IMT measurement, in FCHL affected subjects in comparison to healthy controls and to investigate the potential relationship of IMT with lipids and lipoproteins, blood pressure values, and surrogate markers of insulin resistance.

\section{Subjects and methods}

One hundred and thirteen subjects participated in the present study: 58 (31 men) hyperlipidemic FCHL subjects and 55 (29 men) age-en gender-matched healthy controls. FCHL was diagnosed in a family according to the following criteria: first, a primary hyperlipidemia including fasting total plasma cholesterol (TC) $>6.5$ $\mathrm{mmol} / \mathrm{L}$ (250 $\mathrm{mg} / \mathrm{dL}$ ) and/or fasting plasma triglyceride (TG) concentration $>2.0$ mmol/L (180 mg/dL); second, multiple lipoprotein phenotypes within a family (Fredrickson Classification $1 \mathrm{la}, \mathrm{ll} b$ or $\mathrm{IV}$ ); third, a positive family history of premature cardiavascular disease $(C V D)^{5,14,16}$. Premature CVD was defined as the accurrence of a myocardial infarction (MI) or cerebrovascular accident (CVA) before the age of $60 \mathrm{y}$. Secondary causes of hyperlipidemia (renal or hepatic insufficiency, hypothyroidism and medication), presence of the apo E2/E2 genotype, and subjects with tendon xanthomas or a diagnosis matching familial hypercholesterolemia were excluded. 
Hyperlipidemic FCHL subjects $(n=58)$ included in the present study were characterised by a primary hyperlipidemia, defined as fasting total plasma cholesterol (TC) $>6.5 \mathrm{mmol} / \mathrm{L}(250 \mathrm{mg} / \mathrm{dL})$ and/or fasting plasma triglyceride (TG) concentration $>2.0 \mathrm{mmol} / \mathrm{L}(180 \mathrm{mg} / \mathrm{dL})^{16}$. Eleven $\mathrm{FCHL}$ subjects had a history of previous cardiovascular disease (CVD): 2 had a MI, 3 had angina pectoris, 1 underwent a coronary artery bypass graft, 3 had a CVA and 2 showed peripheral atherosclerotic disease. All healthy control subjects $(n=55)$ had no clinical signs of CVD. The study protocal was approved by the Human Investigations Review Committee and performed according to the Helsinki Declaration. All subjects gave written informed consent.

\section{Measurements}

The measurements were performed in the morning (8.00 - 11.00) after an overnight fast (12-14 h). Subjects had refrained from smoking and did not drink coffee or tea in the morning. Subjects had also abstained from alcohol for at least 72 hours. A medical history was obtained from all participating subjects and a standardised questionnaire was filled out. All patients were weighed in underwear, the height was determined by stadiometer and the body mass index (BMI) was subsequently calculated as weight in kilograms / (height in meters) ${ }^{2}$. The waist circumference was measured at the level of the umbilicus, the hip circumference was measured at the level of the trochanter major and the waist to hip ratio (WHR) was calculated. Both waist-circumference and hip-circumference were measured with the subject in standing position.

Systolic (SBP) and diastolic (DBP) blood pressures were measured twice, with the Omron 705CP (OMRON Health Care GmbH, Hamburg, Germany) in a standardised fashion, with the subject in sitting position after 10 minutes of rest. Cuff size was adjusted to the circumference of the arm, and the arm was placed with the cuff at heart-level. The mean of two measurements was used in the statistical analyses.

\section{IMT-measurement}

The IMT measurements were done with an Ultramark $4+$ (Ultramark 4+, ATL, Bothel, Washington, USA) with a linear array transducer of $7.5 \mathrm{MHz}$. All subjects were measured in a supine position in a quiet room. During the measurements the head was tilted to the contra-lateral side at an angle of $45^{\circ}$. The automated radiofrequency (RF) method used to assess IMT has been described in detail before ${ }^{17}$. Briefly, a B-mode image was obtained from the common carotid artery (CCA) in a longitudinal section just before the widening of the bulb in the bifurcation. An $M$-line was positioned perpendicular to the posterior wall approximately $10-20 \mathrm{~mm}$ proximal to the carotid bulb, showing a clear intimamedia complex during the whole measurement. Subsequently, the ultrasound system was switched to $M$-mode and ECG-triggered RF data collection was started at a sample frequency of $18.4 \mathrm{MHz}$, an $\mathrm{M}$-line update frequency of 800 $\mathrm{Hz}$, for a time period of 5 seconds corresponding to $4-6$ heartbeats. For each heartbeat, the amplitude distribution was evaluated to automatically detect the positions of the walls. Subsequently, the locations of the intima and the media- 
adventitia edge of the posterior wall were determined and IMT was defined as the distance between both edges. The maximum ratio of intima to adventitia amplitude was set at 1.0 to suppress detection of false edges. The resolution for wall thickness detection was approximately $40 \mu \mathrm{m}^{17}$. Only the posterior wall was investigated, because here the reflections from the blood-intima and mediaadventitia transition are distinctly visible, whereas at the anterior wall the trailing edge of the adventitia may obscure the media and intima signals. Each heartbeat within a recording resulted in an estimate of IMT. Measurements were repeated seven times at both left and right CCA. The average of the median values for each measurement obtained on both sides was taken as a representative IMT value. Ultrasound $M$-mode and RF signals method to measure IMT instead of offline B-mode measurement has been validated previously'. The intra-observer variabilities were $5.9 \%(E K)$ and $6.3 \%(M K)$ as determined in 10 subjects on two occasions. The inter-abserver variability was $4.6 \%$ as determined in 10 subjects.

\section{Laboratory methods}

Any lipid lowering medication had been withdrawn for two weeks before blood samples were collected. After the completion of the IMT-measurement fasting venous blood was collected in pre-cooled EDTA $(1-\mathrm{mg} / \mathrm{ml})$ Vacutainer tubes for measurements of lipids, lipoproteins, glucose and insulin. Total cholesteral (TC) and fasting triglyceride (TG) concentrations were measured in duplicate by a commercially available colorimetric assay (Monotest Cholesterol kit, Boehringer Mannheim \#1442350 and GPO-PAP, Boehringer Mannheim, \#701912, respectively). HDL-cholesterol (HDL-C) was determined after phosphotungstate$\mathrm{MgCl} 2$ precipitation of whole plasma. Fasting plasma LDL-cholesteral (LDL-C) was calculated according to the Friedewald formula: $L D L-C=T C-H D L-C-(T G$ $\times 0.45)$, if plasma $T G$ concentration was below $4.5 \mathrm{mmol} / \mathrm{L}(390 \mathrm{mg} / \mathrm{dL})^{19}$. If plasma TG was above $4.5 \mathrm{mmol} / \mathrm{L}, \mathrm{LDL}-\mathrm{C}$ was measured in the density 1.019 1.063 fractions, prepared after equilibrium ultracentrifugation. Nonesterified fatty acids (NEFA) were measured in plasma samples by an enzymatic colorimetric method (Wako Chemicals GmbH, Neuss, Germany).

Glucose (FBG) was measured immediately on a YSI 2300 monitor (Yellow Spring Instruments, USA). Fasting insulin concentration (FI) was determined using an Elisa (Mercodia AB, Uppsala, Sweden), with a cross-reactivity with pro-insulin $<0.01 \%$. Insulin resistance was calculated with the HOMA formula: Resistance = $\mathrm{FI} /\left(7 \times 22.5 \times \varepsilon^{\ln F B G}\right)$, which can be simplified $a$ s $(F \mid \times F B G) /(7 \times 22.5)^{20}$. Plasma apolipoprotein B (apo B) and apolipoprotein A-1 lapo A-1) were determined by commercially available immunonephelometric assays, using calibrated standards according to the International Federation for Clinical Chemistry (Behringwerke, Marburg, Germany) ${ }^{21}$.

\section{Statistical analyses}

All values are expressed as mean \pm standard deviation. To obtain normal distribution, log transformed values for fasting insulin and triglyceride concentrations were used in statistical analyses; values are non-logarithmically listed in Table 8.1 for practical reasons. Differences between FCHL affected 
subjects and healthy controls were calculated using linear regression analyses with age and gender as co-variables ${ }^{22}$.

Age- and gender-corrected Pearson correlation coefficients were determined for the relationship between continuous IMT variable, plasma lipids and lipoproteins, blood pressure values, and surrogate markers of insulin resistance. To test whether variables had an independent effect on the IMT, the effects of such a wariable, adjusted for other independent variables, was analysed by backward stepwise multiple linear regression analyses with IMT as dependent variable ${ }^{2 x}$. FCHL affected status was entered as an independent variable. In all statistical analyses, the statistical package SPSS 8.0 (SPSS Inc. Chicago, III., USA) was used.

Table 8.1 Characteristics of 58 hyperlipidemic FCHL relatives and 55 healthy control subjects.

\begin{tabular}{lcc}
\hline & FCHL $(\mathrm{n}=58)$ & Controls $(\mathrm{n}=55)$ \\
\hline M/F & $31 / 27$ & $29 / 26$ \\
Age $(\mathrm{y})$ & $48.5 \pm 12.9$ & $47.4 \pm 12.9$ \\
BML $(\mathrm{kg} / \mathrm{m} 2)$ & $26.5 \pm 3.3$ & $25.8 \pm 3.7$ \\
Waist $(\mathrm{cm})$ & $92.9 \pm 10.0$ & $90.4 \pm 11.3$ \\
SBP $(\mathrm{mmHg})$ & $141.2 \pm 21.14$ & $132.0 \pm 15.7$ \\
DBP $(\mathrm{mmHg})$ & $8.4 .3 \pm 11.9$ & $80.4 \pm 9.9$ \\
TC $(\mathrm{mmol} / \mathrm{L})$ & $6.2 \pm 1.4^{*}$ & $4.9 \pm 0.8$ \\
TG $(\mathrm{mmol} / \mathrm{L})$ & $2.6 \pm 2.1^{*}$ & $1.1 \pm 0.4$ \\
HDLCC $(\mathrm{mmol} / \mathrm{L})$ & $0.85 \pm 0.24^{*}$ & $0.98 \pm 0.25$ \\
LDL-C $(\mathrm{mmol} / \mathrm{L})$ & $4.2 \pm 1.4^{*}$ & $3.4 \pm 0.8$ \\
NonHDL-C (mmol/L) & $5.4 \pm 1.3^{*}$ & $3.9 \pm 0.8$ \\
Apo B $(\mathrm{g} / \mathrm{L})$ & $1.35 \pm 0.29^{*}$ & $0.99 \pm 0.22$ \\
Glucose $(\mathrm{mmmol} / \mathrm{L})$ & $4.9 \pm 0.7$ & $4.9 \pm 0.5$ \\
Insulin $(\mathrm{pmol} / \mathrm{L})$ & $67.8 \pm 34.5^{*}$ & $50.6 \pm 21.4$ \\
HOMA & $2.1 \pm 1.2^{*}$ & $1.6 \pm 0.7$ \\
\hline
\end{tabular}

BMI = body mass index, WHR = waist to hip ratio, $S B P=$ systolic blood pressure, $D B P=$ diastolic blood pressure, $\mathrm{TC}=$ tatal cholesterol (for $\mathrm{rng} / \mathrm{dL}$ divide by 0.0259 ). TG = plasma triglyceride (for $\mathrm{mg} / \mathrm{dL}$ divide by 0.0113 ), HDL-C $=$ high-density lipoproteincholesterol, LDL-C = low-density lipoprotein tholesterol, NonHDL-C = TC minus HDL-C, glucose $=$ for $\mathrm{mg} / \mathrm{dL}$ divide by 0.0555 , insulin $=$ for $\mu \mathrm{U} / \mathrm{L}$ divide by $6.945, \mathrm{HOMA}$ : calculated measure for insulin resistance.

* $=$ FCHL vs. controls $\mathrm{p}<0.01,+=$ FCHL ws. controls $\mathrm{p}<0.05$

\section{Results}

The characteristics of the subjects studied are presented in Table 8.1. FCHL subjects had significantly higher SBP, fasting total cholesterol concentration (TC), fasting triglyceride levels (TG), low-density lipoprotein cholesterol (LDL-C) and apo B concentrations and lower high-density lipoprotein cholesteral (HDL-C) concentrations compared to healthy subjects. Furthermore, fasting insulin levels 
and calculated insulin resistance (HOMA) were higher in FCHL subjects than in control subjects, comparable with the known state of insulin resistance in FCHL.

The results of the Intima Media Thickness (IMT) measurements are depicted in Table 8.2. Previous studies have shown that IMT increases with age and that IMT is increased in the male population compared to the femalle population ${ }^{6.7}$. Therefore, IMT was corrected for age and gender using linear regression analysis. For technical reasons, no data on IMT were available in one FCHL subject and wo control subjects. Linear regression analyses showed that IMT was significantly increased in FCHL subjects compared to healthy controls, with a difference of $63 \mu \mathrm{m}$ (age-and gender-corrected $\mathrm{p}<0.01$ ). As stated above, 11 FCHL affected subjects were diagnosed with previous CVD. All these different cardiovascular manifestations have been associated with a greater IMT in several studies $9.10,23$. Indeed, in our study population, FCHL subjects with CVD tended to have an increased IMT compared to FCHL subjects without clinical signs of CVD, or healthy controls $(p=0.06)$, respectively (Table 8.2$)$. It is possible that because of the small number of FCHL subjects with CVD and the variation of IMT in these CVD-positive FCHL subjects, the observed differences did not reach the significance level. When FCHL subjects with a history of CVD were excluded from the analyses, a significantly increased IMT in CVD-free FCHL subjects compared to healthy contrals was still abserved, with a difference of $57 \mu \mathrm{m}$ lage-and gender-corrected $p<0.01$ ).

Table 8.2 Intima-Media Thickness (IMT) in 57 FCHL affected subjects (46 CVD negative subjects and 11 CVD positive subjects) and 53 healthy controls ( $\mathrm{p}$-values shown after adjustment for age and gender].

\begin{tabular}{lcccc}
\hline & FCHL tatal & FCHL / CVD & FCHL / CVD + & Controls \\
\hline Number & 57 & 46 & 11 & 53 \\
IMT $(\mathrm{mm})$ & $0.72 \pm 0.15^{*}$ & $0.70 \pm 0.13+$ & $0.80 \pm 0.21 \neq$ & $0.65 \pm 0.14$ \\
\hline
\end{tabular}

$\mathrm{CVD}=$ cardiovascular disease, $\mathrm{IMT}=$ Intima Media Thickness, mean $\pm \mathrm{SD}$;

* = FCHL total vs. controls; age-and gender adjusted $\mathrm{p}<0.01$,

$t=\mathrm{FCHL} / \mathrm{CVD}$ - vs. controls; age and gender adjusted $\mathrm{p}<0.01$,

$t=\mathrm{FCHL} / \mathrm{CVD}+$ vs. controls; age- and gender adiusted $\mathrm{p}=0.06$

The eleven FCHL subjects with previously diagnosed CVD were now excluded from further analyses. Subsequently, we studied whether FCHL specific factors explained the difference in MT. Age- and gender-adjusted univariate Pearson correlations between IMT, lipid and apolipoproteins, blood pressure values and surrogate markers of insulin resistance, all treated as continuous variables, are depicted in Table 8.3 and partly in Figure 8.1. Significantly positive correlations between IMT and BMI, waist-circumference, TC, logTG, LDL-C, nonHDL-chol, apo $B, \log$ insulin and HOMA were observed. However, no significant correlation existed between IMT and blood pressure values, glucose concentrations or family number. 
$\$$ controls FCHL/CVD.

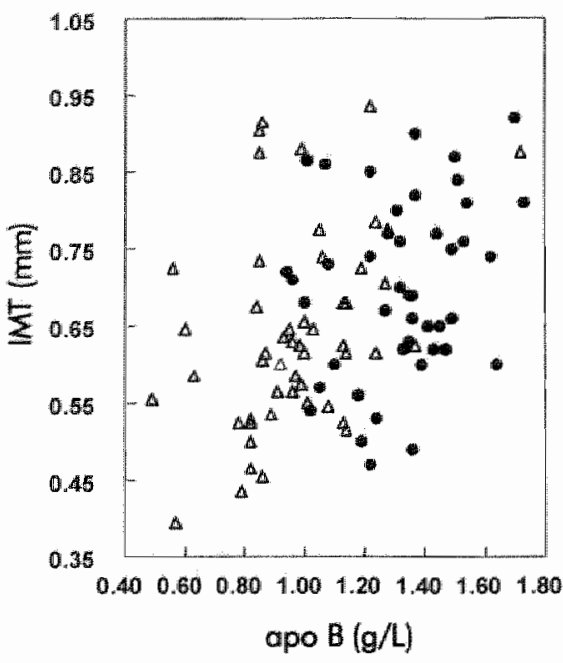

$\triangle$ controls - FCHL/CVD.

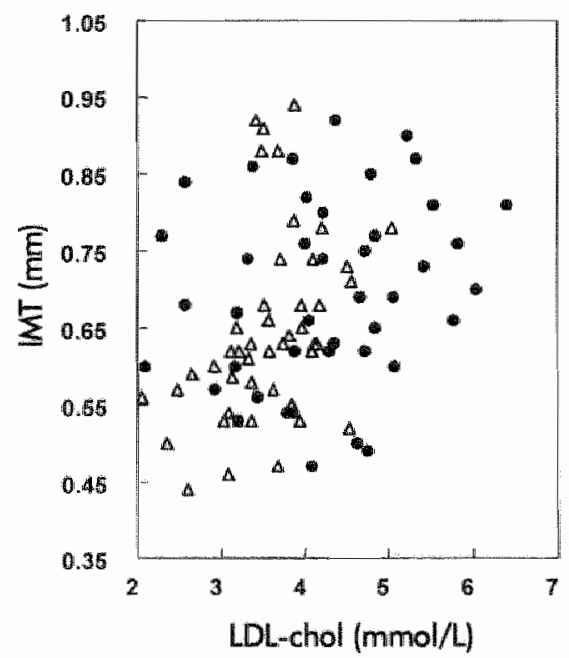

$\triangle$ controls FCHL/OVD.

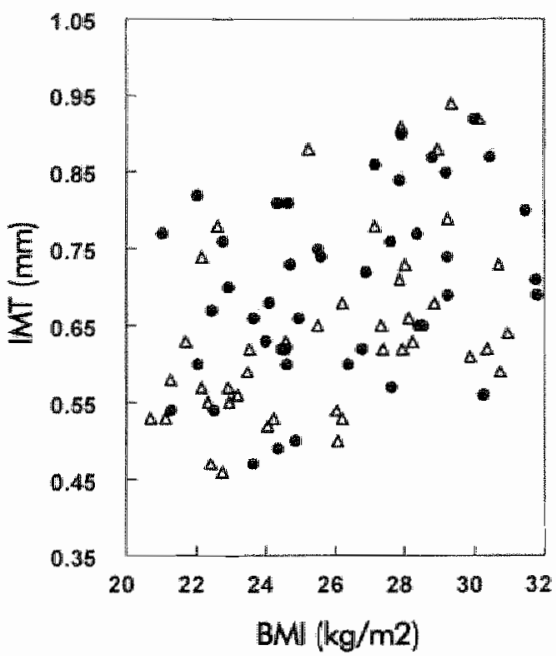

$\triangle$ controls $-\mathrm{FCHL} / \mathrm{CVD}$ -

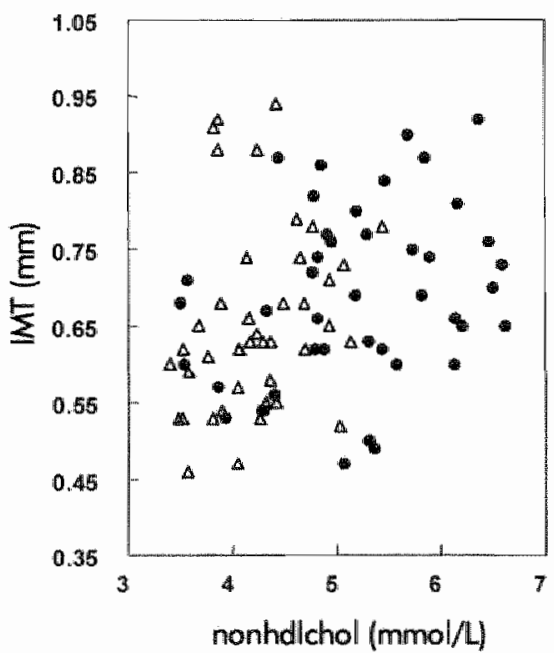

Figure 8.1 Intima media thickness in FCHL alfected subjects, free of previous cardiovascular histary, and healthy controls versus: $A_{p}$ apolipoprotein $B_{;}$B non-HDL-cholesterol; $C$, low-density lipoprotein (LDL) - cholesteral; and D. body mass index (BM). Age- and gender-corrected Pearson correlation coefficient: $A, r=0.35(p<0.001) ; B, r=0.31(p<0.01) ; C, r=0.24(p<0.05)$; D. $r=0.25(\rho<0.05)$. 
Table 8.3 Age- and gender-adjusted Pearson correlation coefficients between intimamedia thickness (IMT), plasma lipids and surrogate markers of insulin resistance variables in $46 \mathrm{FCHL}$-affected subjects without known CVD and 53 heathy controls.

\begin{tabular}{lcc}
\hline Variable & MT & p-value \\
\hline TC & 0.35 & $<0.01$ \\
LDL-C & 0.24 & $<0.05$ \\
HDL-C & 0.02 & $0.87, \mathrm{NS}$ \\
Non-HDL-C & 0.31 & $<0.01$ \\
Log TG & 0.27 & 0.01 \\
Apo B & 0.35 & $<0.001$ \\
Glucose & 0.04 & $0.74, \mathrm{NS}$ \\
Log insulin & 0.26 & $<0.05$ \\
HOMA & 0.29 & $<0.01$ \\
BMI & 0.25 & $<0.05$ \\
Waist & 0.21 & $<0.05$ \\
SBP & -0.03 & $0.76, \mathrm{NS}$ \\
DBP & -0.16 & $0.14, \mathrm{NS}$ \\
\hline
\end{tabular}

$T C=$ total cholesterol, LDL-C = low-density lipoprotein cholesterol, HDL-C = high-density lipoprotein-cholesterol, Non-HDL-C = TC minus HDL-C, TG = fasting plasma triglyceride, Apo $B=$ apolipoprotein $B, H O M A=$ calculated measure for insulin resistance $B M=$ body mass index, $\mathrm{SBP}=$ systolic blood pressure, $\mathrm{DBP}=$ diastolic blood pressure, $N S=$ non significont.

Next, multiple backward linear regression analysis was used to ewaluate whether one of these significantly correlated metabolic factors was the most dominant in predicting an increased IMT. Age and gender were also included as potentially contributing variables to an increased IMT. TC or nonHDL-C, respectively insulin or HOMA were used in the regression analyses because of close interaction between both of these variables. However, this did not alter the final results. These analyses revealed that apolipoprotein B and BMI, besides age and gender, contributed to an increased IMT and explained mare than $50 \%$ of the variance in IMT in our study population (Table 8.4).

Table 8.4 Results of backward stepwise regression analysis in 46 FCHL-affected subjects without known CVD and 53 healthy controls with intima-Media Thickness (IMT) as dependent variable.

\begin{tabular}{lccccc}
\hline Variable & $\beta$ & $\beta \mathrm{SE}$ & Stiand. $\beta$ & $\rho$ & Model $\mathrm{r}$ \\
\hline & & & & & $0.502^{*}$ \\
Intercept & 0.168 & 0.079 & & & \\
Age & $4.860 \mathrm{E}-03$ & 0.001 & 0.479 & $<0.001$ & \\
Gender & $-4.811 \mathrm{E}-02$ & 0.020 & 0.179 & $<0.05$ & \\
Apo B & 0.709 & 0.033 & 0.255 & $<0.001$ & \\
BM & $6.852 \mathrm{E}-03$ & 0.003 & 0.176 & $<0.05$ & \\
\hline
\end{tabular}

Apo $B=$ apolipoprotein $B, B M I=$ bady mass index, $\beta$ SE $=\beta$ standard error, stand $\beta=$ standardised $\left.\beta .{ }^{*}=p<0.00\right\rceil$ 


\section{Discussion}

In the present study, FCHL affected subjects had an increased IMT compared to healthy controls. FCHL subjects with a known history of CVD tended to have an even more increased IMT as expected from reported associations between higher IMT with higher risk of clinical manifestations of cardiovascular disease $e^{9,10,23}$. The increased IMT abserved in FCHL is in line with their known high risk of fatal and non-fatal cardiovascular disease $e^{4.5}$. The annual progression rate of IMT has been estimated to be around $6-10 \mu \mathrm{m}^{24.26}$. Therefore, the observed increase of $57 \mu \mathrm{m}$ in IMT in FCHL affected subjects without previous CVD (mean age 48.5 years) corresponds to approximately 5-9 years of IMT increase, in excess of the average IMT found in age- and gender-matched controls.

In the FCHL study group, 24 out of $58(41.3 \%)$ subjects were currently treated with a statin, an HGM-CoA-reductace inhibitar. Thus, the observed IMT in FCHL is probably even underestimated, because antihyperlipidemic treatment with statins has been shown to slow progression of IMT or even reverse the intimamedia thickening ${ }^{24-27}$. The presently observed higher IMT is also in line with the occurrence of dyslipidemia approximately $15-20$ years earlier in FCHL subjects compared to the general population ${ }^{28}$.

In the present study, well-known metabolic risk factors of atherosclerosis development, including lipids and apolipoproteins, surrogate markers of obesity and surrogate insulin resistance markers, were univariately associated with an increased IMT. Multivariate regression analyses revealed that age, gender, apolipoprotein B and BMI contributed independently to increased IMT. The effects of age and gender on IMT have been described extensively before, ${ }^{6}$, and are expected to be operational in all Western populations. The relationship between IMT and increased apo B concentrations is clinically more important, as all apo B containing lipoproteins are potentially atherogenic. Moreover, in crosssectional $^{29,30}$ and prospective studies ${ }^{31.32}$, apo B has been shown to be a good risk indicator of CVD compared to other lipid levels or smoking, diabetes mellitus and hypertension. In addition, apo B lowering has been shown to result in regression of coronary artery disease ${ }^{\mathrm{x} 3}$.

Because each lipoprotein particle, i.e. very low-density lipoprotein (VLDL), intermediate density lipoprotein, $L D L$, chylomicrons and chylomicron remnants, contains one apo B molecule, an increased apo B concentration is an indicator of increased numbers of circulating lipoproteins. FCHL is characterised by an overproduction of apo B containing lipoproteins, which results in increased $V_{L D L}{ }^{13}$ and $L D L$ concentrations ${ }^{34}$, and the presence of small dense $L D L$ particles ${ }^{35.36}$. In addition, in $\mathrm{FCHL}$, a relative impairment in lipoprotein catabolism ${ }^{14}$ and an increased residence time of VLDL particles, both contributing to higher lipoprotein remnant concentrations, have been documented. Increased flux of atherogenic lipoproteins through the arteries, with in addition increased residence time, is a plausible mechanism for increased exposure of the endothelium to atherogenic lipoproteins in FCHL affected subjects. The present data indicate that increased apo B concentrations, reflecting increased delivery of 
atherogenic lipoproteins to the endothelium and the vessel wall, result in increased IMT and, with time, may be associated with clinical cardiovascular sequelae.

In the present study, increased BMI has been associated with higher IMT. Increased $B M I$ is potentially pro-atherogenic in humans through several pathophysiological mechanisms, including associated hyper-lipidemia, hypertemsion and insulin resistance. Increased BMI has been associated with increased risk of developing CVD, where co-segregation with associated metabolic disorders further enhances cardiovascular risk ${ }^{37}$. In FCHL, abdominal obesity has been associated with increased risk of non-fatal $C A D^{5}$ and hypertension ${ }^{16}$. Furthermore, increased free fatty acids flux from visceral fat directly to the liver can contribute to a hypersecretion of apo B containing triglyceride-rich VLDL from the liver ${ }^{38}$. Moreover, $B M I$ reduction has been associated with reduced secretion of apo $B$ containing particles from the liver ${ }^{38.34}$. Therefore, BMl reduction is a potentially important therapeutic goal in FCHL to slow IMT progression or even promote IMT regression, reduce apo B secretion, and lower blood pressure ${ }^{16}$.

In conclusion, common carotid artery IMT is increased in FCHL affected subjects with a mean age of 48.5 years. In the present study this increase in IMT corresponded to an acceleration of silent atherosclerosis by approximately $5-9$ years. The present findings show the important contribution of an increased number of lipoprotein particles to the development of increased IMT in FCHL. Reduction of abdominal obesity should be tested as a potential therapeutic intervention in FCHL to reduce the secretion of apo B containing lipoproteins and potentially counteract IMT progression. Moreover, early detection of FCHL affected subjects, with subsequent dietary and/or drug treatment, is warranted as the development of subclinical atherosclerosis, associated with future cardiovascular events, is seriously enhanced. 


\section{References}

1. Goldstein IL, Schrott HG, Hazzord WR, Bierman EL, Motulsky AG. Hyperlipidaemia in Coronary Heart Disease. II Genetic analysis of lipid levels in 176 families and delineation of a new inherited disorder, combined hyperlipidaemia. Joumal of Clinical Investigation 1973,52:1544-1568.

2. Nikkilä EA, Aro A. Family study of serum lipids and apolipoproteins in coronory artery disease. Lancet 1973;78:954-959.

3. Genest-Jr JJ, Martin MSS, McNamara JR, Ordovas JM, Jenner J, Myers RH, Silberman SR, Wilson PW, Salem DN, Schaefer EJ. Familial lipaprotein disorders in patients with premature coronary artery disease. Circulation 1992;85:2025-2033.

4. Austin MA, McKnight B, Edwards KKL, Bradley CM, McNeely MJ, Psaty BM, Brunzell JD, Molulsky AG. Cardiovascular disease mortality in familial forms of hypertriglyceridemic: A 20-year prospective study. Circulation 2000; 101:2777-2782.

5. Voors-Pette $C$, de Bruin TWA. Excess coronary heart disease in Familial Combined Hyperlipidemia, in relation to glenetic factors and central obesity. Atherosclerosis $2001 ; 157: 481-489$.

6. Salonen R, Salonen JT. Determinants of carotid intima-media thickness: a populationbased ultrasonography study in Eastern Finnish men. Journal of Internal Medicine $1991 ; 229: 225-231$.

7. Bonithon-Kopp C, Scarabin PY, Taquet A, Tauboul PJ, Malmejac A, Guize L. Risk factors for early caratid atherosclerosis in middllemaged French women. Arteriosclerosis Thrombosis and Vascular Biology 1991;11:966-972.

8. Skoglund-Andersson $C$, Tang $R$, Band MG, de-Faire U, Hansten A, Karpe F. LDL particle size distribution is associated with carotid infima-media thickness in healthy 50-year-ald men. Arteriosclerosis Thrombosis and Vascular Biology 1999;19:2422. 2430 .

9. Burke GL, Evans GW, Riley WA, Sharrett AR, Howard J, Barnes RW, Rosamond W', Crow RS, Rautaharju PM, Heiss G, for the ARIC study group. Arteriall wall thickness is. associated with prevalent cardiowascular disease in middle-aged adults. The Atherosclerosis Risk in Communities (ARIC) Study. Stroke 1995;26:3862-391.

10. Hulthe J, Wikstrand J, Emanuelsson $H$, Wiklund O, defeyter PJ, Wendelhag 1. Atherosclerotic changes in the canotid artery bulb as measured by $\mathrm{B}$-mode ultrasound are associaled with the extent of coronary atherosclerosis. Stroke 1997;28:1189. 1194.

11. Bots ML, Hoes AW, Koudstaal PJ, Hofman A, Grobbere DE. Common caratid intimamedia thickness and risk of stroke and myocardial infarction. The Rotterdam Siudy. Circulation 1997:96:1432-1437.

12. OLeary DH, Polak JF, Kronmal RA, Manolio TA, Burke GL, Wolfson SK. Carotidartery intima and media thickness as a risk factor for myocardial infarction and stroke in older adults. Cardiowascular Health Study Collaborative Research Growp. New England Journal of Medicine 1999;340:14-22. 
13. Venkatesan S, Cullen P, Pacy P, Halliday D, Scott I. Stable isotopes show a direct relation between VLDL apoB overpraduction and serum triglyceride levels and indicate a metabolically and biochemically coherent basis for familial combined hyperlipidemia. Arteriosclerosis Thrombosis and Vascular Biology 1993;13:11101118.

14. Cabezas MC, de Bruin TWA, Jansen H, Kack. LA, Korthandt W, Erkelens DW. Impaired chylamicron remnant clearance in familial combined hyperlipidemia. Arteriosclerosis and Thrombosis 1993;13:804-814.

15. Bredie SJH, Tack CJJ, Smits P. Stallenhoef AFH. Non-obese patients with familial combined hyperlipidemia are insulin resistant as compared with their non-affected relatives. Arteriosclerosis Thrombosis and Vascullar Biology 1997,17:1465-1471.

16. Keulen ETP, Voors-Pette C, de Bruin TWA. Familial dyslipidemic hypentension syndrome: Familial combined hyperlipidemia, and the role of abdiominal fat mass. American Joumal of Hypertension 2001; 1 4,357-363.

17. Hoeks AG, Willekes $C$, Boutouyrie $P$, Brands $P \rrbracket$, Willigers JM, Reneman RS. Automated detection of local artery wall thickness based on $M$-line signal processing. Ultrasound in Medicine and Biology 1997;23:1017-1023.

18. Willekes $C$, Hoeks $A$, Bots $M$, Brands P, Willigers J, Reneman R. Evaluation of offaline automated intima-media thickness detection of the common carotid artery based on M-line signal processing. Ultrosound in Medicine and Biology 1999;25:57-64.

19. Friedewall WT, Levy RI, Fredrickson DS. Estimation of the concentration of lawdensity lipoprotein cholesterol in plasma, without the use of the preparative ultracentrifuge. Clinical Chemistry 1972;18:499-502.

20. Matthews DR, Hosker JP, Rudenski AS, Naylor BA, Treacher DF, Tumer RC. Homeostasis model assessment: insulin resistance and beta-cell function from fasting plasma glucose and insulin concentrations in man. Diabetologia 1985;28:412-419.

21. Albers JJ, Marcovina SM, Kennedy H. International Federation of Clinical Chemistry standardization project for measurements of apolipoproteins A-\| and B. II. Evaluation and selection of candidate reference materials. Clinical Chemistry 1992;38:658-662.

22. Ingelfinger JA, Mosteller F, Thibodeau LA, Ware JH. Biostatistics in clinical medicine. New York, USA: McGraw-Hill, Inc, 1994.

23. Bots $M L$, Hotman $A$, Grobbee DE. Common caratid intima-media thickness and lower extremity arterial atherosclerosis. The Ralterdam Study. Arteriosclerosis Thrombosis and Vasculiar Biology 1994;14:1885-1891.

24. Furberg $C D$, Adams HP, Applegate WB, Byington RP, Espeland MA, Hartwell T, Hunninghake DB, Lefkowitz DS, Probstfield J, Riley WA, Young $B$, for the Asymptomatic Carotid Artery Progression Study (ACAPS] research group. Effect of lovastatin on early carotid atherasclerosis and cardiovascular avents. Circulation $1994 ; 1994: 1679 * 1687$.

25. Wendelhag I, Wiklund $O$. Wikstrand J. Intima-media thickness after cholesterol lowering in familial hypercholesterolemia. A three-year ultrasound study of common caratid and femoral arteries. Atherosclerosis 1995;117:225-236.

26. Hodis HN, Mack WJ, LaBree L, Selzer RH, Liu C. Alaupovic P, Kwong-Fu H, Azen SP. Reduction in carotid arterial wall thickness using lowastatin and dietary therapy: a randomized controlled clinical trial. Annals of Internal Medicine 1996;124:548-556.

27. Smilde TJ, van Wissen $S$, Wollersheim H, Trip MD, Kastelein JP, Stalenhoef AFH. Effect of aggressive versus conventional lipid lowering on atherosclerosis progression 
in familial hypercholesterolaemia (ASAP): a prospective, randomised, double-blind Irial. Lancet 2001;357:577-581.

28. Keulen ETP, Lutgens I, Rijkers $K$, van Lin JMP, de Bruin TWA. The epidemiolagy of cardiovascular risk factors in familial combined hyperlipidemia. Circulation $2001 ; 2 / 2: 61$ (Abstract).

29. Kwiterovich-Jr PO, Coresh J, Smith HH, Bachorik PS, Derby CA, Pearson TA. Comparison of the plasma levels of apolipoproteins B and A-1, and other risk factors in men and women with premature coronary artery disease. American Journal of Cardiology 1992,69:1015-1021.

30. Westerveld HT, wan-Lennep JE, van-Lennep HW, Liem AH, de Boo JA, van der Schrouw YT, Erkelens DW. Apolipoprotein B and coronary artery disease in women: a cross-sectional study in women undergoing their first coronary angiography. Arteriosclerosis Thrombosis and Vascular Biolagy 1998; 18:1101-1107.

31. Wald NJ, Law M, Watt HC, Wu T, Bailey A, Johnson AM, Craig WY, Ledue TB, Hadlow JE. Apolipaproteins and ischaemic heart disease: implications for screening. Lancet 1994,343:75-79.

32. Lamarche B, Tchernof A, Mauriege P, Cantin B, Dagenais GR, Lupien DJ, Depres JP. Fasting insulin and apolipoprotein B levels and low-density lipoprotein particle size as risk factars for ischemic heart disease. Journal of the American Medical Association 1998;279:1955-1961.

33. Brown G, Albers JJ, Fisher LD, Schaefer SM, Lin JT, Kaplan C, Zhao XQ, Bisson BD, Fitzpatrick WF, Dadge HT. Regression of coronary artery disease as a result of intensive lipid-lowering therapy in men with high levels of apolipoprotein B. New England Journal of Medicine 1990;323:1289-1298.

34. Kissebah AH, Alfarsi S, Evans DJ. Low density lipoprotein metabolism in familial combined hyperlipidemia. Mechanism of the multiple lipaprotein phenotypic expression. Arteriosclerosis 1984;4:614-624.

35. Hokanson JE, Krauss RM, Albers JJ, Austin MA, Brunzell JD. LDL physical and chemical properties in familial combined hyperlipidemia. Artieriosclerasis Thrombosis and Vascular Biology 1995; 15:452-459.

36. Bredie SJ, Kiemeney LA, de Haan AF, Demacker PN, Stalenhoef AF. Unherited susceptibility determines the distribution of dense low-density lipoprotein subfraction profiles in familial combined hyperlipidemia. American Journal of Human Genetics 1996,58:812.822.

37. Schulte $H$, Cullen $P, A s s m a n n ~ G$. Obesity, mortality and cardiovascular disease in the Munster Heart Study (PROCAM). Atherosclerosis 1999; 144:199-209.

38. Riches FM, Watts GF, Hua J, Stewart GR, Naoumava RP, Barrett PHR. Reduction in visceral adipose tissue is associated with improvement in apolipoprotein B-100 metabolism in obese men. Joumal of Clinical Endocrinology and Metabolism $1999 ; 84: 2854-2861$.

39. Pumell JQ, Kahm SE, Albers JJ, Nevin DN, Brunzell JD, Schwartz RS. Effect of weight loss with reduction of intra-abdominal fat on lipid metabolism in older men. Journal of Clinical Endocirinology and Metabolism 2000;85:977-982. 


\section{Chapter 9}

General discussion

- Results of this thesis in perspective

- FCHL: diagnostic problems 


\subsection{Results of this thesis in perspective}

FCHL, first delineated in 1973, is nowadays recognised as the most common genetic dyslipidemia in humans with a substantially increased risk of premature cardiovascular disease $(C V D)^{1.3}$. Most of the research in FCHL has focussed upon the pathophysiology of the observed lipid abnormalities and insulin resistance. In addition, the role of (abdominal) obesity in the pathophysiology of FCHL has emerged over the past few years. Recently, androgenic obesity has been linked to increased risk of non-fatal CVD in $\mathrm{FCHL}^{3}$. The relationship between the observed cardiovascular abnormalities described in this thesis and lipid- and apolipoprotein concentrations, insulin resistance and obesity will be discussed below.

In chapter 4, the co-segregation of hypertension with dyslipidemia in FCHL families was described. One-third of the FCHL families studied also met the diagnostic criteria matching Familial Dyslipidemic Hypentension (FDH). This percentage may be even underestimated as some FCHL families had too few relatives in the requested age-range (30-59 years) to match the diagnosis of $\mathrm{FDH}$. Increased waist-circumference, and hence abdominal fat mass, was associated with higher blood pressure values observed in FCHL-affected and non-affected female relatives. As blood pressure values were aiready elevated in non-affected female relatives, it is plausible that a common denominator influences the occurrence of dyslipidemia as well as hypertension in FCHL. Increased free fattly acids flux from visceral adipose tissue may result in overproduction of apo B containing lipoproteins in the liver ${ }^{4}$ as well as hyperactivity of the sympathetic nervous system ${ }^{5,6}$, thus providing a common link between dyslipidemia and hypertension in FCHL. Obesity has been associated with increased risk of cardiovascular disease in the general population ${ }^{7.8}$, as well as in $\mathrm{FCHL}^{3}$. In $\mathrm{FCHL}$, obesity was linked to subclinical atherosclerosis, as measured by intima media thickness (IMT) (chapter 8 ).

In conclusion, in FCHL, (abdominal) obesity plays an important role in lipoprotein overproduction, development of insulin resistance, hypertension and increase in IMT. Therefore, reduction of body weight, especially visceral and subcutaneous abdominal fat mass, is a potentially important therapeutic goal in FCHL to reduce apo B containing lipoprotein secretion by the liver, to improve insulin resistance, to lower blood pressure values, and to slow IMT progression, and perhaps even promote IMT regression.

Insulin resistance is offen observed in FCHL-affected as well as non-affected relatives ${ }^{2,10}$. As insulin plays a piwotal role in lipid metabolism and insulin resistance has already been observed in non-affected relatives, insulin resistance may play a role in the development of some features of FCHL. Insulin resistance has been associated with several clinical and metabolic abnormalities including diabetes mellitus, obesity, hypertension, dyslipidemia, impaired fibrinolytic 
capacity and a pro-coagulant state ${ }^{1-13}$. Increased heart rate corrected QTinterval (QTC) was suggested as an additional feature of the insulin resistance syndrome ${ }^{14}$. A prolonged QTc, abserved in FCHL affected women, has been associated with some components of the insulin resistance syndrome (chapter 5). Whether this QTc prolongation in FCHL is an adaptation mechanism to insulin resistance remains to be elucidated. However, as an increased QTc has been associated with increased risk of cardiac disease related death ${ }^{15-17}$, QTC prolongation in FCHL may add to the high risk of CVD. Chapter 6 describes the increase of endothelium derived pro-coagulant (vWf) and anti-fibrinolytic proteins in FCHI affected subjects, which potentially contributes to the risk of premature CVD found in FCHL. Insulin resistance partly explained the observed increase of plasminogen activator inhibitor 1 (PAl-1) in FCHL affected subjects (chapter 6). Improvement of insulin resistance, by weight reduction or perhaps thiazolidinediones, might have beneficial effects on QTc as well as PAI-1, and may potentially lower the cardiovascular risk burden in FCHL.

As mentioned before, the most important metabolic abnormalities found in FCHL concern the overproduction of apo B containing lipoprotein particles ${ }^{18}$ and impaired lipoprotein clearance with increased residence time. In the fasting state, FCHL men had a 6-fold higher remnant-like lipoprotein cholesterol (RLP-C) concentration than control men, whereas RLP-C concentrations were 2 -fold higher in FCHL women compared to control women (chapter 7). The observed reduction in post-occlusive number of capillaries in $\mathrm{FCHL}$ men has been associated with higher RLP-C in univariate and multivariate analyses (chapter 7). Loss of capillary density and thus diffusion surface can potentially impair clearance of circulating lipoproteins, such as RLP-C. Furthermore, loss of endothelial surface can result in reduced lipoprotein lipase activity, reported in approximately one-third of FCHL-affected subjects ${ }^{19}$, further aggravating the metabolic lipid abnormalities in FCHL and the risk of cardiovascular events.

The contribution of lipoprotein particles to vascular abnormalities in FCHL was further underlined by the association between increased intima media thickness (IMT) and higher lipid- and apolipoprotein concentrations (chapter 8). Multivariate regression analyses revealed that age, gender, apo B and BMI contributed independently to increased IMT (chapter 8). The relationship between IMT and BMI has already been discussed above. The relationship between IMT and increased apo B concentrations is clinically more important, as all apo B containing lipoprotein particles are potentially atherogenic. Furthermore, apo B concentrations reflect total number of lipoprotein particles in the circulation. Increased flux of atherogenic lipoprotein particles through the arteries, with in addition increased residence time, is a plausible mechanism for the increased exposure of endothelium to atherogenic lipoprotein particles and hence increased risk of developing atherosclerosis.

In conclusion, hypertension, QTc prolongation and elevated concentrations of WWF and PAI-1 have been identified as cardiovascular risk factors that potentially contribute to the high risk of cardiovascular disease observed in FCHL. Furthermore, endothelial dysfunction, loss of capillary density and enhanced 
subclinical atherosclerosis have been observed in FCHL-affected subjects (mean age 47 years). Early defection of FCHL-affected subjects, with subsequent dietary and/or drug treatment, is needed as the development of endothelial dysfunction and subclinical atherosclerosis, both associated with future cardiovascular events, is seriously enhanced and present at a relatively young age. Antihyperlipidemic therapy can potentially restore endothelial dysfunction in $\mathrm{FCHL}^{20}$. In addition, antihyperlipidemic therapy with HMG-CoA-reductace inhibitors (e.g. statins) has been shown to slow IMT progression and even promote IMT regression ${ }^{21,22}$. The same results may apply to FCHL as well, although further research is needed. The role of antihyperlipidemic therapy in blood pressure lowering and reversal of QTc prolongation has to be established in future studies as well. Reduction of abdominal obesity, via dietary intervention and promotion of exercise should be tested as a potential therapeutic intervention in $\mathrm{FCHL}$, in order to reduce secretion op apo B containing lipoproteins, to improve insulin resistance, to lower blood pressure and potentially to counteract IMT progression.

\subsection{FCHL: diagnostic problems}

Presently, FCHL can be diagnosed in families with combined hyperlipidemia, multiple lipoprotein phenotype and associated premature cardiovascular disease. No biochemical or genetic marker is available yet to establish FCHL in one individual. Unavailability of a unique, sensitive and specific marker of the disease, FCHL, presents us with a clinical problem: how to diagnose FCHL in one individual?, and another: how should we define FCHL in dinical practice? As outlined in chapter 2, the criteria presented by Goldstein and colleagues in 1973 are used to diagnose FCHL presently, i.e. primary hyperlipidemia, with multiple hyperlipidemic lipoprotein phenotypes and premature cardiovascular disease (CVD) in a family'. Hypercholesterolemia and hypertriglyceridemia are nowadays defined as levels exceeding the $90^{\text {ith }}$ or $95^{\text {th }}$ percentile cut-off values in the population. This potentially leads to a more extreme hyperlipidemia to diagnose FCHL in those countries with established higher lipid concentrations in the population compared to countries with lower mean population cholesterol and triglyceride concentrations ${ }^{23}$. Moreover, a dedine in mean lipid levels in a population over time, e.g. by public information about healthy dietary habits, will also change the $90^{\text {th }}$ or $95^{\text {th }}$ percentille to a lower level, as is presently the case in Finland (Taskinen MR, FCHL workshop, ESCl 2001, Barcelona, Spain). Both mechanisms render comparisons between $\mathrm{FCHL}$ populations and within one FCHL population over time (follow-up) difficult, as different hyperlipidemic population cut-off values will be used.

A multiple lipoprotein phenotype within one family is required to establish the diagnosis of FCHL. In addition, the multiple lipoprotein phenotype can be observed over time within one individual as well. Therefore, a presently normolipidemic subject may, for instance by variation in plasma TG levels, have shown elevated lipid levels in the past. Also, in a cross-sectional survey, a 
normolipidemic subject may develop hyperlipidemia later in life, for instance by gaining weight or developing central abesity. In contrast, changes from hyperlipidemia to normolipidemia or from one hyperlipidemic to another hyperlipidemic phenotype might also occur within one individual ${ }^{24}$. One musi bear these difficulties in classification in mind with every genetic, metabolic or clinical evaluation of $\mathrm{FCHL}$.

Clustering of FCHL with other hyperlipidemic states, like hyperapobetalipoproteinemia and familial dyslipidemic hypertension (see chapter 4), have been reported within families or within individuals. Hyperapobetalipoproteinemia, characterised by normal LDL-cholesterol levels, increased concentrations of small dense LDL (sdLDL), and elevated apo B concentrations, merely differs from $\mathrm{FCHL}$ by definition ${ }^{25.26}$. Sniderman and colleagues proposed to use hyper apo B and hypertriglyceridemia as FCHL criteria to identify those subjects with high risk of developing cardiovascular events. Austin and colleagues have shown that an increase in sdLDL is associated with TG levels above $1.5 \mathrm{mmol} / \mathrm{L}^{27}$. Furthermore, especially the interaction between apo $B$ and sdLDL leads to the highest risk of cardiovascular events in a general population ${ }^{28,29}$. Although using the proposed criteria by Sniderman may identify those FCHL subjects with the highest cardiovascular risk, not all subjects identified as FCHL-affected at present, will be identified. However, these latter subjects are still at risk of developing cardiovascular events. Moreover, the familial association, which has been identified as important contributor to nonfatal risk of $C V D^{3}$, may be neglected using the hyper apo B / hyper TG approach. In addition, the clustering of hype apo B / hyper TG is not unique to FCHL but is also observed in other disorders, including polycystic ovarian syndrome ${ }^{30}$, AlDS $^{31}$, insulin resistance syndrome $e^{32-34}$ and the use of steroids ${ }^{35}$. In $\mathrm{FCHL}$, other associated traits, like reduced $\mathrm{HDL}$-cholesterol and insulin resistance have been observed as well ${ }^{36,37}$. However, these traits are currently not used to diagnose FCHL. Finally, the role of obesity and increased amount of adipose tissue in FCHL that have been described over the past years, are not incorporated in the diagnostic criteria for FCHL yet.

Another problem in specific diagnostic criteria for FCHL is the clustering observed with other clinical entities, like obesity and perhaps type 2 diabetes mellitus. Patients with these disorders may show VLDL overproduction, insulin resistance, enhanced past-prandial lipidemia, increased free fatty acid flux to the liver, sdLDL and increased cardiovascular risk as well ${ }^{11}$. Despite differential diagnostic problems, this overlap gives us the opportunity to study the effect of contributing genes in FCHL and type 2 diabetes mellitus, and vice versa.

During the third FCHL workshop held at the ESCl meeting in May 2001 in Barcelona, Spain, the above mentioned diagnostic problems have been discussed extensively. The important role of FCHL in cardiovascular medicine has been stressed as well. World-wide co-operation is warranted to come to a better definition of FCHL for clinical as well as research purposes and to combine efforts to unravel the genetic abnormalities underlying FCHL. In daily clinical 
practice, a primary combined hyperlipidemia in a subject with a known family history of hyperlipidemia and premature CVD should focus the physician's thoughts on FCHL. In the current national and international guidelines on hyperlipidemia, initiation of treatment depends on absolute risk of a cardiovascular event during the next 10 years ${ }^{38-40}$. However, an established familial hyperlipidemia warrants antihyperlipidemic treatment in any case, despite the absolute risk calculated from tables ${ }^{38 \cdot 40}$. Screening of all family members on hyperlipidemia and other features of FCHL should be conducted as soon as FCHL is suggested as possible diagnosis in a subject, because of the strong association of FCHL with cardiovascular events. Whether this family survey is conducted in a clinical or research setting is of less important to the individual subject, as long as his / hers risk profile is established correctly and proper treatment is initiated whenever needed.

In conclusion, despite the current problems in diagnosing FCHL in daily clinical practice, FCHL is an important disease in cardiovascular biology. Furthermore, current criteria used in clinical science result in the ascertainment of $\mathrm{FCHL}$ families with similar characteristics over the world. In the end, FCHL may be considered more like a syndrome, it might turn out that patients manifest a mixture of disease entities, with a variety of metabolic defects and possible genetic markers ${ }^{4}$. Global uniformity to establish diagnosis of FCHL and worldwide co-operation to unravel the genetic and metabolic pathophysiology of FCHL should be established and expanded as soon as possible. 


\section{References}

1. Goldstein IL, Schrott HG, Hazzard WR, Bierman EL, Molulsky AG. Hyperlipidaemia in Coronary Heart Disease. II Genetic analysis of lipid levels in 176 families and delineation of a new inherited disorder, combined hyperlipidaemia. Journal of Clinical Investigation 1973,52:1544-1568.

2. Austin MA, McKnight B, Edwards KL, Bradley CM, Molveely MJ, Psaty BM, Brunzell JD, Motulsky AJ. Cardiovascular disease mortality in familial forms of hypertiriglyceridemia: A 20-year prospective study. Circulation 2000;101:27772782.

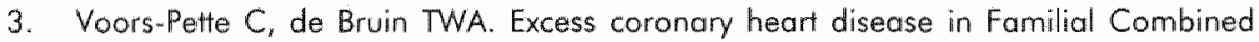
Hyperlipidemia, in relation to genetic factors and central obesity. Atherosclerosis $2001: 157: 481-489$.

4. Riches FM, Watts GF, Hua J, Stewart GR, Naoumova RP, Barrett PH. Reduction in visceral adipose tissue is associated with improvement in apolipoprotein B-100 metabolism in obese men. Joumal of Clinical Endocrinolagy and Metabolism $1999 ; 84: 2854-2861$.

5. Reaven GM, Lithell $H$, Landsberg $L$. Hypertension and associated metabolic abnomalities - the rolie of insulin resistance and the sympathoadrenal system. New England Journal of Medicine 1996,334:374-381.

6. Grekin RJ, Dumont CJ, Vollmer AP, Watts SW, Webb RC. Mechanisms in the pressor effects of hepatic pantial venous fatty acid infusion. American journal af physialogy 1997:273:R324-R330.

7. Seidell JC, Andres R, Sorkin JD, Muller DC. The sagittal waist diameter and mortality in men: the Baltimore Longitudinal Study on Aging. Internal Journal of Obesity Related Metabolic Disorders 1994;18:61-67.

8. Schulte H, Cullen P. Assmann G. Obesity, mortality and cardiovascular disease in the Munster Heart Study (PROCAM). Atherosclerosis 1999:1 44:199-209.

9. Hunt SC, Wu LL, Hopkins PN, Stults BM, Kuida H, Ramirez ME, Lalouel JM, Willians RR. Apolipoprotein, low density lipoprotein subfraction, and insulin assaciations with farmilial combined hyperlipidemia. Study of Utoh patients with familial dyslipidemic hypertension. Arteriosclerosis 1989;9:335-344.

10. Ascaso JF, Merchante A, Lorente Rl, Real JT, Martinez VJ, Carmena R. A study of insulin resistance using the minimal madel in nondiabetic familial combined hyperlipidemic patients. Metabolism 1998;47:508-513.

11. Reaven GM. Banting lecture 1988. Role of insulin resistance in human disease. Diabetes 1988;37:1595-1607.

12. Hiermann Ingwar. The Metabolic Cardiowascullar Syndrome: Syndrome $X$, Reaven's Syndrome, Insulin Resistance Syndrome, Atherothrombogenic Syndrome. Joumal of Cardiovascular Pharmocology 1992,20:55-\$10.

13. Andersen P. Hypercoagulability and Reduced Fibrinolysis in Hyperlipidemia: Relationship to the Metabalic Cardiovascular Syndrome. Journal of Cardiowascular Pharmocology 1992,20:529-\$31. 
14. Dekker JM. Feskens EJ, Schouten EG, Kloowwijk P, Pool J, Kromhout D. QTc duration is associated with levels of insulin and glucase intolerance. The Zutphen Elderly Study. Diabetes 1996:45:376-380.

15. Dekker $\ M$, Schouten EG, Klootwiik P. Pool I, Kromhout D. Association behween QT interwal and coronary heart disease in middle-aged and elderly men. The Zutphen Study. Circulation 1994;90:779-785.

16. Elming H, Holm E, Jun L, Torp Pedersen C, Kober L, Kireshoff M, Malik M, Camm J. The prognostic walue of the QT interval and $Q T$ interwal dispersion in all-cause and cardiac mortality and morbidity in a population of Danish eitizens. European Heart Journal 1998;19:1391-1400.

17. de Bruyne M, Hoes AW, Kors JA, Holman A, van Bemmel JH, Grabbee DE. Prolonged QT interwal predicis cardiac and all-cause montality in the elderly. The Rotterdam Study. European Heant Journal 1999;20:278-284.

18. Venkatesan S, Cullen P, Pacy P, Halliday D, Scott J. Stable isotopes show a direct relation between VLDL apoB overproduction and serum triglyceride levels and indicate a metabolically and biochemically coherent basis for familial combined hyperlipidemia. Arteriosclerosis Thrombosis and Vascular Biology 1993;13:11101118.

19. Babirak S, Brown B, Brunzell J. Familial combined hyperlipidemia and abnormal lipoprotein lipase. Arteriosclerasis and Thrombosis 1992;12:1176-1183.

20. Straes $E$, de Bruin TWA, de Valk $H$, Erkelens DW, Banga JD, van Rijn $H$, Koomans $H$, Rabelink T. NO activity in familial combined hyperlipidemia: potential role of cholesterol remnants. Cardiovascular Research 1997;36:445-452.

21. Hodis HN, Mack WJ, LaBree L, Selzer RH, Liu C, Alaupowic P, Kwong-Fu H, Azen SP. Reduction in carotid arterial wall thickness using lovastatin and dietary therapy: a randomized controlled dinical frial. Annals of Internal Medicine 1996;124:548-556.

22. Smilde TJ, wan Wissen $S$, Wollersheim $H$, Trip MD, Kastelein JJP, Stalenhoef AFH. Effect of aggressive versus conventional lipid lawering on atherosclerosis progression in familial hypercholesterolaemia (ASAP): a prospective, randomised, double-blind trial. Lancet 2001,357:577-581.

23. Verschuren WM, Jocobs DR, Bloemberg BP, Kromhout D, Menotti A, Aravunis $C_{f}$ Blackburn H, Buzina R, Dontas AS, Fidanza F. Serum total cholesterol and long-term coronary hean disease martility in different cultures. Twenty-five-year follow-up of the seven countries study. Journal of the American Medical Association $1995 ; 274: 131-136$.

24. Veerkamp MJ, de Graaf J, Bredie SIH, Hendriks JCM. Stalenhoef AFH. Diagnosis of familial combined hyperlipidaemia (FCH) based on lipid phenolype expression in 32 families: results of a 5-year follow-up study. European Journa of Clinical Unvestigation 2001;31:20 (Abstract).

25. Sniderman AD, Woltson C, Teng B, Franklin FA, Bachorilk PS, Kwiterovich-Jr PO. Association of hyperapobetalipoproteinemia with endogenous hypertriglyceridemia and atherasclerosis. Annals of Internal Medicine 1982;97:833-839.

26. Sniderman A, Teng B, Genest J, Cianflone K, Wacholder S, Kwiterovich P. Familial aggregation and early expression of hyperapobetalipoproteinemia. American Journal of Cardiology 1985;55:291-295. 
27. Austin MA, King MC, Vranizon KM, Krauss RM. Atherogenic lipoprotein phenotype. A proposed gemefic marker for coronary heart disease risk. Circulation 1990;82:495506.

28. Lamarche B, Tchernof A, Moorjani S, Cantin B, Dagenais GR, Lupien PI, Depres JP. Small, densie low-density lipoprotein particles as a predictor of the risk of ischemic heart disease in men. Prospective results from the Quebec Cardiovascular Study. Circulation 1997;95:69-75.

29. Lamarche B, Tchernof A, Mauriege P. Cantin B, Dagenais GR, Lupien PJ, Depres JP. Fasting insulin and apolipopratein $B$ levels and low-density lipoprotein particle size as risk factors for ischemic heart disease. Journal of the American Medical Association 1998;279:1955-1961.

30. Lobo RA, Cormina $E$. The importance of diagnasing the polycystic ovary syndrome. Annals of Internal Medicine 2000;132:989-993.

31. Crook MA, Mir $\mathbb{N}$. Abnormal lipids and the acquired immunodeficiency syndrome: is there a prablem and what shauld we do about it? International Journal of STD and AIDS 1999;10:353-356.

32. Lamarche B, Lewis GF. Atherosclerosis prewention for the next decade: risk assessment beyond low density lipoprotein chalesterol. Canadian Journal of Cardiology 1998;14:841-851.

33. Timar $O$, Sestier $F$, Levy E. Metabalic syndrame $X$ : a review. Canadian Journal of Cardiology 2000; 16:779.789.

34. Laws A. Free fatty acids, insulin resistance and lipoprotein metabolism. Current Opinion in Lipidology 1996;7:172-177.

35. Lajarin F, Zaragoza R, Tovar I, Martinez-Hernandez P. Evolution of serum lipids in two male bodybuilders using anobolic steroids. Clinical Chemistry 1996,42:970 972.

36. Bredie SJH, Tack CJ』, Smits P, Stalenhoef AFH. Non-obese patients with familial combined hyperlipidemia are insulin resistant as compared with their non-affected relatives. Arteriosclerosis Thrombosis and Vascular Biology 1997:17:1465-1471.

37. Ascaso JF, Lorente R, Merchante A, Real JT, Priego A, Carmena R. Insulin resistance in patients with familial combined hyperlipidemia and coronary artery disease. American Journal of Cardiology 1997,80:1484-1487.

38. Simoons $M L_{s}$ Casparie AF. Behandeling en prewentie van coronaire hartziekten door verlaging van de serumcholesterolconcentratie; derde consensus 'Cholesterol'. Therapy and prevention of cononary heart diseases through lowering of the serum cholesteroll levels; third consensus "Cholesterol". Consensus Working Group, CBO]. Nederlands Tijdschrift der Geneeskunde 1998;142:2096-2101.

39. Assmann $G$, Cullen P, Fruchart $C$, Lewis B, Mancini M, Carmena R. Coronary heart disease prevention task force. European Heart Jaurnal 1999;20:841-844.

40. Wood D. European and American recommendations for coronary heart disease prevention. European Heart Journal 1998;19 Suppll AA12-AA19.

41. de Graaf J, Stalenhoef AF. Defeets of lipoprotein metabolism in familial combined hyperlipidaemia. Gurrent Opinion in Lipidology 1998;9:189-196. 


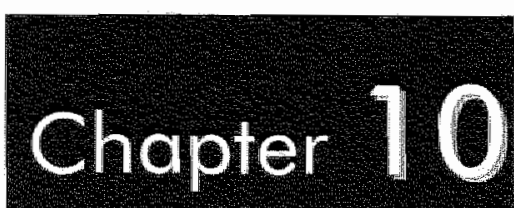

Summary 


\section{Summary}

Chapter 1 describes the background and aims of the research described in this thesis. Cardiovascular disease (CVD) is a main cause of death in our Western society. Several epidemiological studies have identified many risk factors that are convincingly linked to the development of CVD. Multiple combinations of these cardiovascular risk factors will lead to an exponentially increased risk of early $\mathrm{CVD}^{1.3}$. In Familial Combined Hyperlipidemia (FCHL), an increased risk of premature (i.e. before age 60 years) CVD is present. Although FCHL is now known for more than 25 years, most of the research has focussed upon the pathophysiology of lipid abnormalities and insulin resistance observed in FCHL. However, little is known about early manifestations of vascular abnormalities in $\mathrm{FCHL}$, and about the natural history of such vascular abnormalities. Furthermore, there is the consideration that the observed lipid abnormalities and insulin resistant state can not solely explain the known high risk of developing CVD in FCHL.

Chapter 2 addresses the collection of Dutch FCHL families and the criteria used to diagnose and ascertain a family with FCHL. Furthermore, several historic, environmental, anthropometric and clinical data obtained in 35 Maastricht FCHL families are described. In these Dutch FCHL families, 39\% (143 out of 362 relatives) were diagnosed with hyperlipidemia. Moreover, the prevalence of hyperlipidemia among FCHL relatives steeply increased from 15\% (13 out of 86 subjects) under age 30 years, to $71.4 \%$ (25 out of 35 subjects) in the agecategory 60 to 69 years $(p<0.01$ for trend). A striking observation was that in FCHL subjects, hyperlipidemia accurred almost 20 years earlier than in the spouse population. In addition, a significant clustering of the main cardiovascular risk factars (hyperlipidemia, hypertension, obesity and current smoking) in FCHL family members was observed compared to spouses ( $p<0.05$ for trend). The above-mentioned abnormalities together clearly indicate an unfavourable atherogenic risk profile in FCHL. This is underlined by the high prevalence of CVD found in hyperlipidemic relatives compared to spouses.

Chapter 3 reviews our current pathophysiological and genetic understanding of $\mathrm{FCHL}$. Although FCHL was delineated about 25 years ago, the complex FCHL phenotype is not fully understood at present. Several studies have shown abnormalities in lipoprotein metabolism, including hepatic hypersecretion of apolipoprotein B (apo B) containing lipoproteins, ${ }^{4,5}$ and delayed clearance of atherogenic lipoprotein remnants ${ }^{b}$. Except for the above-mentioned abnormalities in lipid metabolism, insulin resistance of adipose and muscular tissue has been documented in $\mathrm{FCHL}^{7,8}$. Furthermore, $\mathrm{FCHL}$ affected subjects often report some increase in body weight, body mass index, waist to hip ratio and waist-circumference, all together representing an increased adipose tissue mass, and, perhaps, reduced muscle mass. Increased free fatty acid (FFA) flux from visceral fat to the liver can contribute to the hypersecretion of triglyceride- 
rich very low-density lipoproteins from the liver, a hallmark of FCHL. The observed abnormalities in liver, adipose tissue and muscle in FCHL provide us with interesting target tissues for differential gene expression studies, as will be reviewed in the near future. It is generally believed that the complex $\mathrm{FCHL}$ phenotypes result from a defect in one or more major genes in combination with multiple modifier genes and gene-environment interaction. Several modifier genes are subsequently described at the end of chapier 3 .

Chapter 4 reports on the simultaneous occurrence of hypertension and hyperlipidemia in FCHL. One-third of 27 FCHL-families was diagnosed with Familial Dyslipidemic Hypertension. Significantly mare relatives $(27.2 \%)$ were diagnosed with dyslipidemic hypertension, compared to spouses (14.2\%). Furthermore, in FCHL women (affected as well as non-affected relatives, without antihypertensive medication) systolic and diastolic blood pressures were higher compared to spouses. Multiple linear regression analysis showed that age, FCHL-affected status and waist-circumference significantly contributed to systolic blood pressure in females. The present study indicaltes that visceral adipose tissue strongly contributes to the high prevalence of dyslipidemic hypertension in FCHL families. Reduction of visceral fat versus treatment of hyperlipidemia and hypertension should be tested as potential therapeutic interventions in FCHLaffected individuals.

Chapter 5 describes the heart rate corrected QT-interval (QTC) as measured in all leads of a 12-lead electrocardiogram in 76 FCHL-affected subjects and 92 healthy controls. QTc interval was significantly prolonged in FCHL-affected women, but not in men, compared to healthy controls (difference of $7.8 \mathrm{msec}$, age-corrected $p<0.011$ ). The observed significantly positive correlations in women between QTc and $\log T G, \log$ insulin and HOMA, and the negative correlation with HDL-cholesterol were in line with the previously suggested relationship between QTc and the insulin resistance syndrome (IRS) ${ }^{10}$. Multivariate regression analyses revealed that plasma insulin, systolic blood pressure, HDL-cholesterol, body mass index and FFA were independent predictors of QTC. In conclusion, in FCHL, prolonged QTc was specifically found in hyperlipidemic FCHL women and associated with components of IRS. QTC prolongation may either relate to the genetic susceptibility to $\mathrm{FCHL}$ in women, or represent an adaptation mechanism to insulin resistance. QTC prolongation may also add to the risk of developing cardiovascular events in FCHL.

Chapter 6 reports on several endothelium-derived proteins of the coagulation and fibrinolytic systems in FCHL. In 70 hyperlipidemic FCHL subjects and 57 healthy controls, fasting plasma concentrations of von Willebrand factor (vWf: pro-coagulant), Tissue Factor Pathway Inhibitor (TFPI) and thrombomodulin (both anti-coagulant), tissue type plasminogen activator ( $t-P A_{;}$pro-fibrinolytic) and plasminogen activator inhibitor 1 (PAl-1; anti-fibrinolytic) were determined. FCHL affected subjects showed significantly higher PAI-1 and $\mathrm{t}-\mathrm{PA}$ levels than healthy controls (PAl-1: $18(3-38)$ vs. $10(1-29) \mathrm{U} / \mathrm{mL} ; \mathrm{p}<0.001$, and t-PA: $10.8 \pm 3.8$ vs. $7.5 \pm 3.9 \mathrm{ng} / \mathrm{mL} ; p<0.001)$. In addition, vWf was significantly higher in 
FCHL subjects compared to healthy controls $1110.0 \pm 35.4 \%$ vs. $94.3 \pm 36.8$ $\%, p>0.05)$. Surrogate markers of insulin resistance explained $50 \%$ of the variation in plasma PAI-1 levels. The observed findings indicate a pro-coagulant, anti-fibrinolytic state of the endothelium, that is dependent on insulin resistance, and potentially contributes to the risk of premature cardiovascular disease found in FCHL. The increased plasma concentrations of the studied endotheliumderived proteins also indicate a dysfunctional endothelium. Further studies to the contribution of PAI-1 and WWF to the risk of cardiovascular disease in FCHL, and the potential treatment of these elevated levels, are warranted.

Chapter 7 describes abnormalities in capillany structure and function observed in FCHL-affected subjects and the possible role of remnant-like lipoprotein cholesterol (RLP-C) concentrations. In 23 (12 men) FCHL-affected subjects and 27 (14 men) healthy controls, capillary density was measured just above the finger nailfold, before and after 4 minutes of arterial occlusion. During the same test, skin blood flow was also measured using laser Doppler fluxmetry. Bosal $(\mathrm{BC})$ en post-ocdusive (POC) number of capillaries were significantly lower in FCHL men compared to healthy men, $113.7 \pm 15.1$ vs. $132.0 \pm 18.0 ; p=0.02$, and $123.0 \pm 19.1$ vs. $142.3 \pm 18.3 ; p=0.03$, respectively. Multivariate regression analyses revealed that $\log R L P-C$ was the only significant, independent contributor to POC. Laser Doppler post-occlusive reactive hyperaemia (LDPRH) was higher in FCHL women compared to healthy females: $537(239-800) \%$ vs. $327(39-365) \% ; p<0.05$. In men no differences in LDPRH were observed. In conclusion, in FCHL men a reduction in structural and functional skin capillaries was observed, and associated with increased atherogenic lipoprotein concentrations. Whether this reduction in capillary surface can be implicated in the pathophysiology of FCHL and its high risk of cardiovascular events, or is the result of adaptation to hyperlipidemia in $\mathrm{FCHL}$, remains to be elucidated.

The increase in LDPRH in FCHL women was an unexpected finding. Previous studies have suggested a reduced LDPRH could be a hallmark of insulin resistance ${ }^{11.12}$, a metabolic sitate that is also frequently observed in $\mathrm{FCHL}$. If should be noted however, that the increased hyperaemic response in FCHL. women was associated with normal capillary density, but that in FCHL men, the normal hyperaemic response was associated with reduced capillary density. These data combined might suggest that arteriovenous shunt flow be increased in $\mathrm{FCHL}$.

Chapter 8 reports on non-invasive ultrasound measurements of intima media thickness (IMT) in 58 FCHL-affected subjects and 55 age- and gender-matched healthy controls. IMT was measured at the left and right common carotid artery approximately $10.20 \mathrm{~mm}$ proximal to the carrotid bulb. FCHL-affected subjects without a previous history of cardiovascular disease $(n=46)$ had a significantly increased IMT compared to healthy controls, with a difference of $57 \mu \mathrm{m}$ (ageand gender-corrected $p<0.011$. A significant positive, age- and gendercorrected, Pearson correlation coefficient was observed between IMT and total cholesterol, non-HDL-cholesterol, LDL-cholesterol, $\log T$, apo B, fasting insulin, calculated insulin resistance (HOMA), BMI and waist-circumference, respectively. 
Multivariate regression analyses revealed that age, gender, apo B, and BMI were independent positive predictors of IMT, explaining a large proportion, $50 \%$, of the observed variation $(p<0.001)$. In conclusion, IMT of the common carotid artery is increased in FCHL-affected subjects (mean age of 48.5 years) and in the present study it corresponded to an acceleration of silent atherosclerosis by approximately 5-9 years. The present finding show the important contribution of atherogenic lipoprotein particles to the development of increased IMT in FCHL.

Finally, chapter 9 sets the results of this thesis in perspective and addresses some points of attention in further research. 


\section{References}

1. Castelli WP. Epidemiology of coronary heart disease: the Fromingham study. American Journal of Medicine 1984;76:4-12.

2. Assmann $G$, Schulte $H$. Relation of high-density lipoprotein cholesteral and triglycerides to incidence of atherosclerotic coronary artery disease (the PROCAM experience). Prospective Cardiovascular Munster study. American Journal of Cordiology 19:92;70:733-737.

3. Yusuf HR, Giles WH, Croft JB, Anda RF, Casper ML. Impact of multiple risk factor profiles on determining cardiovascular disease risk. Preventive Medicine 1998;27:19.

4. Venkatesan S, Cullen P, Pacy P, Halliday D, Scott J. Stable isotopes show a dired relation between $V L D L$ apoB overproduction and serum triglyceride levels and indicate a metabolically and biochemically coherent basis for familial combined hyperlipidemia. Arteriosclerosis Thrombosis and Vascular Biology 1993;13:1110. 1118.

5. Bredie SJ, vam Drongelen J., Kiemeney LA, Demacker PN, Beaty TH, Stalenhoef AF. Segregation analysis of plasma apolipoprotein B levels in familial combined hyperlipidemia. Arteriosclerosis Thrombosis and Vascular Biology 1997;17:834-840.

6. Cabezas MC, de Bruin TWA, Jansen H, Kock LA, Kortlandt W, Erkelens DW. Impaired chylomicron remnant clearance in familial combined hyperlipidemia. Arteriosclerosis and Thrombosis 1993; 13:804-814.

7. Bredie SJH, Tack CJJ, Smits P, Stalenhoef AFH. Non-obese patients with familial combined hyperlipidemia are insulin resistant as compared with their non-affected relatives. Arteriosclerosis Thrombosis and Vascular Biology 1997:17:1465-1471.

8. Hunt SC, WU LL, Hopkins PN, Stults BM, Kuida H, Ramirez ME, Lalovel JM, Williams RR. Apolipoprotein, low-density lipoprotein subfraction, and insulin associations with familial combined hyperlipidemia. Study of Utah patients with familial dyslipidemic hypertension. Arteriosiclerosis 1989;9:335-344.

9. Eurlings PMH, wan der Kallen CJH, Geuits JMW, van Greevenbroek MMJ, de Bruin TWA. Genetic dissection of familial combined hyperlipidemia. Molecular Geneties and Metabolism 2001 in press.

10. Dekker JM, Feskens EJ, Schouten EG, Klootwijk P, Pool J, Kromhout D. QTc duration is associated with levels of insulin and glucose intolerance. The Zutphen Elderly Study. Diabeles 1996:45:376-380.

11. Tur $\mathbb{E}$, Yosipovitch $G, B a r$ YY. Skin reactive hyperemia in diabefic patients. A study by laser Doppler flowmetry. Diabetes Care 1991;14:958-962.

12. Jaap AJ Hammersley MS, Shore AC, Tooke JE. Reduced microvascular hyperaemia in subjects at risk of developing type 2 (non-insulin-dependent) diabetes mellitus. Diabetologia 1994;37:214-216. 
136 


\section{Chapter 11}

Samenvatting 


\section{Samenvatting}

Risicofactoren voor hart- en vaatziekten en vaatafwilkingen in patiënten met Familiaire Gecombineerde Hyperlipidemie.

Hart- en vaaiziekten (HVZ) ziin heden ten dage de belangrijkste doodsoorzaak in de Westerse samenleving. Gedurende de afgelopen decennia is er een scala aan cardiovasculaire risicofactoren beschreven. Een combinatie van deze risicofactoren leidt tot een sterkere verhoging van het cardiovasculaire risico dan vit het risico van een enkele factor zou kunnen worden afgelezen. Bij een aantal ziektebeelden vindt er tevens een clustering van cardiovasculaire risico factoren binnen een familie plaats. Een belasie familie anamnese betreffende HVZ is eveneens een erkende risico factor.

Familiair Gecombineerde Hyperlipidemie (FGH) is een familiaire andoening die gekenmerkt wordt door wisselend verhoogde cholesterol en triglyceride waarden in het bloed. Aangedane personen vit deze families hebben een sterk verhoogd risico op het ontwikkelen van cardiovasculaire aandoeningen, zoals een myocard infarct of een herseninfarct, voor hun $60^{\circ}$ levensjaar. Binnen de $F G H$ onderzoekswereld is gedurende de afgelopen 25 jaar met name veel aandacht vitgegaan naar de pathofysiologische oorzaken die leiden "ot de beschreven afwijkingen in de lipidenstofwrisseling en de rol van insuline resistentie daarin. In hoofdstuk 3 worden de huidige opvattingen en inzichten omtrent deze pathofysiologische oorzaken samengevat. Bii FGH is er sprake van een overproductie van apolipoproteine B (apo B) bevattende lipoproteïnen door de lever, met daarbii een vertraagde klaring van deze lipoproteïnen. Een toename in vrije vetzuur flux van het viscerale vet naar de lever wordt als belangrijkste oorzaak gezien voor de overproductie van lipoproteinen door de lever bij personen met FGH. Daarnaast zijn personen met FGH vaak insuline resistent op zowel spier-als vetniveau. Een toename in vetmassa, met name abdominaal gelokaliseerd, wordt eveneens vaak waargenomen bij individuen met $\mathrm{FGH}$.

Echter, de beschreven pathofysiologische afwijkingen in de lipidenstofwisseling en insuline resistentie binnen het FGH ziektebeeld zijn niet in stad het hoge cardiovasculaire risico volledig te verklaren. Dacmaast zijn er weinig gegevens bekend over vroege vaatafwi kingen bii personen met $\mathrm{FGH}$ en de eventuele rol die lipiden hierin kunnen spelen. In het onderzoek beschreven in dit proefschrift is a an beide vragen aandacht besteed.

Op dit moment is er nog geen unieke marker beschikbaar om FGH binnen een individu te kunnen aantonen. Daarom is een uitgebreid familie onderzoek nog steeds noodzakelijk. Hoofdstuk 2 beschrijft de huidige strategie en de criteria die gebruikt zilin om de diagnose $F G H$ in een familie vast te stellen. Daarmaast worden enkele epidemiologische gegevens beschreven betreffende $35 \mathrm{FGH}$ families uit Maastricht en omgeving. Uit onze gegevens bleek dat bii 39\% (143 van de 362) van de familieleden sprake was van een hyperlipidemie. Verder bleek de prevalentie van de hyperlipidemie sterk toe te nemen met de leeffijd: 
van $15 \%$ (13 van de 86 ) bij familieleden onder de 30 jaar tot ruim $71 \%$ (25 van de 35) bij familieleden met een leeftijd tussen de 60 en 70 jaar $(p<0.01$ voor trend). De hyperlipidemie trad ongeveer 20 jaar eerder op in FGH familieleden vergeleken met onze controle populatie. Daarnaast werd er een significante clustering van cardiavasculaire risicofacioren (hyperlipidemie, hypertensie, obesitas en roken) gevonden bij familieleden met FGH. De hoge prevalentie van HVZ biil familieleden met FGH onderstreepte nogmaals hell hoge cardiovasculaire risico binnen deze patiëntenpopulatie.

In de hoofdstukken 4 tot en met 6 stacin een aantal mogelijke cardiovasculaire risicofactoren beschreven die, indien afwijkend, zouden kunnen bijdragen aan het hoge risico op HVZ binnen de FGH populatie. Hoofdstuk 4 beschriift het gezamenliik voorkomen van hyperlipidemie en hypertensie in een $F G H$ populatie. Eenderde van de 27 anderzochte FGH families voldeed naast de criteria voor FGH tevens aan de criteria voor de diagnose Familiaire Dyslipidemische Hypertensie. Tevens werd de clustering van hypertensie en hyperlipidemie significant vaker waargenomen bij FGH familieleden dan in de controle populatie $(27.2 \%$ vs. $14.2 \%, p<0.01)$. Zowel aangedane als nietaangedane vrouwelilke familieleden hadden een hogere systolische en diastolische bloeddruk ten opzichte van vrouwelijke controle personen. Multipele lineaire regressie analyse bil vrouwen toonde aan dat de hoogte van de systolische bloeddruk met name afhankelijk was van leeftijd, aanwezigheid van hyperlipidemie and taille omtrek. Hieruit werd geconcludeerd dat visceraal vetweefsel een belangrijke bijdraige kan leveren aan de prevalentie van hyperlipidimie en hypertensie in FGH families. Nader onderzoek dient vit te wijzen of reductie in de viscerale vetmassa een mogelijke therapeutische interventie is ter behandeling van hyperlipidemie en hypertensie bii personen met $\mathrm{FGH}$.

Een verlenging van het hartfrequentie gecorrigeerde QT-interval (QTc) is geassocieerd met platselinge hartdood, zowel in patiënten die al een myocard infarct hebben doorgemaakt als in de algemene bevolking. In hoofdstuk 5 werd daarom onderzocht of QTc eventueel verlengd was in een FGH populatie en zo mogelijk zou kunnen bijdragen aan het verhoogde cardiovasculaire risico binnen FGH. QTC werd automatisch gedetecteerd in een 12-afleidingen ECG bii 76 personen met $\mathrm{FGH}$ en 92 gezonde controle personen. $\mathrm{FGH}$ vrouwen hadden een significante verlenging van QTc vergeleken met controle vrouwen (verschil 7.8 msec, leeftij-gecorrigeerde $p<0.011$. Er werd geen verschil tussen de mannelijke populaties gevonden.

Eerder onderzoek suggereerde dat QTc verlenging mogelijk onderdeel zou zijn van het insuline resistentie syndroom. De significante positieve correlaties tussen QTc en $\log T G, \log$ insuline en HOMA (berekende waarde voor insuline resistentie) en de negatieve correlatie met $\mathrm{HDL}$-cholesterol, die in ons onderzoek werden gevonden bij vrouwen, ziin in overeenstemming met bovenstaande suggestie. Multivariate regressie analyse toonde het verband tussen QTc verlenging en componenten van het insuline resistentie syndroom nogmaals aan. 
Concluderend lieten FGH vrouwen een verlengd QTe interval zien, dat geassocieerd was met componenten van het insuline resistentie syndroom. Het blijft de vraag of deze QTc verlenging een gevolg is van de genetische gevoeligheid van vrouwen voor FGH of meer een adaptatie mechanisme voor insuline resistentie. QTC verlenging kan verder mogelijk bijdragen aan het verhoogde cardiovasculaire risico binnen personen met FGH, maar toekomstig follow-up onderzoek zal dit moeten bevestigen.

In de literatuur is de associatie fussen een versterkte stolling en/of onderdrukte fibrinolyse en het optreden van hart- en vaatziekten uitvoerig beschreven. Een versterkte stolling en/of onderdrukte fibrinolyse zou ook kunnen bijdragen aan het hoge cardiovasculaire risica bii personen met FGH. Diverse componenten van het stollings- en fibrinolyse systeem werden onderzocht in 70 hyperlipidemische FGH personen en 57 gezonde controle personen (hoofdstuk 6). FGH personen hadden significant hogere plasma concentraties van plasminageen activator inhibitor 1 (PAl-1) en tissue type plasminogeen activator (t-pa) dan de controle populatie (PAl-1: $18(3-38)$ vs. $10(1-29) \mathrm{U} / \mathrm{mL} ; p<0.001$, en t-pa: $10.8 \pm 3.8$ vs. $7.5 \pm 3.9 \mathrm{ng} / \mathrm{mL} ; \mathrm{p}<0.001)$. Tevens was de concentratie van de von Willebrand factor (vWf) significant toegenomen bij FGH personen ten opzichte van de controle onderzoeksgroep $(110.0 \pm 35.4 \%$ vs. $94.3 \pm 36.8 \%$, $\mathrm{p}<0.05)$. Een aantal componenten van het insuline resistentie syndroom $(\log T G$, $\log$ insuline, glucose en apo B) verklaarde $50 \%$ van de variatie in PAl-1. Hef procoagullante, anti-fibrinolytische karakter van het endotheel kan mogeliik bijdragen aan het hoge cardiovasculaire risico bii personen met $\mathrm{FGH}$. Toekomstige studies zullen de precieze roll van PAI-1 en WWf in het cardiovasculaire risico bii personen met FGH ophelderen.

In hoofdstuk 7 worden veranderingen in de capillaire dichtheid bij personen met FGH en de potentiële rol van remnant-achtige lipoproteinnen (RLP-C) concentraties beschreven. RLP-C bestaan uit chylomicron remnants, apo E verrijkte very low-density lipoprotein ( $\beta$-VLDL) en intermediate density lipoprotein (IDL), allen pro-atherogene remnants. Capillaire dichtheden werden gemeten bij 23 (12 mannen) personen met FGH en 27 (14 mannen) gezonde controle personen. Door middel van capillaire microscopie werd het aantal capillairen proximaal van de nagelriem van de rechter ringvinger in beeld gebracht, voor en na 4 minuten van arteriële occlusie. Tijdens deze test werd eveneens de huiddoorbloeding gemeten met laser Doppler fluximetrie. Het aantal capillairen in FGH mannen was zowel in de basale (BC) als in de post-occlusieve (POC) meting verminderd ten opzichte van controle mannen $(B C: 113.7 \pm 15.1$ vs. $132.0 \pm 18.0 ; p=0.02$, en POC: $123.0 \pm 19.1$ vs. $142.3 \pm 18.3 ; p=0.03$ ). In multivariate regressie analyse bleek logaritmisch getransformeerd RLP-C de enige significante onathankelijke factor te zijn die bijdroeg aan POC. De conclusie was dat in FGH mannen een afname in structurele en functionele huidcapillairen werd waargenomen, die geassocieerd was met een toename van atherogene lipoproteinen concentraties. Toekomstig onderzoek dient uit te wiizen of de afname van capillairen een rol speelt in de pathofysiologie van FGH of meer als een adaptatie aan de hyperlipidemie gezien moet worden. 
Daarnaast was de laser Doppler post-ocdusieve reactieve hyperaemie (LDPRH) significant hoger in $\mathrm{FGH}$ vrouwen dan in controle vrouwen: $537(239-800) \%$ vs. $327(39-365) \% ; p<0.05$. Deze toename in LDPRH bij FGH vrouwen was een onverwachte bevinding. Eerder onderzoek suggereerde een relatie tussen een afgenomen LDPRH en insuline resistentie. Aangezien insuline resistentie ook frequent gezien wordt bij personen met FGH werd op voorhand een afname in LDPRH verwacht. Een duidelijke verklaring voor onze bevinding is vooralsnog nief voorhanden. De combinatie van beide metingen (capillaire dichtheden en fluxmetrie) suggereert wel dat er mogelijkerwijs een toegenomen arterioveneuze shunt flow aanwezig is bij personen met FGH. De toegenomen hypercemische respons bij $\mathrm{FGH}$ wrouwen ging namelijk samen met een normale capillaire dichtheid, terwiil bii FGH mannen een normale hypercaemische respons werd waargenomen bij een afgenomen capillaire dichtheid.

Intima-media dikte (IMT) werd gemeten in 58 personen met FGH en 55 leeftijden geslacht-gematchte gezonde controle personen (hoofdstuk 8). IMT werd in de arteria carotis communis, 10 tot $20 \mathrm{~mm}$ proximaal van de bulbus carotis gemeten middels non-invasieve ultrageluid techniek. FGH personen met een blanco cardiovasculaire voorgeschiedenis $(n=46)$ hadden een significante toename van de IMT vergeleken met de controle populatie (verschil $57 \mu \mathrm{m}$, leeftijd en geslacht gecorrigleerde $p<0.01$ ). Significant positieve, leeftijd en geslacht gecorrigeerde, Pearson correlaties werden gevonden tussen IMT en totaal cholesterol, non HDL cholesterol, LDL-cholesterol, logTG, apo B, nuchter insuline, HOMA (maat voar insuline resistentie), BMI en taille-omtrek. Na multivariate regressie analyse bleven leeftijd, geslacht, apo B en BMI over als onafhankelijke positieve voorspellers van IMT. Deze 4 factoren tesamen verklaarden meer dan 50\% van de variatie in IMT $(p<0.001)$. De toename in IMT bij personen met FGH komt overeen met een acceleratie van vroege atherosclerose van ongeveer 7 jaar. De huidige bevindingen onderstrepen de belangrijke rol van atherogene lipoproteïnen deeltjes in IMT toename bij personen met FGH.

Hoofdstuk 9 plaatst bovenstaande bevindingen verder in perspectief en draagt mogelijkheden voor verder anderzoek aan. Tevens wordt er nog kort ingegaan op de problemen met het diagnostiseren van FGH in de kliniek, die inherent ziin aan de huidige wetenschappeliike definities. 


\section{List of publications}




\section{List of publications}

\section{Articles}

Jacobs MAJM, Keulen ETP, Kanc $K$, Casteleiin $S$, Scheffer $P$, Deville $W$, Heine RJ. Metabolic efficacy of preprandial administration of Lys (B28), Pro (B29) human insulin analogue in IDDM patients. A comparison with human regular insulin during a three-meal fest period. Diabetes Care 1997;20:1279-1286.

Kanc K, Janssen MM, Keulen ETP, Jacobs MAJM, Popp-Snijders C, Snoek FJ, Heine RJ. Substitution of night-time continuous subcutaneous insulin infusion therapy for bedtime $\mathrm{NPH}$ insulin in a multiple injection regimen improves counter-regulatory hormonal responses and worning symptoms of hypoglycaemia in IDDM. Diabetalogia $1998 ; 41: 322-329$.

Keulen ETP, Voors-Pette $C_{r}$ de Bruin TWA. Familial Dyslipidemic Hypertension syndrame, further delineation in Familial Cambined Hyperlipidemia, and the rale of abdominal fat mass. American Joumal of Hypertension 2001; 14:357-363.

Keulen ETP, Kruijshoop M, Schaper NC, Hoeks APG, de Bruin TWA Increased intima media thickness in Familial Combined Hyperlipidemia: association with apolipoprotein B. Arteriosclerosis Thrombosis and Vascular Biology 2001 ; in press.

Allayee $H$, de Bruin TWA, Dominguez KM, Cheng LSC, Ipp $E$, Cantor RM, Krass KL, Keulen ETP, Aovizerat BE, Lusis. Ad, Rotter JI. Genome-scan for blood pressure in Dutch dyslipidemic families reveals linkage to a locus on chromosome $4 \mathrm{p}$. Hypertension 2001 ; in press.

Beeks Ex Janssen RGJH, Kroan AA, Keulen ETP. Geurts JMW, de Leeuw PW, de Bruin TWA. Association between the a-adducin Gly460Trp polymorphism and systolic bload pressure in familial combined hyperlipidemia. American Joumal of Hypertension 2001 ; in press.

Keulen ETP, Rijkers KK, Lutgens I, van Lin JMIP, Schaper NC, de Bruin TWA. QT-interval (QTc) is prolonged in Familial Combined Hyperlipidemia: association with insulin resistance. Submitted.

Keulen ETP, Hamulyak $K_{*}$ de Bruin TWA Pro-coagulant endothelium in Familial Combined Hyperlipidemia. Submitted.

Keulen ETP, Schaper NC, Houben AHM, van Lin JMJP, Lutgens I, Rijkers K, Dallinga-Thie GM, de Bruin TWA. Reduced capillary density in Familial Combined Hyperlipidemia, association with remnant-like lipoprotein particles. Submitted. 
Van der Kallen C.JH, Voors-Pette C, Bouwman FG, Lu NY, van de Hulst RWJ, Janssen MU, Keulen ETP, Boeckx WD, Rotter J!, de Bruin TWA. Evidence of insulin resistant lipid metabalism in adipose tissue in Familial Combined Hyperlipidemia, but not in type 2 Diabetes. Submitted.

\section{Abstracts}

Jacabs MAJM, Kanc K, Keulen ETP, Casteleijn S, Heine RJ. The metabolic efficacy of Lispro human insulin analogue in a multiple injection (MIT) regimen. Neherlands Joumal of Medicine 1995;46:A37.

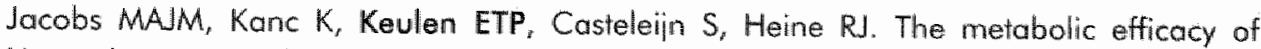
Lispra human insulin analogue in a multiple injection (MIT) regimen. Hormone and Metabolic Research 1995;27:56.

Jacobs MAMM, Keulen ETP, Kanc K, Casteleijn S, Heine RU. Metabolic responses and energy expenditure following preprandial administration of Lispro insulin analogue in IDDM patients. Diabetologia 1995;38(suppl 1):A189.

Kane K, Keulen ETP, Jacobs MAJM, Popp-Snijders C, Naseri K, Heine RJ. Night-time continuous subcutaneous insulin infusion (CSII) therapy enhances counter-regulatory hormonal responses and warning symptoms of hypoglycaemia in IDDM patients. Diabetologia 1995;38(suppl 1):A205.

Nijpels G, Keulen ETP, Bouter LM, Heine RJ. HDL-cholesterol predicts the incidence of cardiovascular disease in persons with impaired glucose tolerance. Diabelologia $1996 ; 39$ (suppl 1):A194.

Keulen ETP, Pette C, de Bruin TWA. Familial Dyslipidemic Hypentension syndrome: delineation in Familial Combined Hyperlipidemia. Atherosclerosis 2000 «suppl $1: 5151: 252$.

Keulen ETP, Rijkers K, Lutgens 1, van Lin JMJP, Schaper NC, de Bruin TWA. Heart-rate corrected QT-interval is prolonged in Familial Combined Hyperlipidemia, and associated with insulin resistance. European Journal of Clinical Investigation $2001 ; 31$ (supp/1):19.

Voors-Pette C, Keulen ETP, de Bruin TWA. Hyperlipidemia iry relation to central obesity in Familial Combined Hyperlipidemia. European Journal of Clinical Investigation 2001,31 (suppl 1):19.

Keulen ETP, Schaper NC, van Lin JMUP, Lutgens I, Rijkers K, Houben AlHM, Dallinga-Thie GM, de Bruin TWA. Reduced past-acclusive capillary density in FCHL, associated with lipoprotein remnants. European Journal of Clinical Investigation 2001,31)(suppl 1):25. 
Keulen ETP, Lutgens 1, Rijkers K, van Lin JMJP, de Bruin TWA. The epidemiology of cardiovascular ristly factors in Familial Combined Hyperlipidemia. Atherosclerosis 2001; suppl 2/2:61.

Keulen ETP, Schaper NC, van Lin JMJP, Lutgens 1, Rilkers K, Houben AJHM, Dallinga-Thie GM, de Bruin TWA Structural loss of functional capillaries in Familial Combined Hyperlipidemia, related to lipoprotein remnants. Atherosclerosis 2001 "suppl 2/2:143.

Keulen ETP, Hamulyak $K$, de Bruin TWA. Pro-coagulant endothelium in Familial Combined Hyperlipidemia. Drugs Affecting Lipid Metabolism congress, September 2001, New York, USA.

Keulen ETP, Kruijshoop M, Schaper NC, Hoeks APG, de Bruin TWA. Increased intima media thickness in Familial Combined Hyperlipidemia is associated with increased nonHDL cholesterol and apolipoprotein B concentrations. Drugs Affecting Lipid Metabolism congress, September 2001, New York, USA. 
Dankwoord 


\section{Dankwoord}

Nu ik aan het eind van dit boekje gekomen ben, rest mij nog één taak: eenieder bedanken die heeft bijgedragen aan de totstandkoming ervan. Dankzii de inspanningen en bijdragen van velen kon dit proefschrift worden gerealiseerd. Daarom wil ik op de laatste pagina's van dit boekje een aantal mensen, in willekeurige volgorde, van harte bedanken:

Allereerst een speciaal woord van dank aan alle deelnemers uit de FGH-families. Zonder de voortdurende bereidwilligheid van velen om weer aan een volgend onderzoek deel te nemen, was de totstandkoming van dit boekje niet mogelijk geweest. De diverse verhalen en anekdotes uit de verschillende families die ons ter ore kwamen, verstevigden de band tussen onderzoekers en proefpersonen. De hartelijke ontvangst tijdens diverse huisbezoeken zal ik nooit vergeten.

Mijn promotor, Prof. Dr. T.W.A. de Bruin, beste Tjerk, jouw enthousiasme voor het FGH-onderzoek en jouw verhuizing van Utrecht naar Maastricht, boden mij de mogelijkheid terug te keren naar het Limburgse grondgebied. Ons niet direct realiserend hoeveel tiid het in kaart brengen van nieuwe FGH-families zou kosten, is het, mede door jouw inzet en enthousiaste begeleiding, toch gelukt om diverse vasculaire gebieden bij FGH-personen in kaart te brengen. Met name jouw onnavolgbare manier om diverse mogelijke oorzaken en gevolgen van gevonden afwiikingen te combineren, hebben onze artikelen een extra dimensie gegeven.

Met name wil ik Josephine van Lin noemen. Josephine, zonder jouw onaflatende inzet was het nooit mogelijk geweest alle FGH-families nouwkeurig in kaart te brengen. Vele twijfelaars werden, na grondige uitleg, door jou over de streep getrokken om toch aan de diverse onderzoeken deel te nemen. Met grote precisie bereidde je alle studies voor en een half woord was vaak al genoeg. Met plezier denk ik terug aan onze vele autoritten naar Noord-Limburg. Josephine, ik hoop dat je als paranimf deze promotie ook een beefje als jouw promotie wilt beschouwen.

Bij dit alles mogen de student-assistenten Kim en Isabelle niet vergeten worden. Kim en Isabelle, jullie hebben beiden gedurende ruim anderhalf jaar vele screeningen voor jullie rekening genomen. De vele hulp bij de diverse onderzoeken heb ik zeer op prijs gesteld. De vele verhalen over jullie nieuwe vriend jes zal ik niet vergeten. Wellicht tot ziens als taekomstige collega's.

Alle medewerkers, oud-medewerkers en student-assistenten wan het Laboratorium Moleculair Metabolisme en Endocrinologie en Laboratorium Endocrinologie: Carla, Marleen, Vicky, Margee, Jan, Rob, Freek, Ellen, Wim, Paul, Geertie, Gabrielle, Jeroen, Esther, Marsha, Kirsten, Liesbeth, Sabien, 
Angèle en Martiin. Ik wil jullie bedanken voor de gezellige tijd op het lab, de vele honderden bepalingen en mijn inwijdingen in het maleculair en genetisch werk.

Min mede-AlO's Petra, Christine, Margriet, Mireille, Cyriel, Marrigie, Wilko, Esther, Kim en Jörgen. Vele uren op het lab. Vind ik genoeg proefpersonen? Kriig ik wel goede resultaten? Samen een doel, velen nog hard zwoegend, sommigen al klaar. Het eindpunt is mooil

Dr. N.C. Schaper, beste Nicolaas, gezien jouw expertise in diabetes mellitus, en met name de diabetisch voet, werden tijdens onze besprekingen waar mogeliik steeds paralellen getrokken tussen FGH en diabetes. Beide dezelfde insuline resistente grondslag, maar toch zo verschillend. Onze verschillende insteek in de insuline resistentie heeft miin kennis over mogelijke pathofysiologische mechanismen binnen het metabole syndroom sterk verbreid. Met name het microcirculatie onderzoek was één van jouw stokpardjes, die we tot een goed einde hebben weten te brengen.

Alle leden van de vakgroep Interne Geneeskunde en met name de werkgroep Endocrinologie wil ik van harte bedanken voor het attenderen van mogelijke FGH probands op ons onderzoek en de goede samenwerking.

Claudia, Monique en Dorien van het circulatie-lab wil ik bedanken voor het soepele inplannen van alle onderzoeken en het gebruik van de diverse onderzoekskamers. De ondersteuning van Boy bii het microcirculatie onderzoek wordt zeer op prijs gesteld.

Dr. G.M. Dallinga-Thie, beste Geesje, jouw remnant-like lipoprotein particles (RLP) metingen voegden een extra dimensie toe aan het microcirculatie onderzoek en hield de band tussen Maastricht en Utrecht staande.

Carina van Zandvoort-Pernot, René van Oerle en Dave Hellenbrand, medewerkers van het lab speciële stolling, worden bedankt voor alle 'citraat'bepalingen waardoor de pro-coagulante, anti-fibrinolytische status van FGH kon worden beschreven. Martin Nyziel wordt bedankt voor het attenderen op de mogelijkheden wan stollingsonderzoek bii personen met FGH. Dr. K. Hamalyuk wil ik bedanken voor de hulp en het commentaar bij de apmaak van het stollingsartikel. De link tussen FGH en stolling/fibrinolyse zal in de toekomst meerdere gezamenlijke projecten tot gevolg hebben.

Prof. Dr. A.P.G. Hoeks, beste Arnold, bedankt voor de geboden mogeliikheden intima media dikte metingen te verrichten bij de FGH personen. De technische ondersteuning van Jean Willigers wordt zeer op prijs gesteld.

De goede samenwerking met Dr. Rob van Dijk, Dr. Edith Feskens en Dr. Marga Ocke, van het RIVM, zal in de toekamst hopelijk vervolgd worden. De resultaten wan alle voedingsboekjes zullen nog verder geanalyseerd worden. 
Prof. Dr. H. Jansen en mevrouw A.J. Zonneveld ben ik erkentelijk voor de LPL en $\mathrm{HL}$ bepalingen. De resultaten van de post-heparine belasting zullen nog verder worden uitgewerkt.

Zonder de inzet van Ruud Schmeitz, Jacqueline Pisters, Trudie Zeegers en Gregor Franssen medewerkers van het MEMIC, was de realisatie van een uitgebreide, gekoppelde en centrale FGH database niet mogelijk geweest.

Alle leden van de promotie commissie: Prof. Dr. P.W. de Leeuw, Prof. Dr. H.J.G.M. Crijns, Prof. Dr. M.J.A.P. Daemen, Prof. Dr. D.E. Grobbee en Prof. Dr. C.D.A. Stehouwer wil ik bedanken voor hun commentaar op en het goedkeuren van mijn manuscript.

Prof. Dr. H.F.P. Hillen (Academisch Ziekenhuis Macstricht) en Dr. B.J. Looii (Maasland Ziekenhuis. Sittard) wil ik bedanken voor de geboden mogelijkheid mij verder te bekwamen binnen de interne geneeskunde. Prof. Dr. H.F.P. Hillen wordt tevens bedankt voor alle ondersteuning.

Een speciaal woord nog voor Dr. William van Houtum, mijn paranimf. Beste William, in 1990 zijn we samen begonnen aan de studie geneeskunde in Amsterdam. Onze wegen verliepen lange tijd parallel met vele uren gezamenlijik studeren, eten, computeren en snookeren. De eerste stappen in het onderzoek brachten je naar Texas, de mijne begonnen bij jouw latere promotor Prof. Dr. Rob Heine. Na ons artsexamen had iii genoeg artikelen verzameld om al snel te promoveren en dus vervolgde iij je weg via een $\mathrm{AGN}$ (IO-schap naar de opleiding tot internist in Alkmaar en Leiden. I $\mathrm{k}$ vervolgde mijn weg middels een promotieonderzoek in Maastricht. Nu, drie jaar na jou, zal ook ik mijn promotieboekje verdedigen en mijn weg tot internist vervolgen. Door de afstand is het contact noodgedwongen wat minder, maar de vriendschap is onveranderd. Het schaken per e-mail moet in de taekomst nog op gang komen. Bedankt dat je min paranimf wilt zijn.

Zoals bij zovele voorgangers is Tiny Wouters onmisbaar voor hel perfect redigeren van dit proefschrift. Beste Tiny, bedankt voor al je ondersteuning en "De Greef" kan zich opmaken voor een feestie!

Dimitri Delnoye ben ik zeer erkenteliik voor de mooi ontworpen kaft. Een grote neven- en nichtenschare met veel aanhang biedt vele voordelen.

Lieve pa en ma, jullie hebben dit alles mogelijk gemaakt. Ik kon gaan en staan waar ik wilde, kon gaan studeren en op jullie steun kon ik altijd rekenen. Ook nu jullie eerste kleinkind er is, ziin jullie, net zoals mijn schoonouders, altijd bereid waar nodig bij te springen. Bedankt voor alles.

Lieve Bianca, je hebt me al het mooiste gegeven wat ik me had kunnen wensen. Zonder jouw steun en geduld was dit boekje niet mogelijk geweest. Volgens jou was ik sinds de geboorte van Eva vaak thuis a an het werk. Nu de opleiding tof 
internist is begonnen, zal dit minder vaak voorkomen en zal er wat meer op jouw schouders terecht gaan komen. Maar al mijn vrije lijd besteed ik aan jullie.

Lieve Eva, papa"s meisje: een glimlach van jou verdriff alle vermoeidheid en stelt onderzoek en werk in een schaduw. 


\section{Curriculum Vitae}




\section{Curriculum Vitae}

Eric Keulen werd op 31 maant 1972 geboren te Geleen. Na het behalen van het Atheneum diploma aan de Albert Schweitzer Scholengemeenschap (thans Graaf Huyn College) te Geleen, begon hil in 1990 aan de studie geneeskunde aan de Vrije Universiteit te Amsterdam. In 1994, tijdens het vierde jaar van de doctoraalfase begon hij zijn wetenschapsstage op de afdeling Diabetologie van het Academisch Ziekenhuis der Vrije Universiteit (AZVU) te Amsterdam o.I.v. prof. Dr. RJ Heine. Deze eerste aanraking met klinisch wetenschappeliik onderzoek resulteerde in anderhalf jaar durende onderzoeksperiode op diverse plaatsen binnen het diabetes onderzoek in het AZVU en in Hoorn. In augustus 1997 werd het artsexamen cum laude behaald.

In oktober 1997 begon hii, o.l.v. prof. Dr. TWA de Bruin als assistent in opleiding aan zijn promotie onderzoek getiteld "cardiovascular abnormalities in Familial Combined Hyperlipidemia', waarvan de resultaten in dit boekwerk ziijn beschreven. In maart 2000 schonk zijn wrouw Bianca hem een wolk van een dochter, Eva genaamd. In oktober 2001 is hii gestart met de opleiding interne geneeskunde in het Maasland ziekenhuis te Sittard, opleider Dr. BJ Looil. 